\title{
PRESSAFE-Disp: A Method For The Fast Seismic Assessment of Existing Precast RC Buildings After The Emilia Earthquake Of May 2012
}

\section{Marco Bovo}

UNIBO DISTAL: Universita degli Studi di Bologna Dipartimento di Scienze e Tecnologie Agro-Alimentari

Lucia Praticò ( $\square$ lucia.pratico3@unibo.it)

UNIBO: Universita di Bologna https://orcid.org/0000-0002-0148-8146

Marco Savoia

UNIBO DICAM: Universita degli Studi di Bologna Dipartimento di Ingegneria Civile Ambientale e dei Materiali

\section{Research Article}

Keywords: precast RC buildings, seismic fragilities, cladding panel, friction-based connections, PRESSAFE-disp

Posted Date: June 29th, 2021

DOl: https://doi.org/10.21203/rs.3.rs-653540/v1

License: (9) (1) This work is licensed under a Creative Commons Attribution 4.0 International License. Read Full License

Version of Record: A version of this preprint was published at Bulletin of Earthquake Engineering on February 14th, 2022. See the published version at https://doi.org/10.1007/s10518-022-01318-x. 


\title{
PRESSAFE-disp: a method for the fast seismic assessment of existing precast RC buildings after the Emilia earthquake of May 2012
}

\author{
Marco Bovo1, Lucia Praticò ${ }^{2}$, Marco Savoia ${ }^{2}$ \\ ${ }^{1}$ Department of Agricultural and food sciences -Agricultural Engineering (DISTAL), University of \\ Bologna, Viale Fanin 48, Bologna, Italy \\ ${ }^{2}$ Department of Civil, Chemical, Environmental, and Material Engineering (DICAM), University of \\ Bologna, Viale Risorgimento 2, Bologna, Italy
}

*Corresponding author. Email: lucia.pratico3@unibo.it

\begin{abstract}
The existing precast reinforced concrete structures, especially those not specifically designed against the earthquakes, have proved to be inadequate to withstand the remarkable seismic demands related to the presence of heavy roof elements. In fact, the cantilever columns entailing large top displacements and the poor devices adopted to connect different precast elements have shown high sensitivity to seismic actions. After the lesson learned from the recent Emilia earthquake of May 2012, causing many collapses and severe damage, reliable seismic design criteria have been established for the design of new precast structures and for the strengthening of the existing ones. Despite this, a large percentage of the existing precast buildings in the Italian territories actually has not been object of interventions and remains in an unsafe condition with regards to the seismic actions. In this context, the methods for a rapid seismic assessment can be very helpful both to estimate the current safety level of large building stocks and to plan the necessary strengthening interventions, possibly at the wide scale of an industrial area.

To this aim, the paper proposes a new method, named PRESSAFE-disp (PRecast Existing Structure Seismic Assessment by Fast Evaluation-displacements), for the fast evaluation of the fragility curves of precast structures. The method follows the approach of the PRESSAFE method, but different damage criteria have been introduced in order to take into account the relative displacements and the sliding between different precast elements. The damage criteria considered, applicable to both structural elements and perimeter cladding elements conceived as non-structural elements, have been properly selected in order to capture the damage mechanisms observed during the several building inspections conducted by the authors in the aftermath of the 2012 Emilia earthquakes.

In the present configuration, the method allows a comprehensive explanation of the seismic behaviour of the existing precast buildings and could be effectively adopted, for example, in earthquake loss estimations and seismic risk assessments of large Italian industrial areas, as well as of wide seismic-prone territories of the Mediterranean area.
\end{abstract}

Keywords: precast RC buildings; seismic fragilities; cladding panel; friction-based connections; PRESSAFE-disp. 


\section{Introduction}

The seismic events which shook the northern Italy in May 2012, as well as several past seismic events in the Mediterranean area, have caused significant damage or even the collapse of buildings realized with precast technologies. The earthquake represents a serious test bench for existing precast reinforced concrete (RC) buildings since they were usually designed with non-redundant schemes in order to allow easy and fast assembling operations. In addition, even though the seismic activity of the Italian territory was well known since many years (INGV 2020), wide areas of Italy, Emilia Romagna Region included, were considered non-seismic zones by national building codes until the re-classification proposed in 2003 (OPCM 2003). As a consequence, a large percentage of the existing buildings was designed by means of static analyses by taking into account only vertical loads and wind action (Savoia et al. 2017). Thus, several precast buildings, built in the Italian territory before 2003, have simply-supported elements (beams and floor slab elements) with shear forces transmitted at the support level through friction resistance only. Indeed, steel connection devices, mandatory in seismic zones and fundamental to ensure the global safety of precast structures (Brunesi et al. 2015), usually were not adopted in those regions.

The lesson learnt after the 2012 Emilia sequence represented an occasion for engineers and researchers for both collecting data concerning structural damage on precast structures (Savoia et al. 2012, Liberatore et al. 2013, Belleri et al. 2014, Bournas et al. 2014, Magliulo et al. 2014, Savoia et al. 2017) and developing reliable models to investigate the seismic behaviour of such buildings. Concerning the latter aspect, the possibility of having a large amount of data on the structural deficiencies of precast buildings boosted the investigations of many international researchers, with research and reports covering different aspects of these structures (Liberatore et al. 2013, Belleri et al. 2014, Bournas et al. 2014, Bovo and Savoia 2018, Ercolino et al. 2018, Bovo and Savoia 2019). With specific reference to the seismic fragility functions, different authors focused on particular classes of precast buildings (e.g. considering 
specific types of connections or claddings, or considering only one type of collapse mechanism but neglecting the others). As a consequence, the outcomes of the various studies (Casotto et al. 2015, Buratti et al. 2017) are not simple to compare, thus the results cannot be generalized to a widespread stock of buildings. Furthermore, in other cases, the seismic fragility functions have been obtained for stocks that collect structures with very different dynamic features. In this way, the fragilities represent an average evaluation of seismic performances of a certain group of buildings but are not properly valid, in general, for an individual building or for narrow classes of buildings in the stock.

With the aim of providing a more uniform approach, Bovo and Savoia (2021) proposed a method for the fast seismic assessment of different classes of one-story precast RC buildings, selected on the basis of international reports and databases (Regione Emilia Romagna 2020). The PRESSAFE (PRecast Existing Structure Seismic Assessment by Fast Evaluation) methodology allows to define, in a simplified way, the seismic fragilities of existing precast structures not designed for seismic actions. The method, starting from the seismic deficiencies and weaknesses shown by the precast structures during past earthquakes, provides the fragility curves of different building typologies quite common in the South-European countries. By following the approach initially proposed in Bovo and Savoia (2021), an alternative method called PRESSAFE-disp (PRecast Existing Structure Seismic Assessment by Fast Evaluationdisplacements) is presented and described in this paper. The main goal of this method is to provide a simplified procedure to evaluate the seismic fragility curves of different precast RC buildings typical of the Emilia Romagna territories, in Italy, but very common also in other regions of the Mediterranean area. Indeed, starting from the numerous building inspections conducted by the authors in the aftermath of the earthquakes, the method proposed here, differently from the PRESSAFE method, introduces damage mechanisms taking into account relative displacements and sliding between precast elements, as well as different typologies of cladding elements. The damage criteria, adopted for both structural components and perimeter 
cladding elements considered as non-structural elements, have been properly selected and modelled in order to reproduce the damage mechanisms observed during the building surveys. In this study, different precast frames have been selected and investigated with incremental dynamic analyses (IDA) considering, for each building category, 8 vibrating periods ranging from $0.25 \mathrm{~s}$ to $3.0 \mathrm{~s}$, by varying the column gross cross-section (the set of periods considered is $\check{T}_{1}=0.25,0.5,0.75,1.0,1.5,2.0,2.5$ and $\left.3.0 \mathrm{~s}\right)$. The frames have been analysed by considering or excluding the presence of three common typologies of perimeter elements (i.e., RC horizontal cladding panels, RC vertical cladding panels and masonry infill walls), in order to simulate the perimeter frames or the internal bare frames of a precast building, respectively. Therefore, 120 different frame classes have been analysed in the work, i.e. 24 internal frames and 96 perimeter frames, selecting various geometrical-structural parameters and configurations.

Two seismic fragility functions, related to severe damage and collapse state, have been obtained from the outcomes of the dynamic analyses. By interpolating the fragility functions over the set of the 8 periods of vibration selected, 3D fragility surfaces of each category have been derived. For each frame category, the analytical expressions for the two fragility surfaces have been established by numerical interpolation. The fragility surface provided in this work is a useful tool allowing to define the fragility curve of a frame (internal or perimeter) starting from the knowledge of its structural category and the value of the first period of vibration $T_{1}$. Moreover, the fragility functions at failure of the perimeter elements have been also obtained and reported for the three non-structural panel/wall typologies considered in the analyses.

Finally, the combined fragility function of the whole precast structure has been statistically derived by combining the fragility functions of its sub-elements (i.e. frames), assuming that the events describing the attainment of a prescribed damage state for the different frames are statistically compatible and independent. As confirmed in recent studies (Silva and Horspool 2019), the availability of mathematical functions connecting vibrating period and fragility curves represents a powerful tool, not commonly provided in other studies concerning fragility 
functions. Indeed, it could be adopted to carry out statistical calculations based on vulnerability models, like seismic loss and damage assessments, considering the uncertainty in the period of vibration.

The simplified approach, introduced in the framework of this study, allows a fast evaluation of the fragility curves of a precast frame, starting from the knowledge of few structural information which can be collected through a building survey or a visual inspection. Hence, the functions can be statistically combined in order to assess the fragility of the entire precast RC building with a direct approach which can be useful for performing rapid seismic risk evaluations. In particular, the methodology is deemed suitable for multiple applications at a territorial scale, for example in the case of large numbers of building stocks located in productive areas, and may be adopted for the identification of the most sensitive productive areas of a region. This may help to define specific economic measures for seismic risk reduction, or may be considered as a tool to support decision, for instance in the context of the Civil Protection seismic plan definition.

A schematic overview of the main steps of the PRESSAFE-disp methodology, which is described in the following sections, is illustrated in Figure 1. 


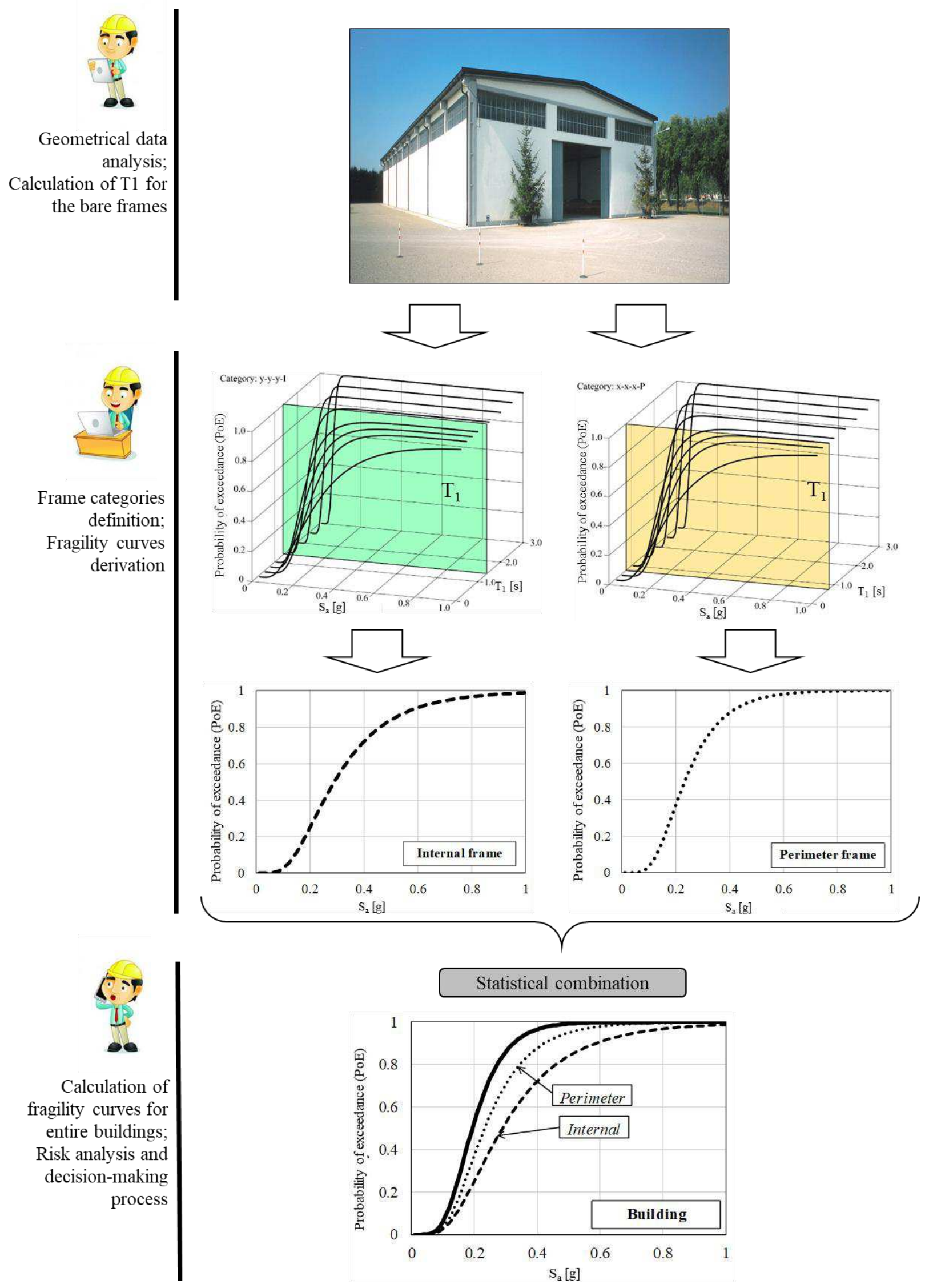

Figure 1. Overview of the application of the PRESSAFE-disp methodology. 


\section{Main damage and collapse mechanisms observed in precast RC buildings after the 2012 Emilia earthquake}

The 2012 Emilia earthquakes hit an area with many medium-to-large industrial and agrifood districts, causing extended damage and several collapses of the precast RC buildings (Liberatore et al. 2013, Bournas et al. 2014, Savoia et al. 2017). From the outcomes of the building surveys in the earthquake aftermath, about 4000 production buildings, i.e. $45 \%$ of the total number in the area, were tagged as unsafe (equivalent to red-colour tag of ATC 1989), resulting in more than 3000 requests of regional funds for the retrofit and the reconstruction process (Agenzia Regionale per la ricostruzione 2018).

To this regard, also past earthquakes in other countries caused widespread structural collapses or serious damage to this building typology (Tzenov et al. 1978, Tapan et al. 2013), highlighting the international character of this criticality.

The seismic vulnerability of the Italian precast RC buildings has been largely acknowledged by engineers and researchers after the 2012 seismic events, as mentioned before. Due to the regular layout and the simple static scheme usually adopted for these highly standardised buildings (i.e., simply-supported horizontal elements above cantilever RC columns, with infilled masonry walls or precast cladding panels along the perimeter (Savoia et al. 2012, Bellotti et al. 2014), the damage mechanisms observed in Emilia can be collected within a few common types, and summarized herein:

- the failure at the base of the columns due to the insufficient longitudinal and transverse reinforcement bars, resulting in inadequate flexural capacity (see Figure 2a);

- the sliding of roof elements and, in several cases, even their fall, caused by the absence or inadequacy of steel connection devices between columns and beams or between beams and roof slab elements. Where the steel elements were absent, the sliding 
mechanism was even eased by the presence of neoprene pads between the precast RC elements (see Figure 2b and 2c);

- the collapse of the non-structural walls along the perimeter of the buildings i.e., the detachment and the fall of the horizontal (Figure 2d) and vertical cladding panels (Figure 2e) and in-plane failure of masonry infills (Figure 2f).

It is evident that, when precast RC buildings are subjected to a strong ground-motion, the damage may affect both the structural and the non-structural elements, and all these aspects should be taken into account in a consistent structural model. Moreover, the non-linear contribution due to second order effects should be considered since it may increase displacements and the corresponding damage for tall and flexible structures, like those considered in the present study. Accordingly, the method presented in this study has been developed considering suitable structural characteristics of the precast existing buildings, coherent with the in-field observations collected. Thus, various structural parameters have been selected, in order to model the seismic behaviour of the precast buildings in Emilia Romagna, as detailed in the next Section.
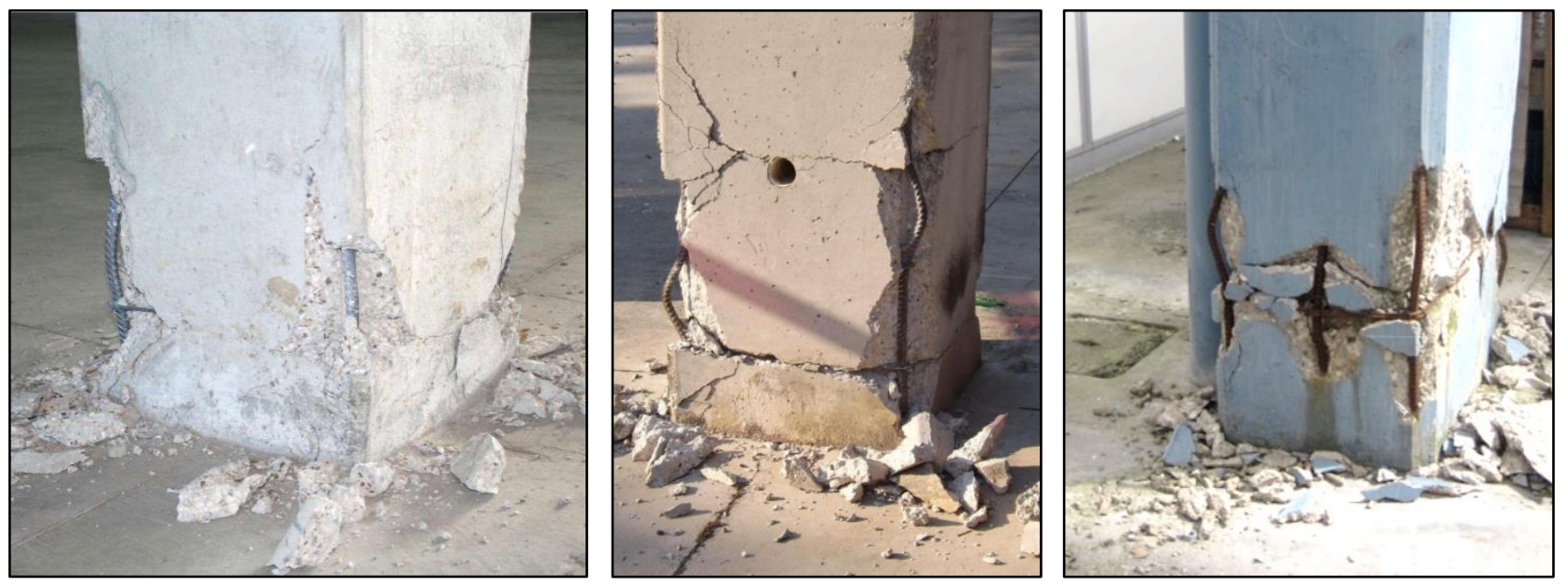

(a) 

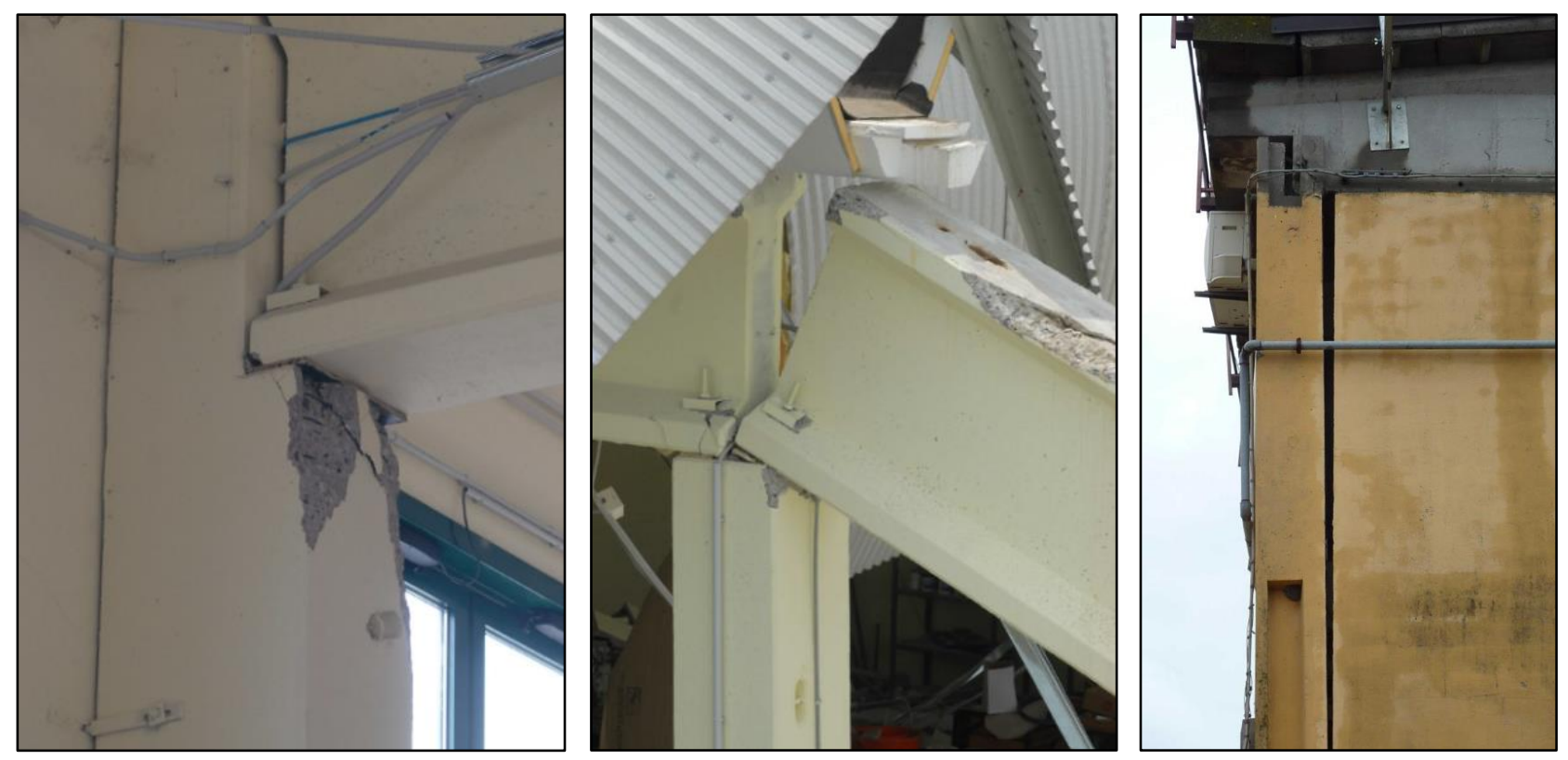

(b)
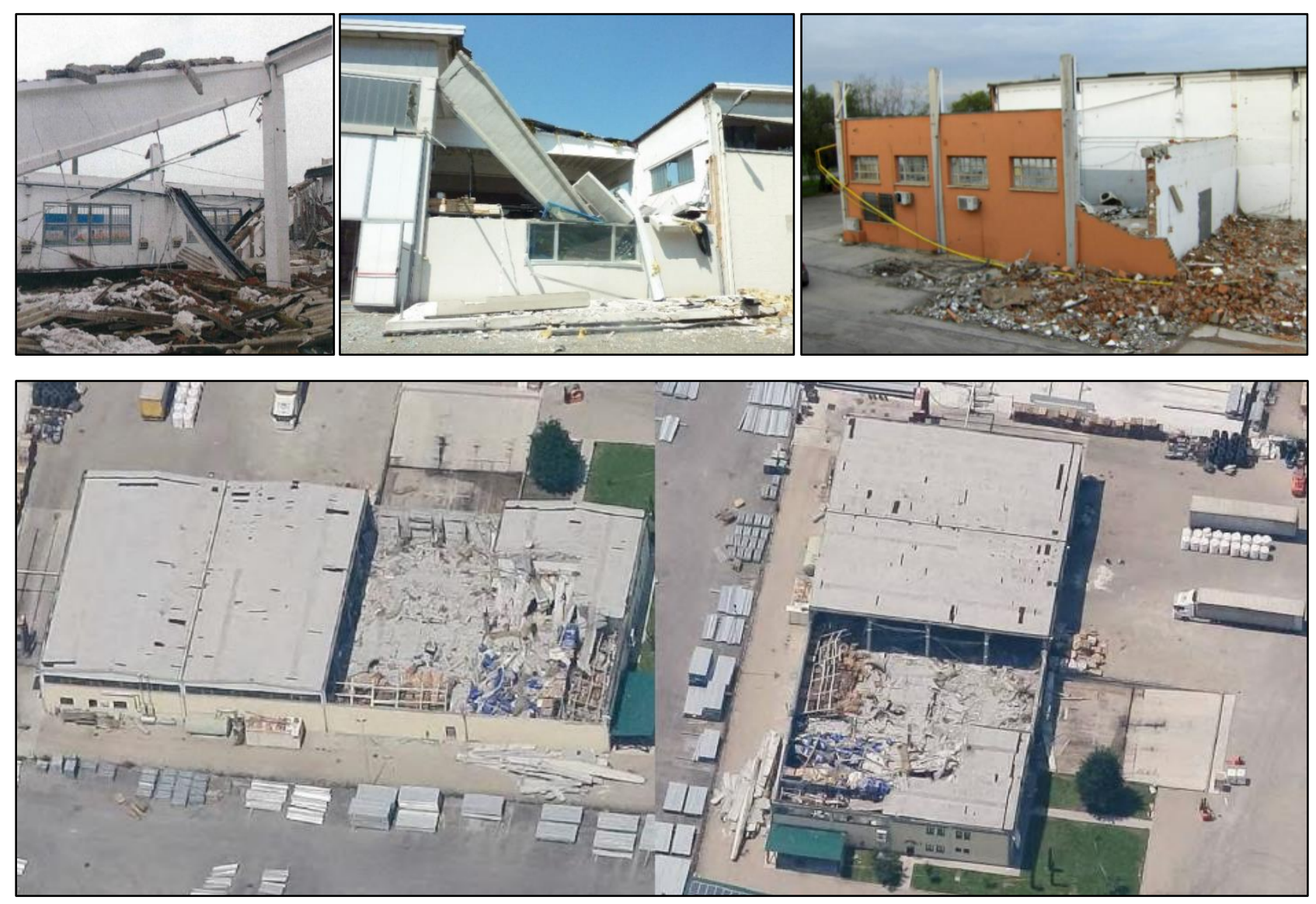

(c) 

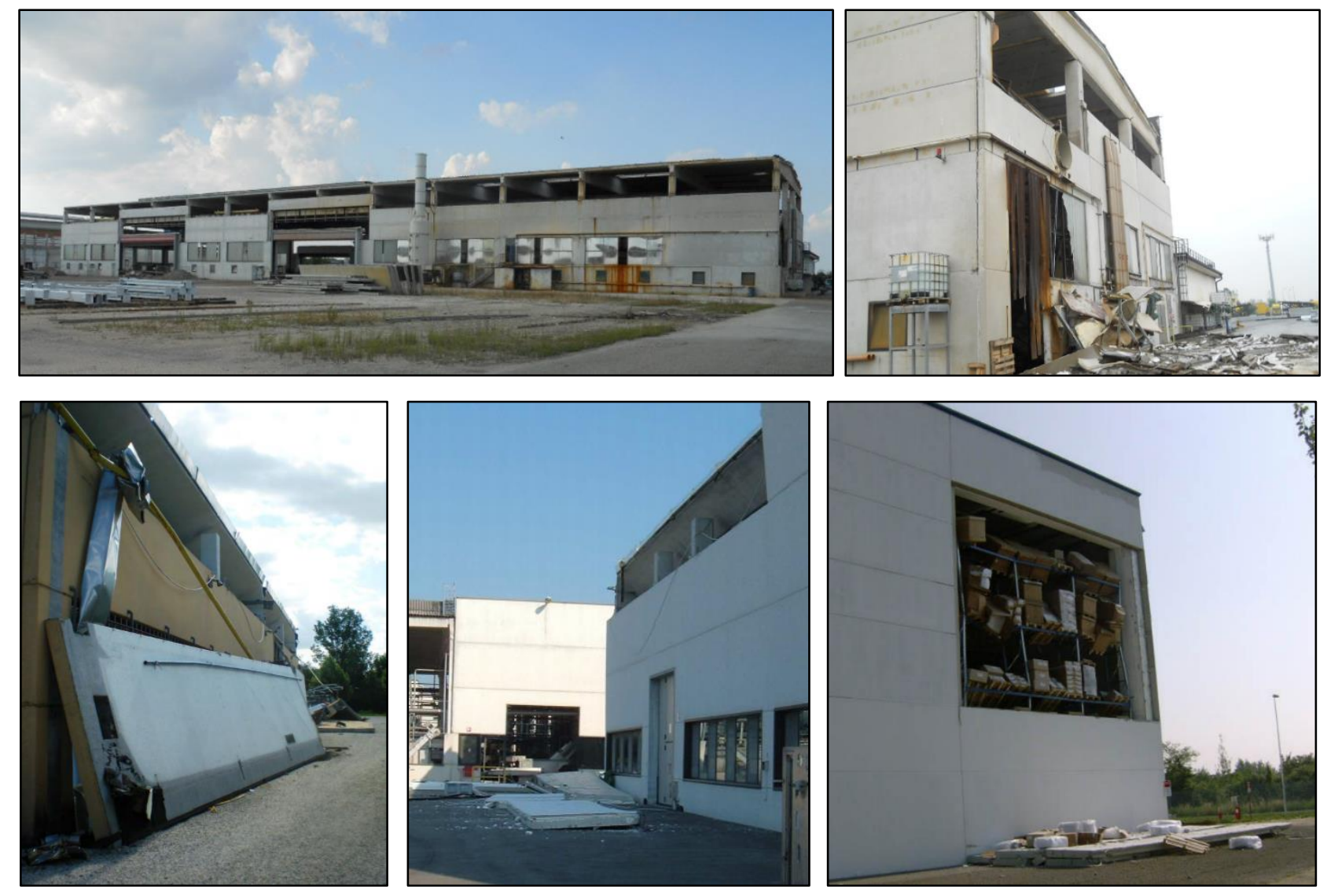

(d)
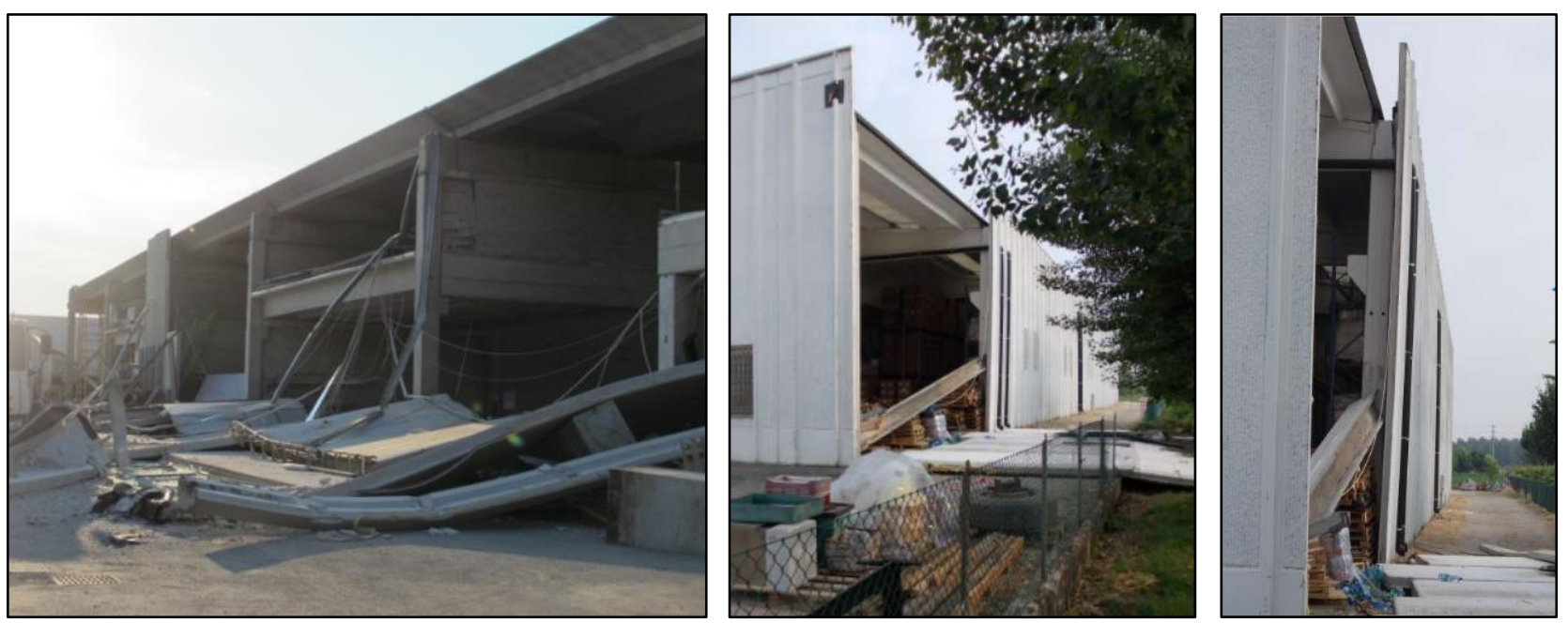

(e) 

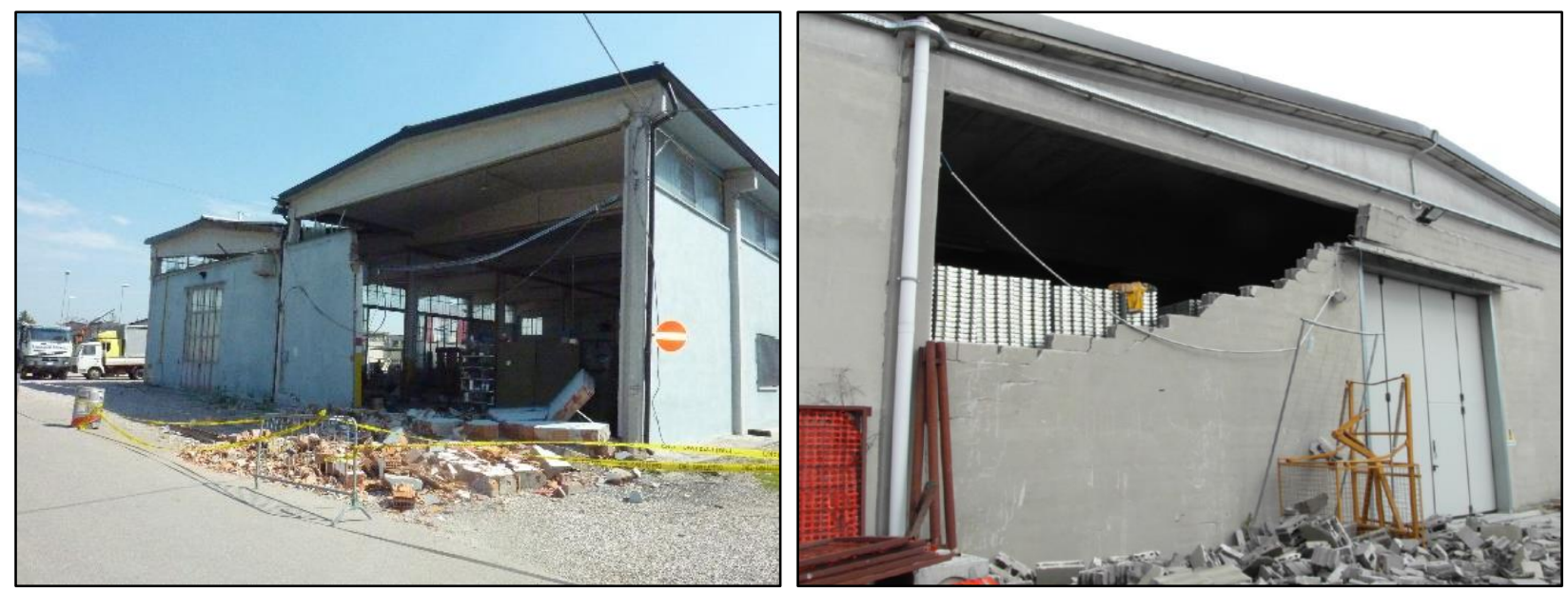

(f)

Figure 2. Details of the main damage typologies in precast RC buildings after the Emilia earthquake of 2012: (a) damage at the column base; (b) sliding and (c) fall of precast beams and roof slab elements; collapse of (d) horizontal and (e) vertical cladding panels; (f) failure of masonry infill walls. 


\section{PRESSAFE-disp method}

\subsection{Description of the methodology}

The aim of the methodology is to estimate the seismic vulnerability of one-story existing precast RC buildings, adopting mechanical models which must be simple but capable of reproducing the damage and collapse mechanisms described in Section 2.

The method is based on the following main steps:

- classification of the building stock to be investigated, starting from the data of reports and building surveys in the aftermath of May 2012. This is achieved by identifying the most important parameters which mainly influence the response of these buildings when hit by the ground motion;

- analysis of the behaviour of the internal frames and perimeter frames identified in the previous step. Considering the hypothesis of flexible diaphragm for this class of buildings, internal frames and perimeter frames are studied separately, the latter being characterized by the presence of cladding panels or masonry infills;

- incremental dynamic (time-history) analyses with reference to the finite element models of internal and perimeter frames;

- definition of the fragility curves and the fragility surfaces for each class of internal and perimeter frames. The fragility surfaces are defined as a function of the first vibrating period of the frames. Obviously, internal and perimeter frames could have different values of the period of vibration;

- definition of the (combined) fragility curve for the entire building, statistically derived starting from the knowledge of the fragility functions of its frames.

Each step of the methodology is widely described in the following Sections. 


\subsection{Building features and typologies}

The first step involves the identification and classification of the most widely used precast structural typologies not designed for the seismic actions, drawn from databases collecting the surveys of experts and engineers, carried out after the Emilia 2012 seismic event (Bellotti et al. 2014, Ongaretto et al. 2019).

The most common structural layout is constituted by cantilever columns supporting the horizontal roof elements, which are precast principal beams bearing perpendicular precast floor slab secondary elements. The foundations are usually isolated plinths, not linked by beams as presently mandatory in seismic zones. More complex (and rare) layouts, such as multi-storey buildings or structures with shed roof, are not considered.

The structure in elevation is quite slender since the typical height ranges from 6.0 to $9.0 \mathrm{~m}$, and the square or rectangular column sectional dimensions are $40 \mathrm{~cm}$ to $80 \mathrm{~cm}$. Most of the building mass is concentrated at the roof level, where monolithic prestressed beams are inserted in top forks above the columns or placed on thick corbels, so behaving as simply-supported elements, with or without steel connectors. If the steel elements are absent, the support strength against the horizontal forces relies on the frictional resistance, which can be negatively influenced by the presence of interposed neoprene pads. The floor slab elements sustained by the main beams constitute the top roof level, providing a flexible in-plane behaviour due to the lack of continuity and the insufficiency of the connections. The features of the most common roof elements (i.e. main beams and roof slab elements) have been collected and presented in Bovo and Savoia (2021).

In those few cases where mechanical devices connecting beams and columns were present, they were constituted by 2 steel dowels with $\emptyset 16$ or $\emptyset 25$ diameter, whereas the steel connections between slab elements and main beams were thin L-shaped plates. The connections proved to be stronger if compared with the friction-based support, since they have been able to prevent the horizontal sliding of the roof elements, as in many documented situations. 
Masonry infill walls and precast cladding panels usually represent the building cladding elements on the perimeter, connected to the frames of the buildings. In more recent buildings, horizontal or vertical precast cladding panels are directly connected to the structural frame elements (columns and/or perimeter beams), while the older buildings have masonry walls placed between consecutive columns.

Among the connection typologies of the horizontal cladding panels, the two most frequently observed in the Emilia Romagna industrial areas are illustrated in Figure 3. The first one is constituted by strong steel brackets, both supporting the horizontal panels and providing the connection to the columns. These steel profiles are usually designed to sustain the weight of the panel, with a slope that allows to prevent the out-of-plane displacement of the panel. The second type of panel-column connections consists of a steel channel placed in the column concrete cover and a hammer head strap fastened by means of a bolt in the panel (Colombo et al. 2016). In the case of a seismic action, this layout cannot guarantee the out-of-plane resistance of the panel because the shear deformation capacity of the connection is limited; as a result, this type of connection has proved to be very fragile during the Emilia seismic events. Finally, the vertical panels are usually connected to the perimeter upper beams through a bolted angular profile, as illustrated in Figure 4.

All these characteristics have been selected from the in-situ surveys, and through the analysis of previous studies focused on the capacity of the frame elements and the different connections in precast buildings (ReLUIS 2007, Biondini et al. 2013, Bournas et al. 2013, Magliulo et al. 2015, Zoubek et al. 2016, Belleri et al. 2018). For details see Table 1. 


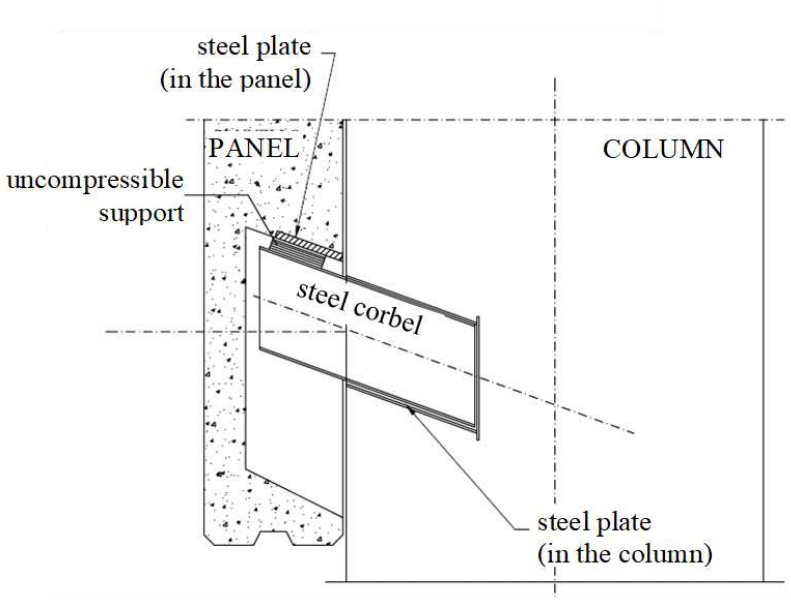

(a)

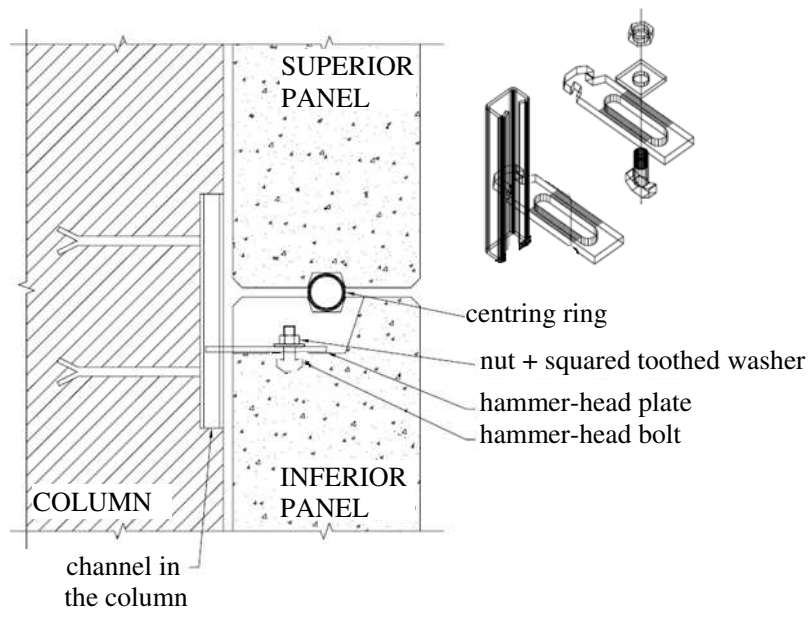

(b)

Figure 3. Schemes of two typical connections for horizontal cladding panels, adapted from Reluis Report (2007): connection adopted for (a) the (h1) frame class and (b) for the (h2) frame class.

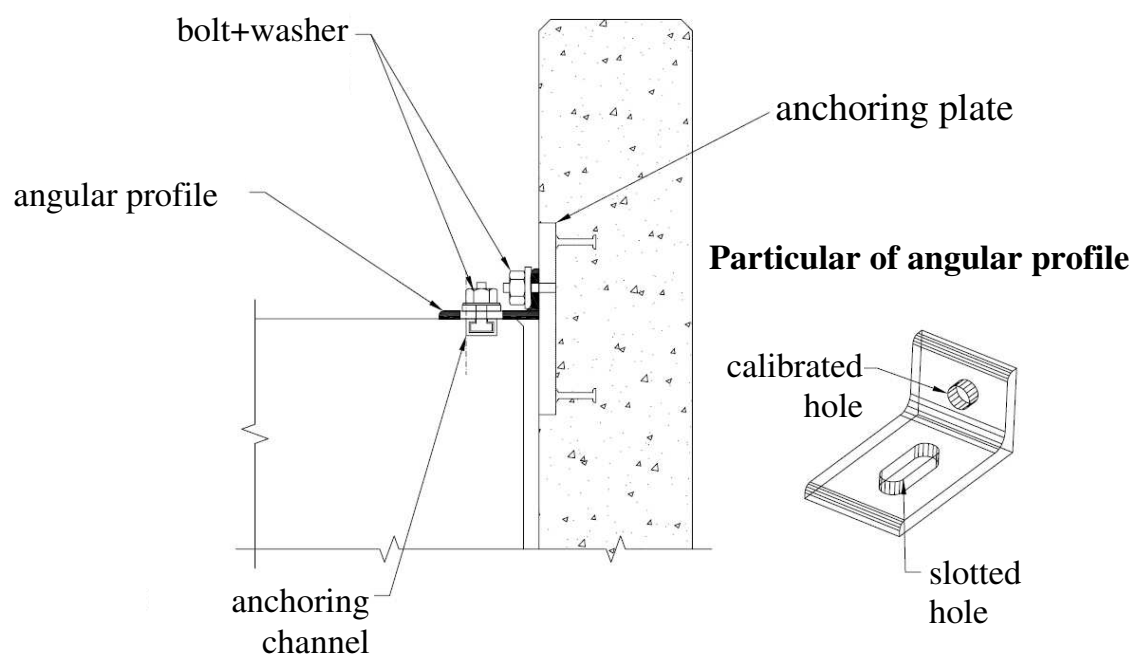

Figure 4. Scheme of a typical connection for vertical cladding panels, adapted from Reluis Report (2007).

Therefore, the most common existing precast buildings of the Emilia Romagna region can be classified according to the four main criteria schematized in Figure 5:

- The first criterion is the value of the yielding moment at the column base, classified here through four reference values corresponding to four letters, from the lowest one (A) to the highest one (D); 
- The second criterion is the beam-column connection, labelled with letters (L), (M) or $(\mathrm{H})$, depending on the strength level of the typologies described above;

- The third criterion is the roof slab-beam connection defined as low strength typology (L) or high strength typology (H).

- The fourth criterion is the type of perimeter panel, being one of the three aforementioned typologies, i.e. masonry infill walls (m), horizontal cladding panels (h) and vertical cladding panels (v). As far as perimeter frames with horizontal cladding panels are concerned, two different types of connections are considered in this study: the frames are labelled (h1) or (h2), when the steel corbel or the anchor channel connections are used, respectively.

Therefore, 24 internal frame (I) categories and 96 perimeter frame (P) categories have been considered, the latter being further sub-classified according to the fourth criterion.

Each category for each internal (bare frame) and perimeter frame of the buildings is thus labelled through 4 letters. The first 3 letters correspond to the first three criteria adopted. For example, one of the 24 internal frame categories is A-L-L-I, characterized by a column flexural capacity of $180 \mathrm{kNm}$ (letter A), low strength of both beam-column and slab element-beam connections with neoprene pads (L-L). The final (I) stands for 'internal frame'. Similarly, one of the 96 perimeter frames has the same first three letter classifications, plus a (P) that indicates a perimeter frame. For perimeter frames, the final letter defines the type of infill that can be (m) masonry wall, (h1) or (h2) horizontal cladding panels or (v) vertical cladding panels, according to the fourth criterion. 


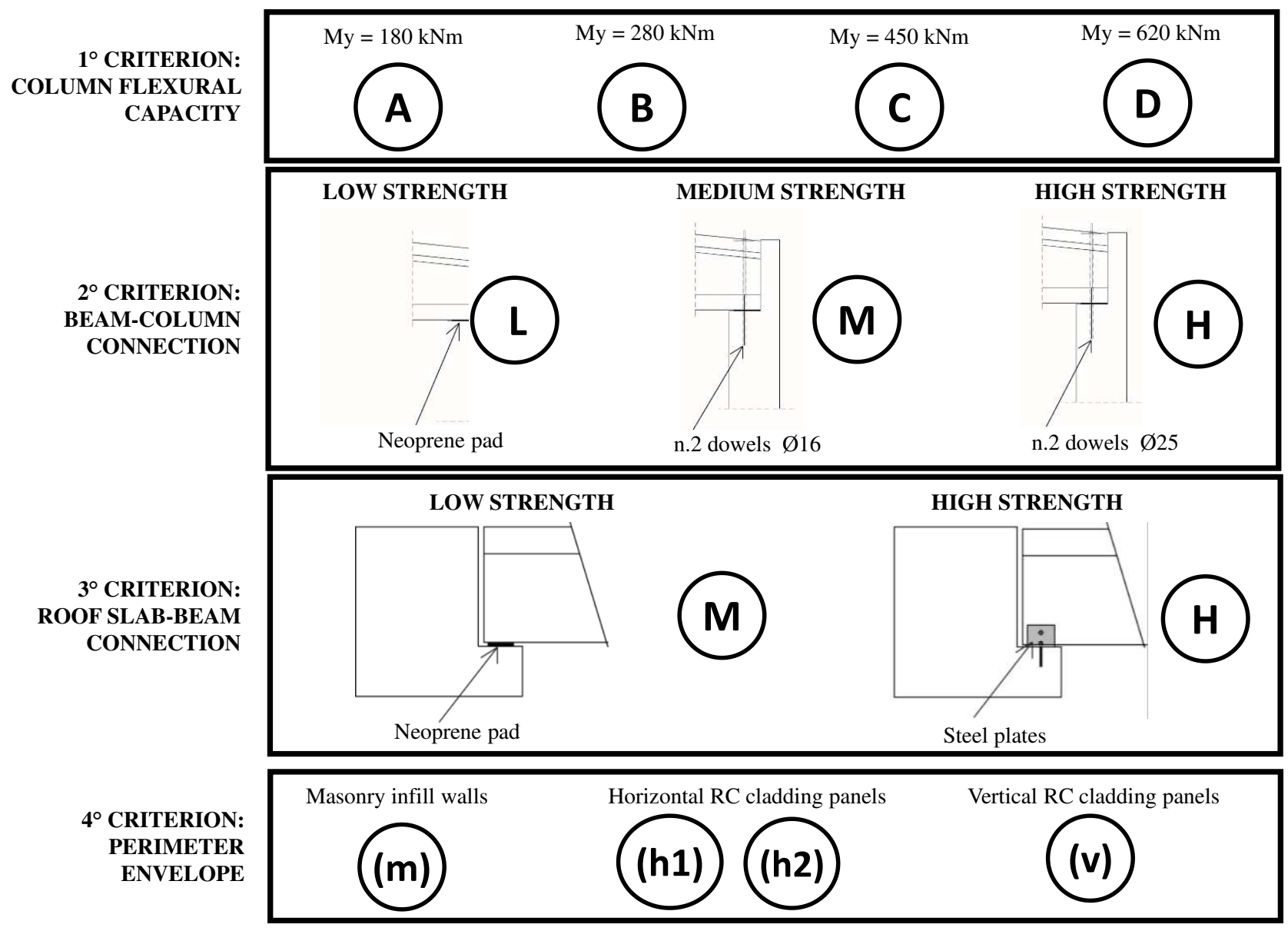

Figure 5. Frame classification criteria adopted in the PRESSAFE-disp method.

Table 1. Materials and geometries assumed for the four different base column flexural capacity levels ( $\mathrm{f}_{\mathrm{cm}}$ : concrete mean cylindrical compressive strength; $\mathrm{R}_{\mathrm{ck}}$ : concrete characteristic cubic compressive strength; fym: steel mean yielding stress; H: building height; Lb: beam spans; Lfs: span of the floor slab elements).

\begin{tabular}{cccccccc}
\hline $\begin{array}{c}\text { Base-column } \\
\text { flexural capacity }\end{array}$ & $\begin{array}{c}\mathrm{f}_{\mathrm{cm}} \\
{[\mathrm{MPa}]}\end{array}$ & $\begin{array}{c}\mathrm{R}_{\mathrm{ck}} \\
{[\mathrm{MPa}]}\end{array}$ & $\begin{array}{c}\text { Steel } \\
\text { class }\end{array}$ & $\begin{array}{c}\mathrm{f}_{\mathrm{ym}} \\
{[\mathrm{MPa}]}\end{array}$ & $\mathrm{H}[\mathrm{m}]$ & $\mathrm{Lb}[\mathrm{m}]$ & $\mathrm{Lfs}[\mathrm{m}]$ \\
\hline $\mathrm{A}$ & 37.05 & 35.0 & FeB32k & 425.40 & 6.0 & 10.0 & 8.0 \\
\hline $\mathrm{B}$ & 37.05 & 35.0 & FeB32k & 425.40 & 6.0 & 16.0 & 12.0 \\
\hline $\mathrm{C}$ & 41.20 & 40.0 & FeB44k & 524.40 & 8.0 & 15.0 & 10.0 \\
\hline $\mathrm{D}$ & 41.20 & 40.0 & FeB44k & 524.40 & 8.0 & 27.0 & 15.0 \\
\hline
\end{tabular}

\subsection{Finite element modelling}

The seismic analyses of the frames belonging to the different categories have been performed on finite element (FE) models realized in OpenSees (2015) (see Figure 6). Figure 6a depicts the FE model of an internal frame (I), whereas Figures $6 b, 6 c$ and $6 d$ show the models adopted for 
perimeter frames with the presence, respectively, of masonry infilled walls, horizontal and vertical precast RC cladding panels.

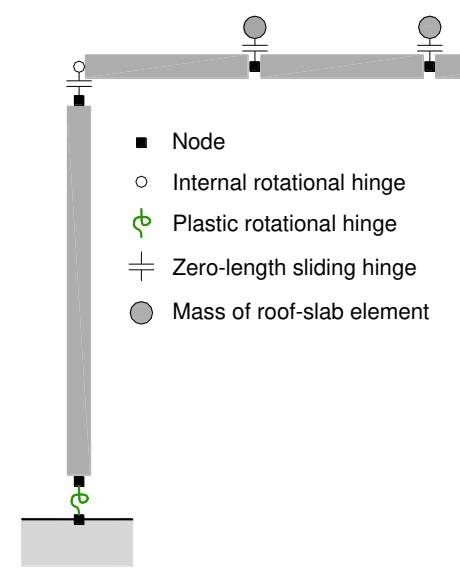

(a)

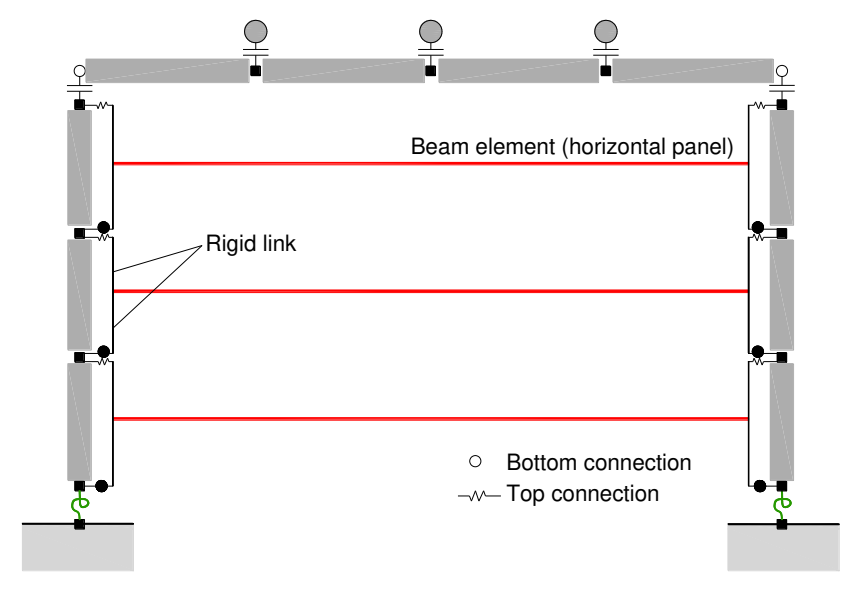

(c)

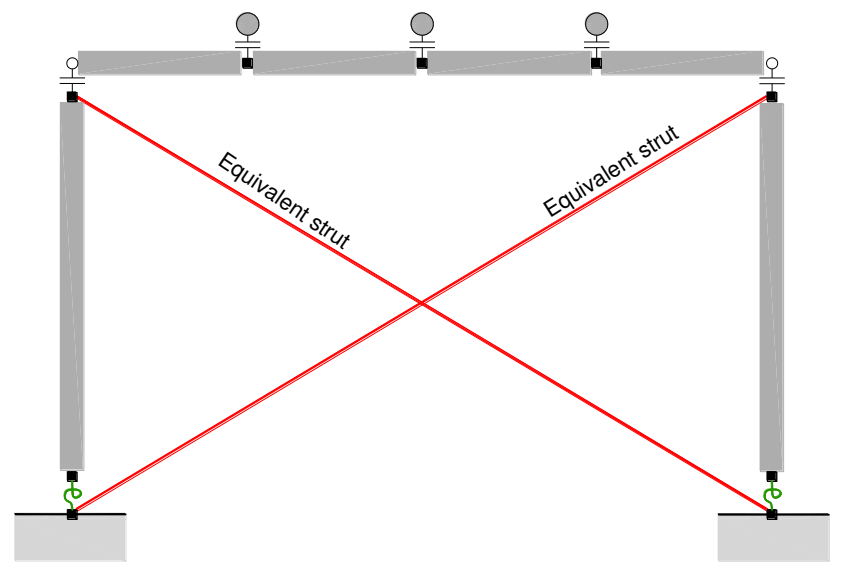

(b)

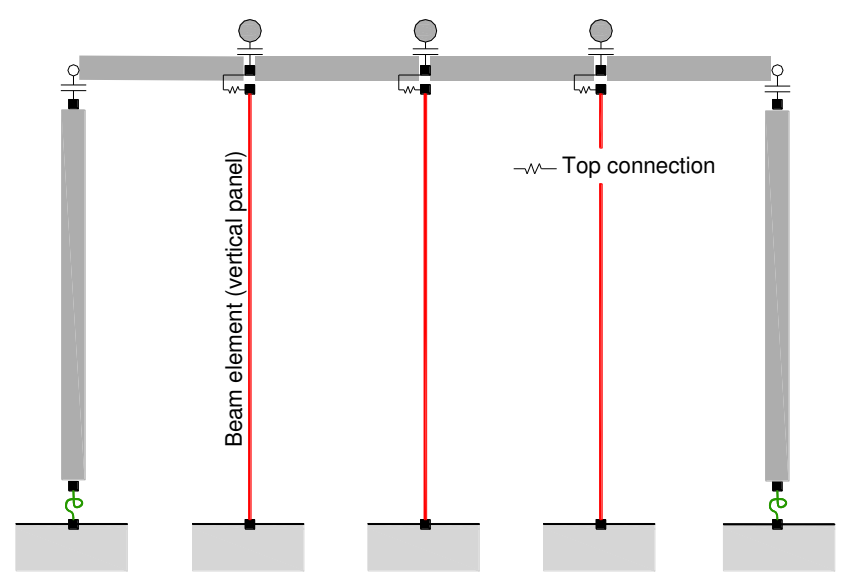

(d)

Figure 6. FE modelling of the different frame typologies: (a) Internal frame; Perimeter frame with (b) masonry infill walls, (c) horizontal cladding panels and (d) vertical cladding panels.

\subsubsection{Frames}

The main elements of an internal frame (i.e. vertical columns and horizontal beams) have been modelled with 1-D elastic beam elements. The columns are fully clamped at the base and have pinned-pinned connections with upper beams.

The nonlinear behaviour of the columns has been accounted for by introducing plastic hinges at the column base, defined in terms of simplified trilinear moment-rotation laws (see sub- 
Figure a1 in Figure 7), where: $M_{y}$ is the yielding moment depending on the flexural capacity level (i.e. A, B, C or D); $M_{u}$ is the ultimate moment assumed equal to $1.05 \times M_{y} ; \theta_{\mathrm{y}}$ and $\theta \mathrm{u}$ are the corresponding rotations evaluated according to EuroCode 8 (2005). The plastic hinges have been defined by adopting the hysteretic uniaxial material in OpenSees (2015) with the following values for the damage parameters: pinchX=1.0, pinchY=1.0, damage $1=0.0$, damage $2=0.08$ and beta $=0.12$ in order to consider the hysteretic degradation of the $\mathrm{RC}$ elements when subjected to cyclic loadings (Kurtman 2007, Bovo and Buratti 2019).

Moreover, the nonlinear behaviour of the beam-column connections has been modelled with a zero-length sliding hinge which is rigid-plastic if the connections are friction-based without mechanical devices (see sub-Figure a2 in Figure 7), or elastic-plastic if dowels are present (see sub-Figure a3 in Figure 7). The numerical parameters adopted to define the behaviour of the connections are summarized in Table 2. It is worth noting that the red circles in Figures $7 \mathrm{a}$ represent the attainment of a collapse condition of the structural frame, as further explained in the following. Finally, the column cross-sections have been selected, for each building category, in order to obtain specific values of the period of vibration of the frame (i.e. $\check{T}_{1}=0.25,0.5,0.75$, $1.0,1.5,2.0,2.5$ and $3.0 \mathrm{~s})$.

\subsubsection{Perimeter infill walls/panels}

The infill walls considered in the study are unreinforced masonries with hollow clay bricks with mean compressive strength $\mathrm{f}_{\mathrm{c}}=3.5 \mathrm{MPa}$ and hydraulic lime mortar with mean compressive strength $\mathrm{f}_{\mathrm{c}}=4.0 \mathrm{MPa}$. The masonry infill walls in the perimeter of the building have been modelled by means of two equivalent diagonal struts (see Figure 6b). This strategy provides a suitable approximation of the global response of the frame (Crisafulli et al. 2000, Asteris et al. 2011). The axial behaviour of the equivalent struts has been modelled in OpenSees by using the hysteretic model assuming the values indicated in Table 2, as suggested in Fardis (1996) and Celarec et al. (2012). Since the strut behaviour is a function of the frame geometry, four 
different curves are obtained and reported in sub-Figure b1 in Figure 7, for the four aforementioned frame typologies (A), (B), (C) and (D). The failure for masonry infill walls has been assumed to be the crushing of the masonry struts.

On the other hand, the perimeter elements of the more recent buildings are typically constituted by precast cladding panels, horizontally or vertically arranged. The former panels may typically assume in two main configurations. In the first solution (h1), the panels are hung at the columns in four points by means of mechanical steel devices: usually the lower ones (bottom connections) bear the self-weight of the panels, whereas the upper (top connections) prevent the outward overturning and the horizontal column-panel slip. In the second solution (h2), the lowest series of panels directly leans on the foundation beams and the outward overturning is prevented by two top connections realized as in Figure 3. Then, the upper series of panels directly leans on the lower one with analogous top connections. The FE model describing this typology of frames is reported in Figure 6c. The behaviour of the connections for both (h1) and (h2) typologies is shown in sub-Figure b2 in Figure 7. The values adopted in the FE models are reported in Table 2 and have been defined respectively for (h1) and (h2) connection typologies starting from the experimental outcomes reported in Belleri et al. (2016) and Del Monte et al. (2019). Three horizontal panel series have been considered in the models. Lastly, the FE model simulating frames with vertical cladding panels (see Figure 4) is reported in Figure 6d. The vertical panel is clamped at the base and connected to the roof beam of the structure by means of the anchor-channel connections type HRC-U-M180 studied in Zoubek et al. (2016). The law implemented for the top connection of the vertical panels is shown in subFigure b3 in Figure 7, and the corresponding parameters are reported in Table 2. For each vertical panel, two anchor-channel devices have been considered. It is worth noting that the red circles in Figures $7 \mathrm{~b}$ correspond to the attainment of the failure of non-structural perimeter walls/panels. Since the dynamic analyses continue until the attainment of a collapse condition for the structural frame, also the post-failure behaviour of non-structural elements is defined. 


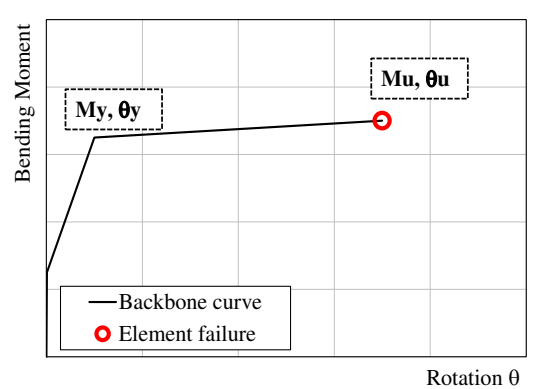

(a1)

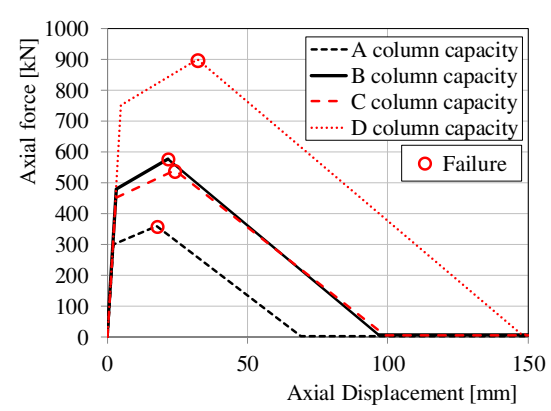

(b1)

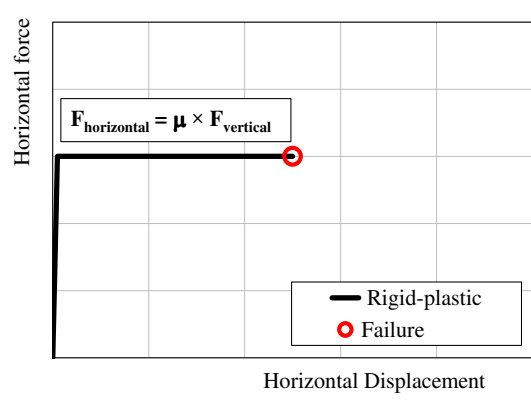

(a2)

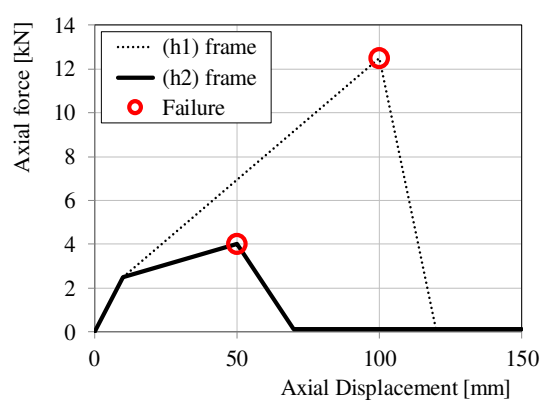

(b2)

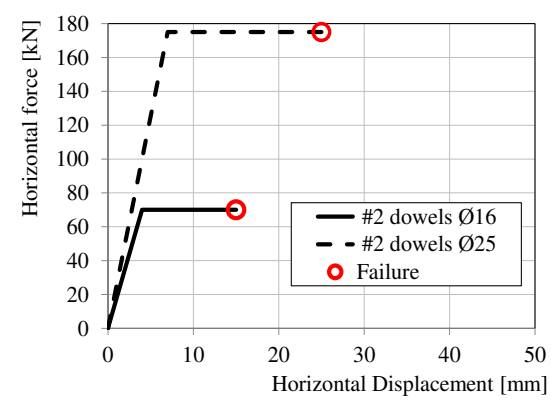

(a3)

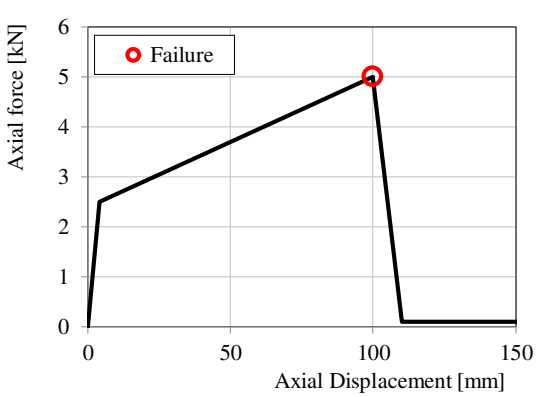

(b3)

Figure 7. Nonlinear laws adopted in the FE models. (a) Structural elements: (a1) Momentrotation constitutive law for the plastic hinges at the base of the columns; (a2) Forcedisplacement shear law for zero-length sliding hinges simulating friction-based connections; (a3) Force-displacement shear law for zero-length sliding hinges simulating mechanical device-based connections. (b) Non-structural perimeter infill walls/panels: (b1) Forcedisplacement axial laws of the equivalent struts modelling the perimeter masonry infill walls; (b2) Force-displacement axial laws adopted for the column-panel connections of horizontal cladding panels; (b3) Force-displacement axial law adopted for the beam-panel connections of vertical cladding panels (top connection).

Table 2. Parameters defining the mechanical properties of connections and equivalent masonry struts adopted in the numerical models $(\mathrm{F}=$ force, $\mathrm{d}=$ displacement).

\begin{tabular}{|c|c|c|c|c|c|c|}
\hline \multicolumn{7}{|c|}{ Numerical parameters adopted for perimeter and internal frames } \\
\hline Connection typology & \multicolumn{3}{|c|}{$\mathrm{F}_{\text {collapse }}[\mathrm{kN}]$} & \multicolumn{3}{|c|}{$\mathrm{d}_{\text {collapse }}[\mathrm{mm}]$} \\
\hline Beam - column with neoprene pads & \multicolumn{3}{|c|}{$0.1 \times \mathrm{F}_{\text {vertical }}$} & \multicolumn{3}{|c|}{100.0} \\
\hline Floor slab - beam with neoprene pads & \multicolumn{3}{|c|}{$0.1 \times \mathrm{F}_{\text {vertical }}$} & \multicolumn{3}{|c|}{50.0} \\
\hline Beam - column with $2 \emptyset 16$ dowels & \multicolumn{3}{|c|}{70.0} & \multicolumn{3}{|c|}{4.0} \\
\hline Beam - column with $2 \varnothing 25$ dowels & \multicolumn{3}{|c|}{180.0} & \multicolumn{3}{|c|}{5.0} \\
\hline Floor slab - beam with steel plates & \multicolumn{3}{|c|}{30.0} & \multicolumn{3}{|c|}{22.0} \\
\hline \multicolumn{7}{|c|}{ Numerical parameters for perimeter frames only } \\
\hline Connection/strut typology & $\mathrm{F}_{1}[\mathrm{kN}]$ & $\mathrm{d}_{1}[\mathrm{~mm}]$ & $\mathrm{F}_{2}[\mathrm{kN}]$ & $\mathrm{d}_{2}[\mathrm{~mm}]$ & $\mathrm{F}_{3}[\mathrm{kN}]$ & $\mathrm{d}_{3}[\mathrm{~mm}]$ \\
\hline Connection of horizontal panels (h1) & 2.5 & 10.0 & 12.5 & 100.0 & 0.1 & 120.0 \\
\hline Connection of horizontal panels (h2) & 2.5 & 10.0 & 4.0 & 50.0 & 0.1 & 70.0 \\
\hline Top connection of vertical panels* & 5.0 & 4.0 & 10.0 & 100.0 & 0.1 & 110.0 \\
\hline Masonry strut (A category) & 300.0 & 2.2 & 360.0 & 17.6 & 3.6 & 68.9 \\
\hline Masonry strut (B category) & 480.0 & 3.2 & 576.0 & 21.7 & 5.8 & 96.8 \\
\hline Masonry strut (C category) & 450.0 & 3.14 & 540.0 & 24.2 & 5.4 & 99.0 \\
\hline Masonry strut (D category) & 750.0 & 4.9 & 900.0 & 32.2 & 9.0 & 147.7 \\
\hline
\end{tabular}

* The models assume the presence of two anchor channels for each vertical panel. 


\subsection{Definition of damage and collapse states}

\subsubsection{Frames}

Following the indications reported in Section 2 regarding the observed damage, two limit states have been considered for the frames. They refer to a severe damage and a collapse condition of the main structural elements, respectively.

The severe damage condition has been set at the attainment of the yielding bending moment of the base-section of a column.

The collapse condition has been defined at the attainment of one of the following subconditions:

- the ultimate rotation for a column;

- the displacement capacity in one of the sliding hinges shown in Figure 6a, adopting a displacement-based collapse criterion for the connections.

The second criterion has been properly selected in order to simulate the common collapse mechanism observed in the aftermath of the Emilia earthquake, where the horizontal sliding of heavy beams or roof slab elements, in several cases, caused the complete unseating and the subsequent fall of the elements.

The attainment of the element or connection failure, indicated by the red circles in Figures $7 \mathrm{a}$, identifies the collapse of the frame, at which the dynamic analyses have been interrupted. The possible attainment of a failure condition has been evaluated step-by-step during the dynamic time-history analysis. Moreover, in the IDA procedure, the second-order effects (P- $\Delta$ ) have been also considered. In particular, in very flexible structures, like those investigated here where cantilever columns support heavy masses, the non-linear second order effects may cause large displacements at the roof level and may increase the seismic damage anticipating the structural collapse. 


\subsubsection{Perimeter infill walls/panels}

It seems worth highlighting that, in the aftermath of the Emilia earthquakes, the most commonly observed damage to non-structural elements concerned the perimeter walls/cladding panels. Hence, the failure of perimeter infill walls and cladding panels has been also considered and recorded in the dynamic analyses. For the masonry infill walls, the failure of the panels has been identified at the attainment of the peak point in the strut axial behaviour (see sub-Figure b1 in Figure 7).

Analogously, the failure of the horizontal cladding panels has been identified with the attainment of the peak point in the behaviour of the connection supporting the panel (see subFigure b2 in Figure 7). To this regard, it is to be highlighted that most of the precast buildings in the Emilia Romagna territories presents the (h2) connection typology described in Section 3. The (h2) type of connections showed a very high sensitivity to seismic actions, whereas the (h1) one resulted to be significantly less weak.

Finally, the failure of the vertical panels has been identified with the failure of the mechanical devices (top connections in Figure 6d) connecting the panels to the structural elements (in this case the roof beam). Again, the failure of the connection has been registered at the attainment of the peak point of the constitutive law (see sub-Figure b3 in Figure 7).

After the attainment of the failure point for non-structural perimeter walls/panels, the analyses continue according to the post-peak behaviour shown in Figures 7b. The analyses have been then interrupted at the attainment of one of the aforementioned collapse conditions related to the structural frames. In all cases, the non-structural walls/panels failure condition has been evaluated independently from the structural collapse condition of the whole frame. 


\section{Incremental dynamic analysis}

In order to evaluate the seismic response of the various frames, nonlinear time-histories analyses have been performed, considering as input the 30 ground motion records selected in Vamvatsikos and Fragiadakis (2010). Both the horizontal and vertical components of the ground motions have been considered, covering a wide range of frequency, time, duration and amplitude. The free field records have been extracted from PEER Strong Motion Database (accessed in 2020), following the criteria of selection adopted by Vamvatsikos and Fragiadakis (2010).

The main characteristics of the records considered are collected in Table 3 and the 5\%-damped acceleration response spectra of the 30 horizontal ground motions are reported in Figure 8 a. In the Figure, the 5\% damped elastic spectra of the 30 recorded horizontal ground motions are represented together with their average spectrum (in red). No scaling factor have been used in the selection phase. The distance from the source, between $15.1 \mathrm{~km}$ and $32.6 \mathrm{~km}$, has been selected to avoid the directivity effects. The dataset adopted has an average value of horizontal over vertical peak ground acceleration ratio, i.e. PGAh/PGAv (see Figure 8b), comparable with that expected for seismic far fault records (PEER Strong Motion Database 2020). Following the criteria given in the PEER Report (2013), the vertical records considered do not present pulsevelocity shape.

The Incremental Dynamic Analyses (IDA) have been performed according to the methodology outlined by Vamvatsikos and Cornell (2002), to consider the record-to-record variability. The analyses have been carried out on 960 different FE models, considering, for each frame typology (i.e. 24 internal and 96 perimeter frames for a total of 120 frames), 8 different column cross-sections corresponding to 8 vibrating periods of the frames. The use of 8 periods of vibration allows to obtain a set with 8 fragility curves for each frame typology, which have been subsequently combined to determine one fragility surface considered as a function of the value of the first period of vibration (see the next Section). 
The intensity measure (IM) considered in the IDA procedure is the $5 \%$-damped first mode spectral acceleration, $S_{a}\left(T_{1}, 5 \%\right)$ or $S_{a}$ in the following, and the engineering demand parameter (EDP) adopted is the maximum horizontal displacement at the roof level.

Table 3. Set of 30 horizontal ground motions adopted for time-history analyses as extracted from PEER Database (2020).

\begin{tabular}{|c|c|c|c|c|c|c|c|c|}
\hline Event name & Year & Station & $\begin{array}{c}\text { Comp. } \\
{\left[{ }^{\circ}\right]}\end{array}$ & Soil* & $\mathrm{M} \dagger$ & $\begin{array}{c}\mathrm{R} \S \\
{[\mathrm{km}]}\end{array}$ & $\begin{array}{c}\mathrm{PGA}_{\mathrm{H}} \\
{[\mathrm{g}]}\end{array}$ & $\begin{array}{c}\mathrm{PGA}_{\mathrm{V}} \\
{[\mathrm{g}]}\end{array}$ \\
\hline San Fernando & 1971 & LA, Hollywood Stor. Lot & 180 & $\mathrm{D}$ & 6.6 & 21.2 & 0.174 & 0.164 \\
\hline San Fernando & 1971 & LA, Hollywood Stor. Lot & 090 & D & 6.6 & 21.2 & 0.210 & 0.164 \\
\hline Imperial Valley & 1979 & Compuertas & 285 & D & 6.5 & 32.6 & 0.147 & 0.074 \\
\hline Imperial Valley & 1979 & Plaster City & 135 & D & 6.5 & 31.7 & 0.057 & 0.026 \\
\hline Imperial Valley & 1979 & El Centro Array \#12 & 140 & $\mathrm{D}$ & 6.5 & 18.2 & 0.143 & 0.069 \\
\hline Imperial Valley & 1979 & Cucapah & 085 & $\mathrm{D}$ & 6.5 & 23.6 & 0.309 & 0.135 \\
\hline Imperial Valley & 1979 & Chihuahua & 012 & $\mathrm{D}$ & 6.5 & 28.7 & 0.270 & 0.216 \\
\hline Imperial Valley & 1979 & El Centro Array \#13 & 140 & $\mathrm{D}$ & 6.5 & 21.9 & 0.117 & 0.049 \\
\hline Imperial Valley & 1979 & Westmoreland Fire Station & 090 & $\mathrm{D}$ & 6.5 & 15.1 & 0.074 & 0.086 \\
\hline Imperial Valley & 1979 & Chihuahua & 282 & $\mathrm{D}$ & 6.5 & 28.7 & 0.254 & 0.216 \\
\hline Imperial Valley & 1979 & El Centro Array \#13 & 230 & $\mathrm{D}$ & 6.5 & 21.9 & 0.139 & 0.049 \\
\hline Imperial Valley & 1979 & Westmoreland Fire Station & 180 & $\mathrm{D}$ & 6.5 & 15.1 & 0.110 & 0.086 \\
\hline Imperial Valley & 1979 & Compuertas & 015 & $\mathrm{D}$ & 6.5 & 32.6 & 0.186 & 0.074 \\
\hline Imperial Valley & 1979 & Plaster City & 045 & $\mathrm{D}$ & 6.5 & 31.7 & 0.042 & 0.026 \\
\hline Superstition Hills & 1987 & Wildlife Liquefaction Array & 090 & $\mathrm{D}$ & 6.7 & 24.4 & 0.180 & 0.402 \\
\hline Superstition Hills & 1987 & Wildlife Liquefaction Array & 360 & $\mathrm{D}$ & 6.7 & 24.4 & 0.200 & 0.402 \\
\hline Loma Prieta & 1989 & Agnews State Hospital & 090 & $\mathrm{D}$ & 6.9 & 28.2 & 0.159 & 0.074 \\
\hline Loma Prieta & 1989 & Hollister Diff. Array & 255 & $\mathrm{D}$ & 6.9 & 25.8 & 0.279 & 0.154 \\
\hline Loma Prieta & 1989 & Anderson Dam Downstrm & 270 & $\mathrm{D}$ & 6.9 & 21.4 & 0.244 & 0.155 \\
\hline Loma Prieta & 1989 & Coyote Lake Dam Downstrm & 285 & $\mathrm{D}$ & 6.9 & 22.3 & 0.179 & 0.096 \\
\hline Loma Prieta & 1989 & Sunnyvale Colton Ave & 270 & $\mathrm{D}$ & 6.9 & 28.8 & 0.207 & 0.107 \\
\hline Loma Prieta & 1989 & Anderson Dam Downstrm & 360 & $\mathrm{D}$ & 6.9 & 21.4 & 0.240 & 0.155 \\
\hline Loma Prieta & 1989 & Hollister South \& Pine & 000 & $\mathrm{D}$ & 6.9 & 28.8 & 0.371 & 0.197 \\
\hline Loma Prieta & 1989 & Sunnyvale Colton Ave & 360 & $\mathrm{D}$ & 6.9 & 28.8 & 0.209 & 0.107 \\
\hline Loma Prieta & 1989 & Halls Valley & 090 & $\mathrm{C}$ & 6.9 & 31.6 & 0.103 & 0.057 \\
\hline Loma Prieta & 1989 & WAHO & 000 & $\mathrm{D}$ & 6.9 & 16.9 & 0.370 & 0.271 \\
\hline Loma Prieta & 1989 & Hollister Diff. Array & 165 & $\mathrm{D}$ & 6.9 & 25.8 & 0.269 & 0.154 \\
\hline Loma Prieta & 1989 & WAHO & 090 & $\mathrm{D}$ & 6.9 & 16.9 & 0.638 & 0.271 \\
\hline Northridge & 1994 & LA, Baldwin Hills & 090 & B & 6.7 & 31.3 & 0.239 & 0.091 \\
\hline Northridge & 1994 & LA, Hollywood Storage FF & 360 & $\mathrm{D}$ & 6.7 & 25.5 & 0.358 & 0.139 \\
\hline
\end{tabular}

In the IDA procedure, each record has been scaled up to the attainment of at least one between the two collapse conditions, considering also the P- $\Delta$ effects. The results of the time-history analyses have been 28800 IDA curves, statistically combined in order to generate 960 numerical fragility curves (see the procedures in Silva et al. 2019) and then 120 fragility 
surfaces in which the value of the first vibrating period $T_{1}$ has been also considered as a variable (see Section 5).

The introduction of the cladding elements causes a significant stiffening of the perimeter frame with respect to the bare frame, changing the original elastic vibrating periods. Hence, for the sake of clarity and to avoid misleading, the outcomes presented in the following will be referred to the first period of vibration of the bare frame $T_{1}$ even if the record scaling has been performed with reference to $S a\left(T_{1}^{*}, 5 \%\right)$ (where $T_{1} *$ is the elastic vibrating period of a perimeter frame with cladding elements and, obviously, $T_{1} *<T_{1}$ for each category). Thus, the period of vibration for the perimeter frame has been calculated by removing the perimeter infills/panels from the FE model. Therefore, for the application of the method, the potential user should adopt the same procedure. This aspect makes the method more user-friendly since it simplifies considerably the procedure, especially for applications to existing buildings for which some structural parameters and details may be very complex to be determined through visual inspections only. Moreover, this allows a more direct comparison between frames with and without panels.

As an example, Figure 9 provides the percentage of attainment of the two different collapse mechanisms (failure of columns or sliding of roof elements). The results are reported for the sake of brevity for some representative frame categories only, i.e. A-L-L-I, A-M-H-I, A-H-H-I, CL-L-I, C-M-H-I and C-H-H-I, for $T_{1}=1 \mathrm{~s}$. The figure highlights that, for frames with friction-based support, i.e. A-L-L-I and C-L-L-I, most of the collapses can be attributed to sliding mechanisms. On the contrary, considering the frames with high-strength beam-column and roof slab element-beam connections, i.e. A-H-H-I and C-H-H-I, most of the collapses can be attributed to the failure of the columns. This confirms the reliability of the retrofitting criterion suggested by the Legislative Decree No. 74/2012 (2012) in the aftermath of the events. Indeed, the strengthening of the connections between precast elements has positive significant benefits preventing the fall of the roof elements, and can be considered the first effective retrofitting intervention to be introduced in order to reduce the vulnerability of these buildings. 


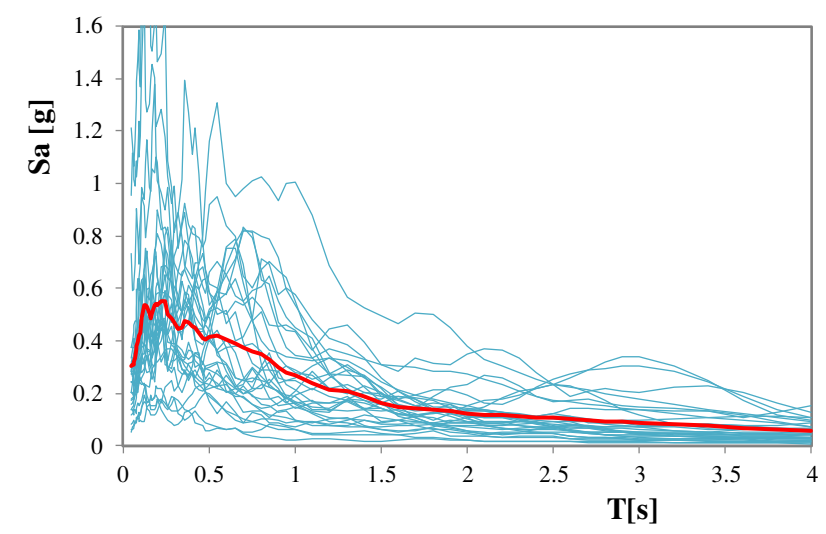

(a)

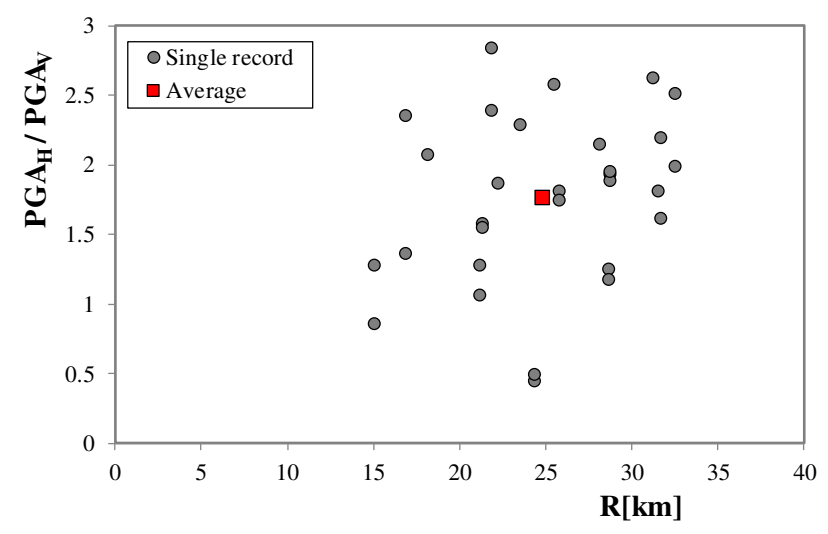

(b)

Figure 8. Seismic inputs adopted for the dynamic analyses: (a) 5\%-damped acceleration response spectra of the 30 horizontal ground motions and mean value (in red); (b) horizontal/vertical peak ground acceleration vs. closest distance to fault rupture (R) for the records selected.

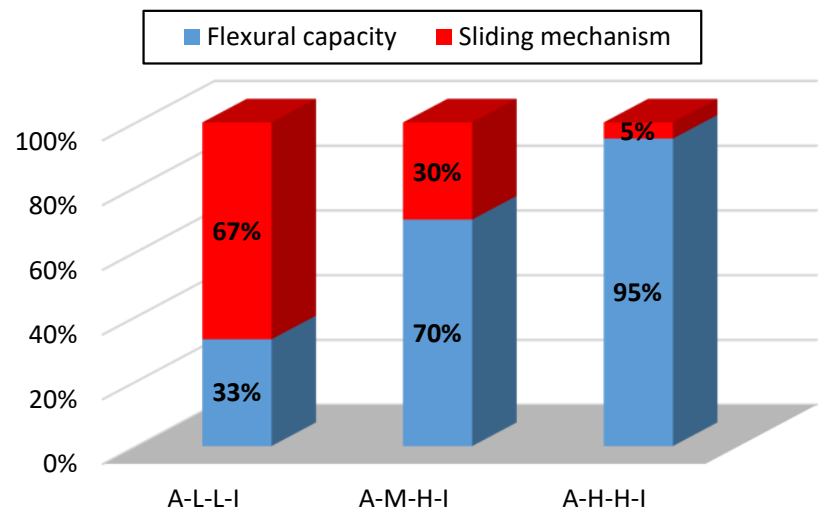

(a)

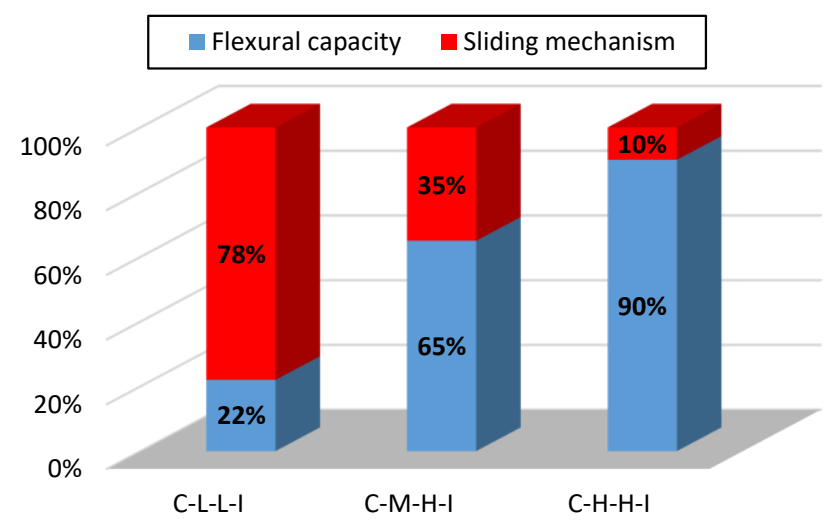

(b)

Figure 9. Percentage of attainment of the two collapse mechanisms for some frame typologies with two different base-column flexural capacity (for $T_{1}=1 \mathrm{~s}$ ). (a) Level A; (b) Level C. 


\section{Definition of fragility curves and surfaces of the frames}

\subsection{Fragility functions at collapse and severe damage}

By means of the results of the IDA curves, for each frame typology, the cumulative fraction of structures reaching a specific damage state for the 30 accelerograms has been calculated, providing a set of points. An empirical IM-based fragility function has been thus derived, by interpolating the so obtained set of points expressing the cumulative number corresponding to each IM. In particular, the set of points, representing the fragility for a given damage state of a frame with a specific period of vibration, has been fitted with a log-normal cumulative distribution function having the following form:

$$
\mathrm{F}(s)=\Phi\left[\frac{\ln \left(\frac{s}{\mu}\right)}{\sigma}\right]
$$

where: $s$ represents $S_{a}, \Phi[\cdot]$ is the standardized normal distribution function, $\mu$ and $\sigma$ are the main descriptors of the fragility function (i.e., the mean and the standard deviation, respectively). These parameters have been calibrated through the maximum likelihood function (see Eq.(2)), imposing the maximisation of $\ln \mathrm{L}$ (see Eq.(3)) in order to find the best fitting function for each numerical IDA dataset of points:

$$
\begin{gathered}
\mathrm{L}=\prod_{i=1}^{N}\left[\mathrm{~F}\left(s_{i}\right)\right]^{x_{i}} \cdot\left[1-\mathrm{F}\left(s_{i}\right)\right]^{1-x_{i}} \\
\frac{\partial \ln \mathrm{L}}{\partial \mu}=\frac{\partial \ln \mathrm{L}}{\partial \sigma}=0
\end{gathered}
$$

where: $S_{i}$ represents the i-th $S_{a}$ value, $x_{i}$ the corresponding probability of failure, $N$ is the total number of points (i.e., 30 points) for a specific damage state, and a specific frame category.

In Figures 10 and 11, the (best fitting) fragility curves resulting from the regression procedure are shown for some representative building categories and for three periods of vibration (i.e. $0.5 \mathrm{~s}, 1.0 \mathrm{~s}$ and $2.0 \mathrm{~s}$ ), at collapse and severe damage limit states, respectively.

It is worth noting again, for the sake of the clarity, that the outcomes presented in the following, for perimeter frames, refer to the vibrating period of the bare frames $T_{1}$ (without the presence 
of non-structural walls/panels), in order to simplify the comparisons between the behaviour of different categories.

Considering a specific value of $S_{a}$ (horizontal axis), the probability of exceedance (PoE) in both limit states (vertical axis of the fragility curves) increases with the increase of the period of vibration, meaning that the flexible frames (longer periods) are more likely to collapse or to be subjected to severe damage, due to large displacements and P- $\Delta$ effects. This effect is clearly visible for the internal frames, whereas it is not always valid for perimeter frames, in particular for those with masonry infill walls, which highly influence the structural behaviour (e.g. see sub-Figures a1, b1, c1, d1, e1, f1 in Figure 10 and 11).

Moreover, as expected, for a specific value of $S_{a}$ for each category, all the severe damage fragility curves in Figure 11 are characterized by higher PoE values with respect to the corresponding collapse fragility curves in Figure 10.

The increase of the flexural capacity at the base of the column, for instance from class A-L-L to class D-L-L, is reflected in a progressive decrease of the PoE for both limit states. Similarly, the benefit of having strong connections between the roof elements is evident by comparing the curves of frame category C-L-L and those of C-M-H.

For all frame categories, the presence of the perimeter elements on one hand has a positive effect in lowering the vulnerability of the frames if compared with that of the internal ones, on the other hand, it influences the shape of the fragility curves in a different way depending on the value of the period considered. This is only partially true for perimeter frames with vertical cladding panels, being the fragility curves very similar to those of the internal frames, due to the poor column-panel connections (see sub-Figures a3, b3, c3, d3, e3, f3 in Figure 10 and 11). As far as the different connection types of the horizontal cladding panels are concerned, the perimeter frame categories with the (h2) connections are significantly more vulnerable than those with (h1) connections. Indeed, the fragility curves of the frames with the (h1) connection 
typology have higher mean values than the ones with the (h2) typology, as can be seen in Figures 10 and 11 (see sub-Figures a2, b2, c2, d2, e2 and f2).

In addition, in order to perform some general comparisons, the collapse fragility curves are plotted in Figure 12 for the frame categories A-L-L, B-L-L and C-M-H, for various cladding typologies and different periods of vibration. The results obtained for the A-L-L category for frames with period of $1.5 \mathrm{~s}$ are shown in Figure 12 a. For a specific $S_{a}$ value, the masonry infilled frames (A-L-L-P(m)) show lower values of PoE at collapse, followed by those with horizontal cladding panels with (h1) connection (A-L-L-P(h1)). As mentioned before, horizontal cladding panels with (h2) connection (A-L-L-P(h2)) and vertical panels (A-L-L-P(v)) do not produce a relevant modification of the internal frame (A-L-L-I) fragilities, resulting in a very slight decrease of the PoE. The C-M-H frame category, characterized by higher strength of both columns flexural capacity and connections, exhibits an analogous behaviour (see Figure 12b). With reference again to the perimeter frame category A-L-L-P, in Figure 12c the behaviour of frames with horizontal cladding panels and the (h2) connection (A-L-L-P(h2)) is compared with those with the (h1) connection typology (A-L-L-P(h1)). The figure confirms that the former frames are more vulnerable if compared with the latter, independently of the value of the vibrating period of the frames.

Finally, the fragility curves for the 8 periods investigated are reported in Figure $12 \mathrm{~d}$ for the frame typology B-L-L-P(h2). As expected, with the increase of the period, a general decrease in both the $S_{a}$ value for a prescribed PoE (i.e. the collapse acceleration) and the $S_{a}$ dispersion (i.e. scattered tendency of the collapse acceleration dataset) occurs. 


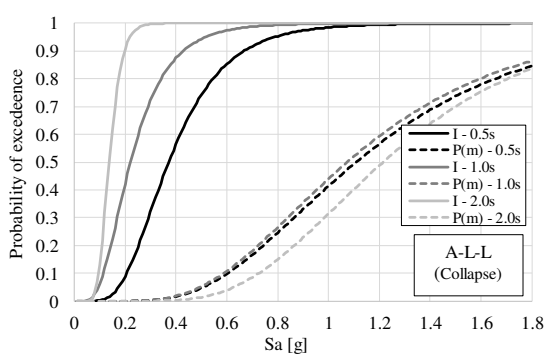

(a1)

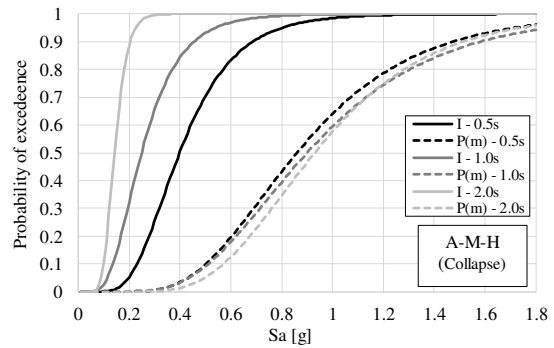

(b1)

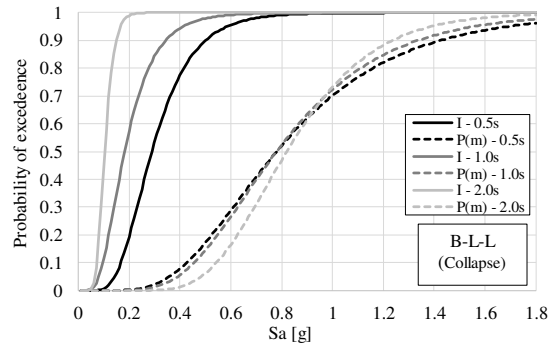

(c1)

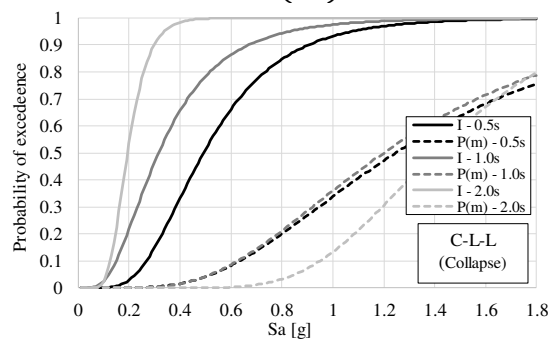

(d1)

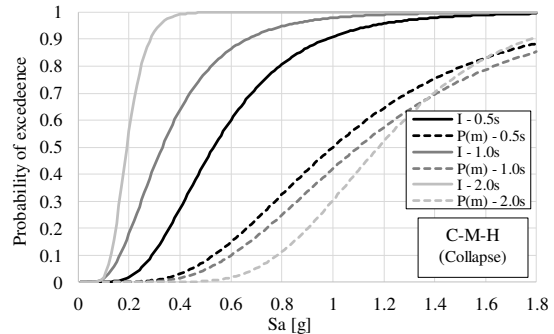

(e1)

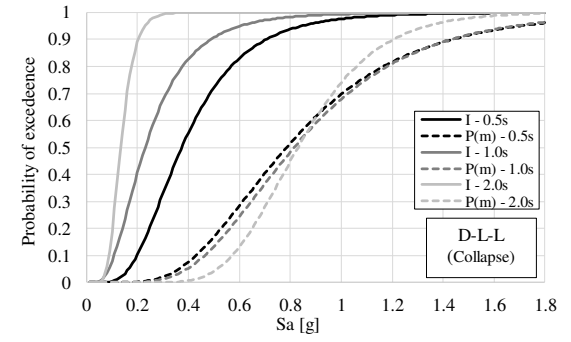

(f1)

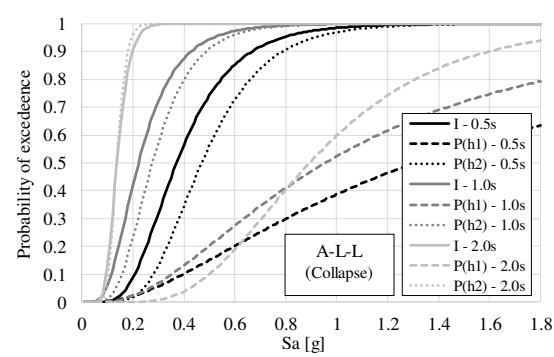

(a2)

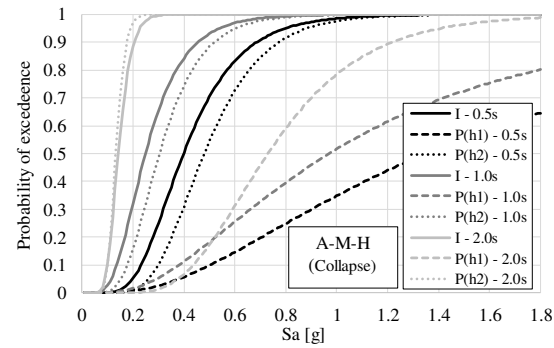

(b2)

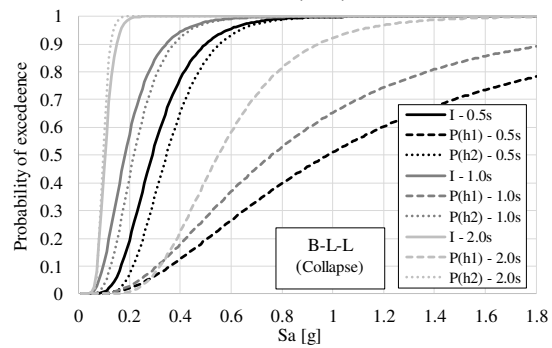

(c2)

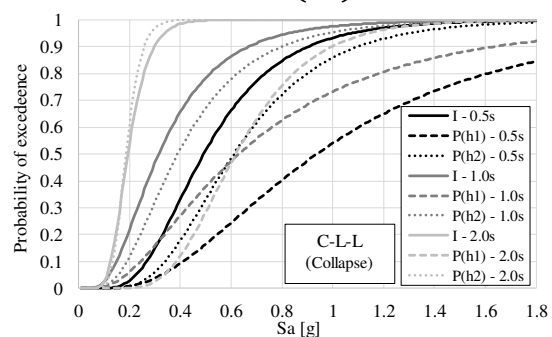

(d2)

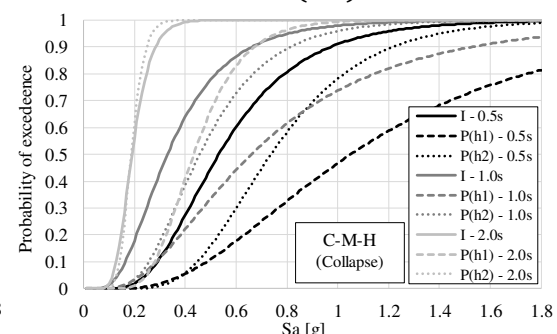

(e2)

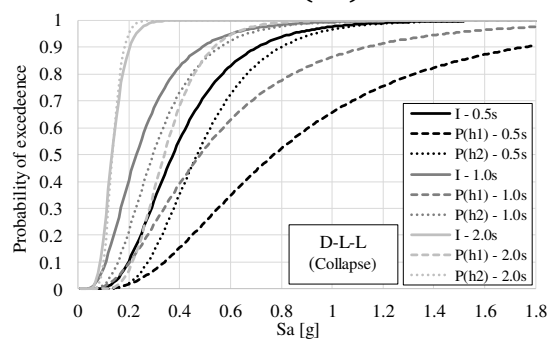

(f2)

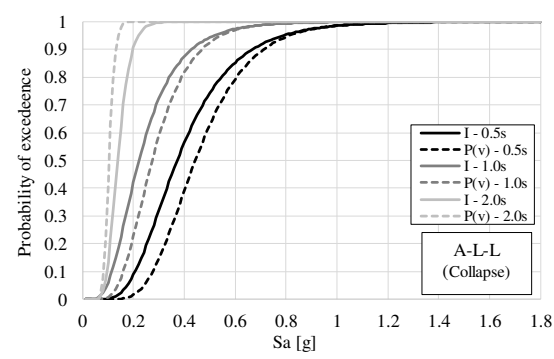

(a3)

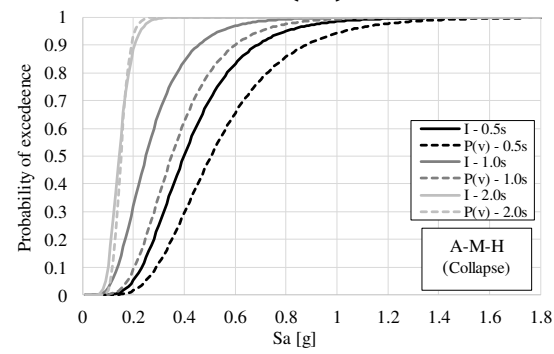

(b3)

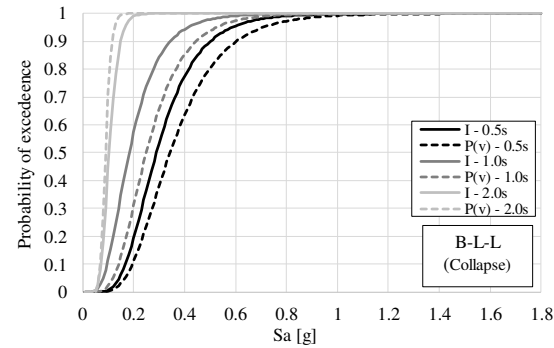

(c3)

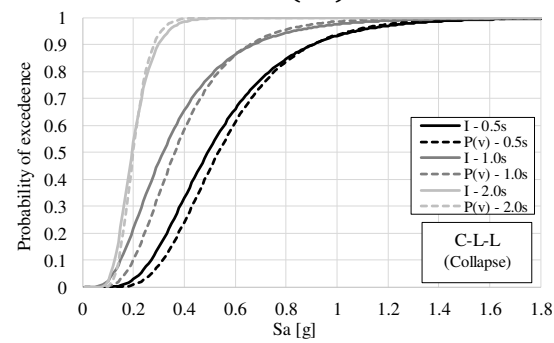

(d3)

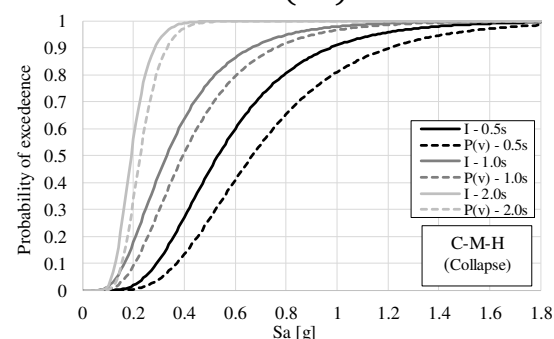

(e3)

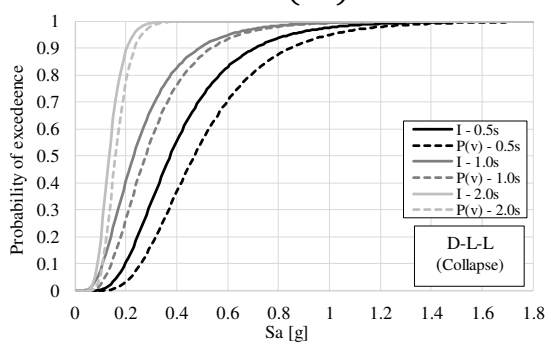

(f3)

Figure 10. Collapse fragilities for some relevant frame categories (I: internal frame; $\mathrm{P}(\mathrm{m})$, $\mathrm{P}(\mathrm{h} 1), \mathrm{P}(\mathrm{h} 2)$ and $\mathrm{P}(\mathrm{v})$ : perimeter frame with masonry infill walls, vertical and horizontal panels respectively). 


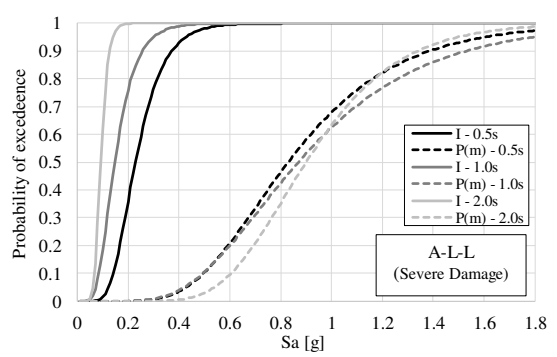

(a1)

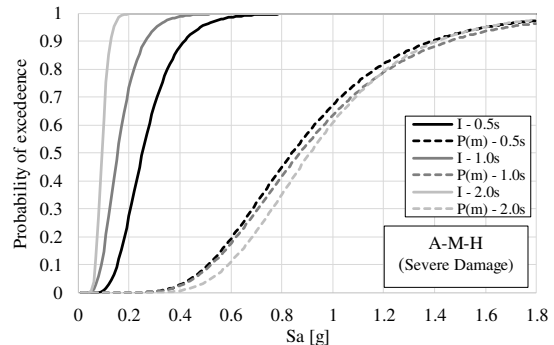

(b1)

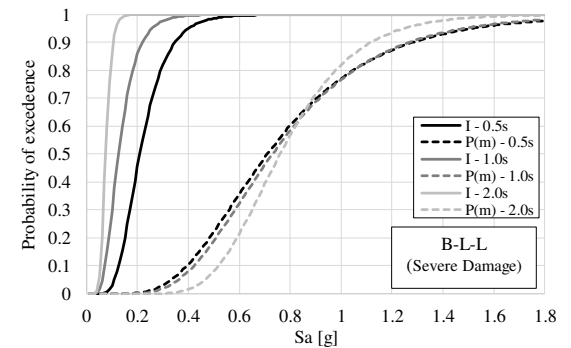

(c1)

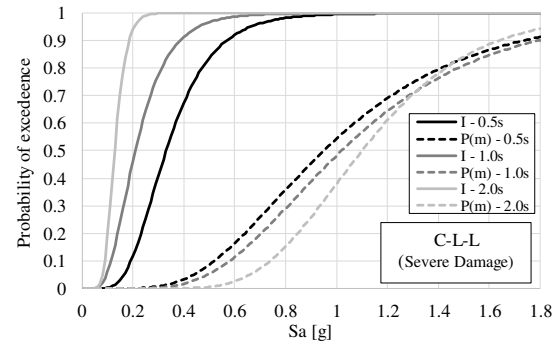

(d1)

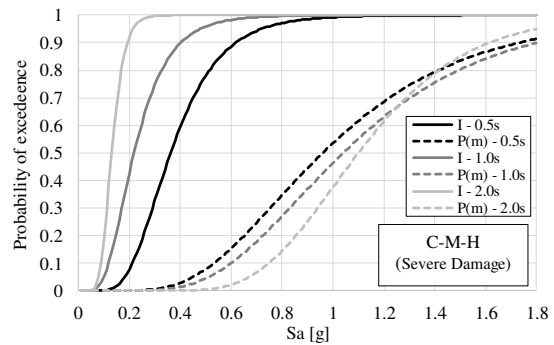

(e1)

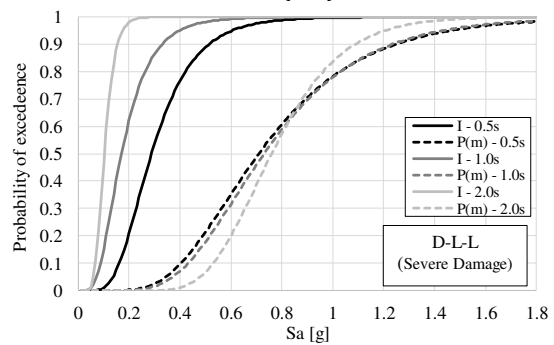

(f1)

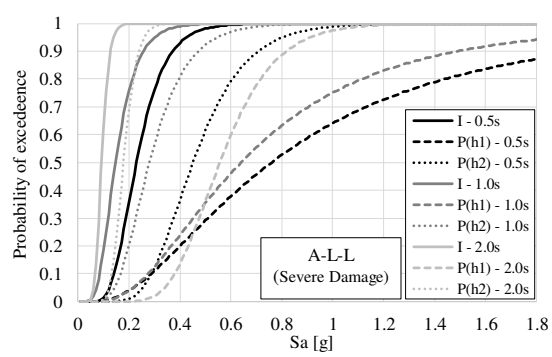

(a2)

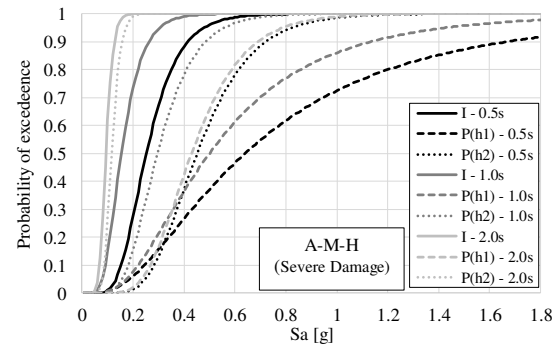

(b2)

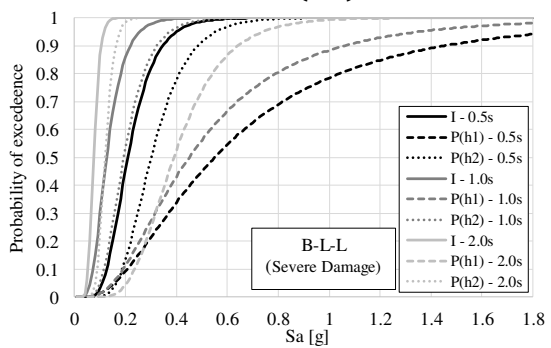

(c2)

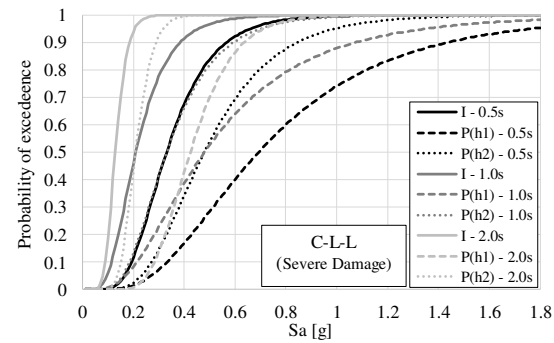

(d2)

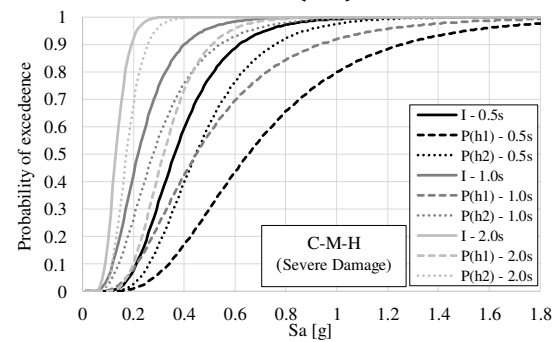

(e2)

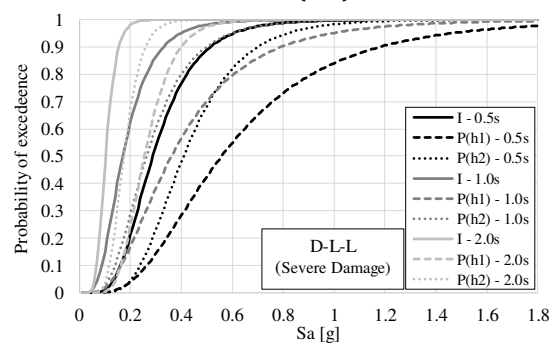

(f2)

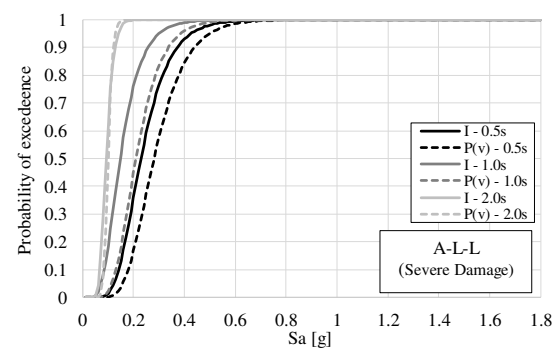

(a3)

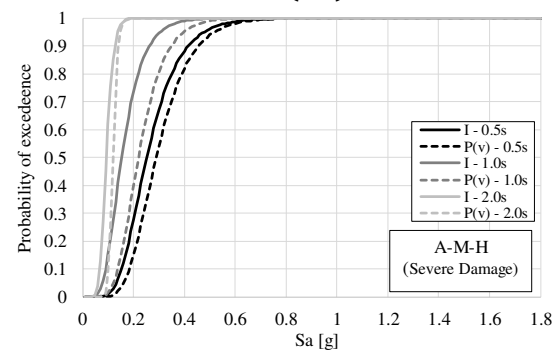

(b3)

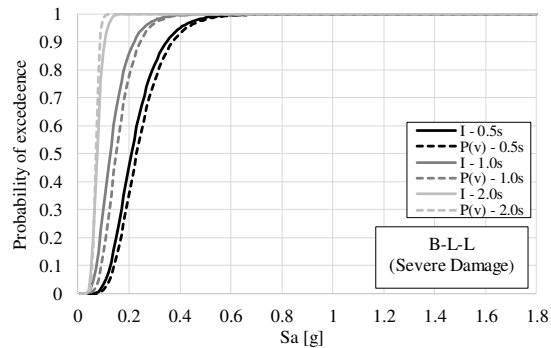

(c3)

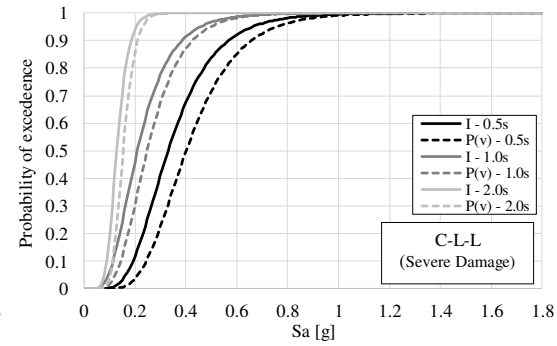

(d3)

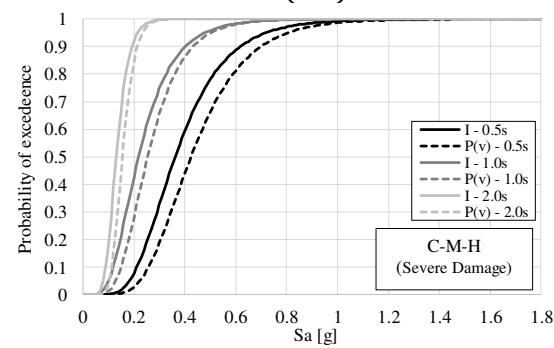

(e3)

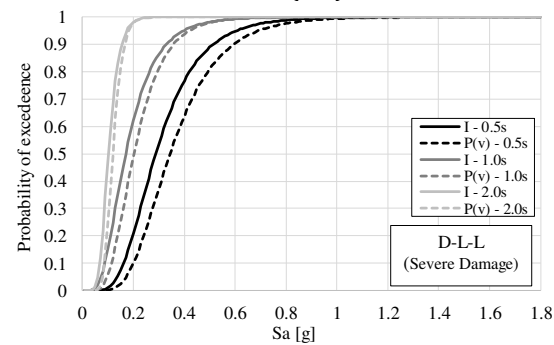

(f3)

Figure 11. Severe damage fragilities for some relevant frame categories (I: internal frame; $\mathrm{P}(\mathrm{m})$, $\mathrm{P}(\mathrm{h} 1), \mathrm{P}(\mathrm{h} 2)$ and $\mathrm{P}(\mathrm{v})$ : perimeter frame with masonry infill walls, vertical and horizontal panels respectively). 


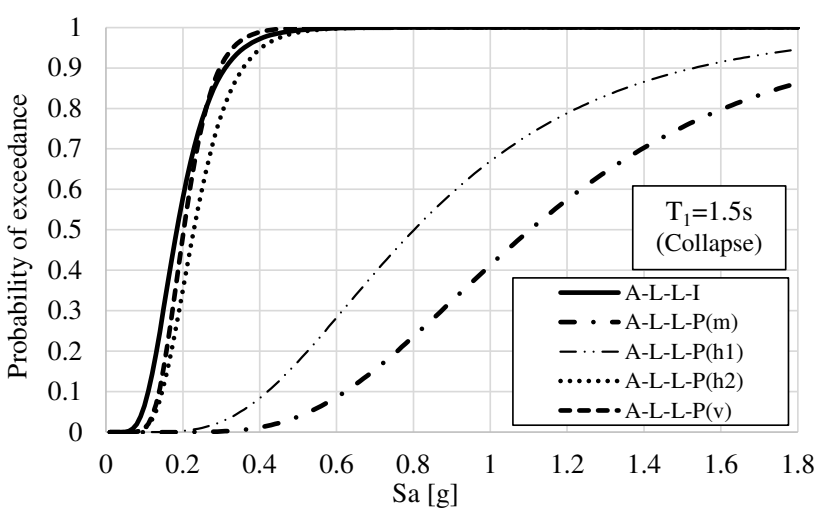

(a)

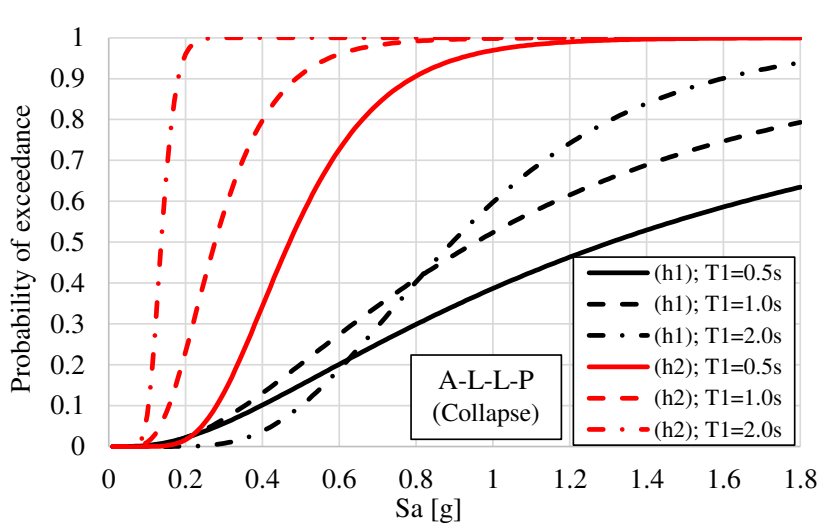

(c)

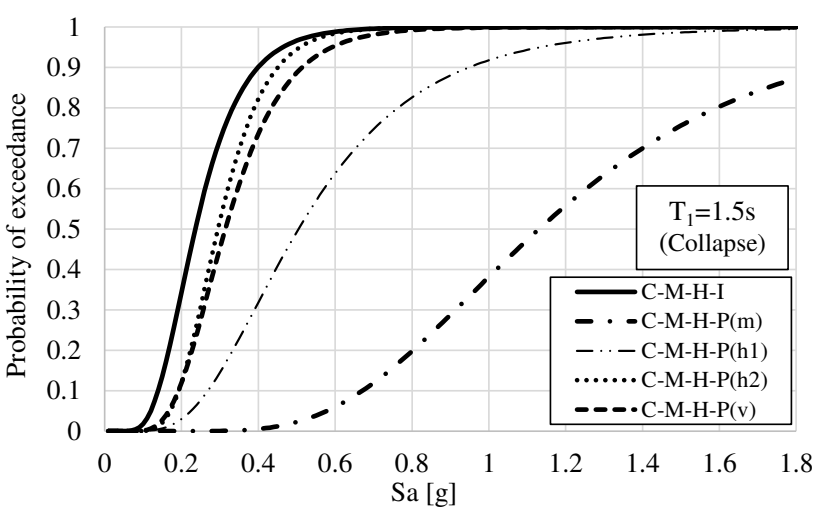

(b)

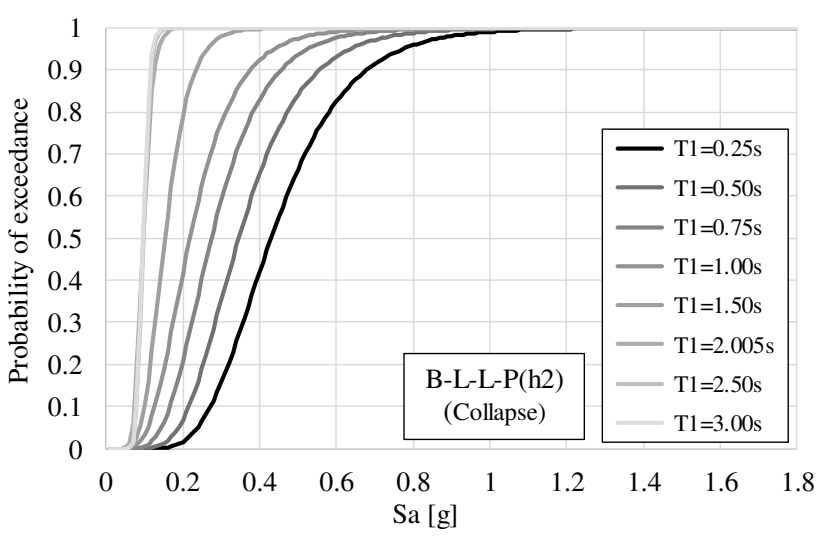

(d)

Figure 12. Collapse fragility functions of frames with perimeter walls. (a) Behavior of structures with different types of perimeter cladding elements (m: masonry walls; $\mathrm{h} 1$ and $\mathrm{h} 2$ : horizontal cladding panels with different connections; v: vertical cladding panels) for frame category A-LL-P with low flexural capacity and $T_{1}=1.5 \mathrm{~s}$ and (b) for frame category C-M-H-P with high flexural capacity and $T_{1}=1.5 \mathrm{~s}$; (c) Effect of the variation of typology with the horizontal cladding panels (h1) and (h2) on the seismic capacity of A-L-L-P frames for three different vibrating periods. (d) Effect of the vibrating period on the fragility of the frame category B-L-L$\mathrm{P}(\mathrm{h} 2)$ very common in the Emilia Romagna region. 


\subsection{Fragility surfaces at collapse and severe damage}

The fragility curves have been defined, for each structural typology, for 8 different periods of vibration $T_{1}$ and for the two limit states selected, i.e. structural collapse and structural severe damage. In order to provide the vulnerability of the frames as a function of $T_{1}$, the $2 \mathrm{D}$ fragility curves $\mathrm{F}\left(S_{a}\right)$ have been assembled for the creation of 3D smoothed fragility surfaces, expressed in the form $\mathrm{R}\left(S_{a}, T_{1}\right)$. The mathematical functions expressing the variation of the statistical fragility curve parameters $(\mu, \sigma)$ with the value of the vibrating period have been firstly identified. In particular, the selected trend functions of the two fragility curve descriptors referring to collapse are the following:

for $0<T_{1} \leq 2.0 \mathrm{~s}$

$\mu^{\mathrm{C}}\left(T_{1}\right)=\mathrm{a} 1 \cdot T_{1}{ }^{2}+\mathrm{a} 2 \cdot T_{1}+\mathrm{a} 3$

for $2.0 \mathrm{~s}<T_{1}<3.0 \mathrm{~s}$

$\mu^{\mathrm{C}}\left(T_{1}\right)=\mu^{\mathrm{C}}(2.0)$

for $0<T_{1}<3.0 \mathrm{~s}$

$$
\sigma^{\mathrm{C}}=\mathrm{b} 1 \cdot T_{1}{ }^{3}+\mathrm{b} 2 \cdot T_{1}{ }^{2}+\mathrm{b} 3 \cdot T_{1}+\mathrm{b} 4
$$

Analogous functions for the severe damage limit state are:

for $0<T_{1} \leq 2.0 \mathrm{~s}$

for $2.0 \mathrm{~s}<T_{1}<3.0 \mathrm{~s}$

for $0<T_{1} \leq 3.0 \mathrm{~s}$
$\mu^{\mathrm{SD}}=\mathrm{c} 1 \cdot T_{1}{ }^{2}+\mathrm{c} 2 \cdot T_{1}+\mathrm{c} 3$

$\mu^{\mathrm{SD}}\left(T_{1}\right)=\mu^{\mathrm{SD}}(2.0)$

$$
\sigma^{\mathrm{SD}}=\mathrm{d} 1 \cdot T_{1}{ }^{3}+\mathrm{d} 2 \cdot T_{1}{ }^{2}+\mathrm{d} 3 \cdot T_{1}+\mathrm{d} 4
$$

where: $T_{1}$ (in seconds) is the first vibrating period of the bare frame, and the coefficients a1-d4 have been obtained by fitting the IDA data through a nonlinear regression procedure based on the least squares' method (see Tables 4 and 5 for internal and perimeter frames, respectively). The effectiveness of the regression is proved by the value of the coefficient of determination, being $\mathrm{R}^{2}$ always greater than 0.9 and frequently over 0.95 . 
Table 4. Coefficients of Eqs. (4)-(5) for fragility surfaces of internal frames, as obtained by regression analysis.

\begin{tabular}{|c|c|c|c|c|c|c|c|c|c|c|c|c|c|c|}
\hline gory & a1 & a2 & a3 & b1 & b2 & b3 & b4 & c1 & c2 & c3 & d1 & d2 & d3 & d4 \\
\hline A-L-L-I & 0.067 & -0.325 & 0.513 & 0.084 & -0.467 & 0.614 & 0.273 & 0.035 & -0.176 & 0.301 & 0.083 & -0.467 & 0.655 & 0.162 \\
\hline A-L-H-I & 0.068 & -0.302 & 0.508 & 0.079 & -0.514 & 0.559 & 0.273 & 0.037 & -0.194 & 0.271 & 0.090 & -0.448 & 0.675 & 0.146 \\
\hline A-M-L-I & 0.070 & -0.306 & 0.564 & 0.078 & -0.462 & 0.589 & 0.281 & 0.036 & -0.174 & 0.325 & 0.075 & -0.425 & 655 & 171 \\
\hline A-M-H-I & 0.072 & -0.359 & 0.560 & 0.059 & -0.316 & 0.385 & 0.322 & 0.044 & -0.215 & 0.341 & 0.067 & -0.379 & 0.510 & .222 \\
\hline A-1 & 0.069 & -0. & 0.523 & 0.084 & -0.504 & 0.589 & 0.254 & 0.032 & -0 & 39 & 0. & -0.439 & 88 & \\
\hline A-H & 072 & -0 . & 0.571 & 0.065 & -0.284 & 0.397 & 0.348 & 0.041 & -0.194 & 0 & 0. & -0.352 & 36 & \\
\hline B- & 050 & -0.252 & 0.400 & 0.079 & -0.430 & 0.565 & 0.255 & 0.036 & -0.179 & 32 & 0.059 & -0.338 & 0.449 & \\
\hline B-L-H-I & 0.051 & -0.234 & 0.396 & 0.074 & -0.473 & 0.514 & 0.255 & 0.038 & -0.197 & 0.254 & 0.064 & -0.324 & 0.462 & 0.230 \\
\hline B-M-L-I & 0.053 & -0.237 & 0.440 & 0.073 & -0.426 & 0.542 & 0.263 & 0.037 & -0.177 & 0.305 & 0.053 & -0.308 & 0.449 & 0.276 \\
\hline B-N & 0.047 & -0.265 & 0.440 & 0.076 & -0.400 & 0.559 & 0.232 & 0.037 & -0.166 & 0.254 & 0.064 & -0.338 & 0.462 & 0 \\
\hline & 0 & -0.249 & 0.408 & 0.079 & -0.464 & 0.542 & 0.237 & 0.033 & -0.174 & 0.271 & 0.053 & -0.318 & 0.471 & \\
\hline B-H & 0.05 & -0.249 & 0.408 & 0.087 & -0.387 & 0.582 & 0.275 & 0.034 & -0.161 & 0. & 0.057 & -0.314 & 0.471 & \\
\hline $\mathrm{C}-\mathrm{-}$ & 070 & -0.358 & 0.624 & 0.086 & -0.491 & 0.675 & 0.284 & 0.054 & -0.270 & 0.445 & 0.067 & -0.381 & 0.513 & \\
\hline C-L-H-I & 0.064 & -0.376 & 0.587 & 0.083 & -0.457 & 0.608 & 0.293 & 0.055 & -0.278 & 0.481 & 0.066 & -0.419 & 0.554 & 0.2 \\
\hline C-M-L-I & 0.067 & -0.365 & 0.580 & 0.078 & -0.462 & 0.729 & 0.284 & 0.057 & -0.270 & 0.401 & 0.074 & -0.377 & 0.462 & 0.270 \\
\hline C-M-H-I & 0.092 & -0.467 & 0.735 & 0.085 & -0.447 & 0.553 & 0.321 & 0.066 & -0.321 & 0.499 & 0.068 & -0.389 & 0.541 & 0.247 \\
\hline C-H-L-I & 0.063 & -0.383 & 0.563 & 0.083 & -0.479 & 0.547 & 0.301 & 0.052 & -0.286 & 0.519 & 0.073 & -0.390 & 0.598 & 0.238 \\
\hline$C-1$ & 8 & -0.434 & 0.809 & 0.081 & -0.425 & 0.531 & 0.337 & 0.063 & -0.337 & 0.449 & 0.065 & -0.377 & 0.595 & \\
\hline & & -0 & 0.527 & 0.113 & -0. & 0.780 & 0.274 & 0.053 & -0.260 & 0.399 & 0.0 & -0.456 & 0.623 & \\
\hline & 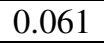 & -0.356 & 0.495 & 0.108 & -0.567 & 0.702 & 0.282 & 0.054 & -0.268 & 0.431 & 0.081 & -0.502 & 0.673 & 0. \\
\hline D-M-L-I & 064 & -0.346 & 0.490 & 0.103 & -0.573 & 0.842 & 0.274 & 0.056 & -0.260 & 0.359 & 0.090 & -0.451 & 0.561 & 0.262 \\
\hline D-M-H-I & 0.066 & 346 & 0.506 & 0.113 & -0.601 & 0.702 & 0.282 & 0.050 & -0.268 & 431 & 0.090 & -0.424 & 0.673 & 0.231 \\
\hline D-H-L-I & 0.064 & -0.315 & 0.580 & 0.108 & -0.580 & 0.749 & 0.288 & 0.051 & -0.273 & 0.359 & 0.079 & -0.442 & 0.685 & 0.229 \\
\hline D-H-H-I & 0.069 & -0.319 & 0.580 & 0.105 & -0.604 & 0.710 & 0.288 & 0.053 & -0.273 & 0.383 & 0.084 & -0.410 & 0.598 & 0.274 \\
\hline
\end{tabular}

Table 5a. Coefficients of Eqs. (4)-(5) for fragility surfaces of perimeter frames with masonry infill walls, as obtained by regression analysis.

\begin{tabular}{|c|c|c|c|c|c|c|c|c|c|c|c|c|c|c|}
\hline Cat & a1 & a2 & a3 & b1 & b2 & b3 & b4 & c1 & c2 & c3 & d1 & d2 & d3 & d4 \\
\hline A-L-L-P(m) & 0.034 & 044 & 1.095 & & 111 & 0.527 & 290 & & 0.074 & .797 & 094 & -0.440 & 0.543 & .244 \\
\hline & & & & & & & & & & & & & & \\
\hline & & & 18 & & & & & & & & & & & \\
\hline & 14 & 17 & 852 & & & 16 & & & 65 & & 63 & & 354 & \\
\hline A-H- & .033 & -0.041 & 1.229 & 086 & & 521 & 329 & -0.010 & 0.064 & 778 & 087 & -0.397 & 0.627 & 0.200 \\
\hline A-H- & 0.014 & 0.017 & 0.818 & 080 & -0.389 & 0.418 & 290 & -0.007 & 0.059 & 0.776 & 0.069 & -0.270 & .382 & .256 \\
\hline B-L & 0.011 & -0.004 & 0.779 & 0.043 & -0.160 & 0.090 & 449 & 0.003 & 0.024 & .699 & 0.064 & -0.278 & 0.251 & 0.393 \\
\hline B-L & 0 & 34 & 0.795 & 47 & 4 & 0.093 & 485 & 03 & 22 & 50 & 61 & & 64 & 58 \\
\hline B- & 0.010 & 4 & 857 & 0.041 & -0.149 & 0.089 & .409 & 3 & 25 & 92 & 69 & 78 & 59 & 354 \\
\hline B-1 & 11 & -0.004 & 0.724 & 0.039 & -0.150 & 0.097 & 9 & 03 & 26 & 36 & 70 & 275 & 0.226 & .405 \\
\hline B-H & 0.011 & -0.004 & 857 & 039 & 2 & 086 & 11 & 03 & 23 & 34 & 61 & 0.270 & 0.276 & 0.354 \\
\hline B-H & 0.011 & -0.004 & .771 & 0.040 & $1 / 6$ & 0.082 & 19 & .003 & 22 & 13 & 0.069 & -0.267 & 0.259 & 0.354 \\
\hline C-L & 0.012 & 0.093 & 1.167 & 19 & -0.525 & 0.546 & 34 & -0.011 & 0.129 & .886 & 0.071 & 0.298 & 0.275 & 0.398 \\
\hline & 0. & 095 & 120 & 9 & & 91 & 396 & -0.010 & 17 & 51 & 78 & 77 & 0.297 & 362 \\
\hline & & & 0 & 119 & & 524 & & .010 & 33 & 0.957 & 0.064 & -0 . & 0.288 & 0.438 \\
\hline C-1 & 012 & 0.162 & 924 & 0.100 & -0.444 & 0.472 & 0.355 & -0.019 & 48 & .889 & 0.072 & -0.303 & 0.280 & 0.385 \\
\hline $\mathrm{C}-\mathrm{H}$ & 0.011 & 0.098 & 097 & 114 & .488 & 0.491 & 96 & -0.011 & 0.121 & .913 & 0.070 & -0.327 & 0.297 & 0.398 \\
\hline $\mathrm{C}-\mathrm{H}-$ & -0.013 & 52 & 1.016 & 093 & 439 & 453 & 0.366 & -0.019 & 163 & 0.960 & 0.06 & -0.276 & 0.280 & 0.416 \\
\hline D-L-1 & -0.002 & 0.036 & 0.773 & 0.072 & -0.302 & 0.260 & 0.408 & 0.004 & 0.020 & 0.701 & 0.060 & -0.248 & 0.201 & 0.395 \\
\hline D-L- & -0.002 & 0.034 & 0.850 & 0.067 & 299 & 0.237 & 0.428 & 0.004 & 0.019 & 0.701 & 0.061 & -0.223 & 0.193 & 0.427 \\
\hline & -0.00 & & 765 & 0.068 & & 237 & 0.4 & & 0.019 & 0.694 & 0.064 & & 0.207 & \\
\hline & 2 & & 850 & 0.067 & & 50 & & 44 & 20 & 0.715 & 0.054 & 225 & 0.201 & 0.427 \\
\hline & 2 & & 50 & & & 250 & & 04 & 19 & 0.659 & 0.057 & -0.240 & 0.221 & 0.356 \\
\hline D-H & -0.002 & 0.037 & 0.719 & 0.066 & 84 & 281 & 0.408 & 0.004 & 0.018 & 0.771 & 0.066 & .245 & 0.181 & 0.407 \\
\hline
\end{tabular}


Table 5b. Coefficients of Eqs. (4)-(5) for fragility surfaces of perimeter frames with precast horizontal cladding panels (h1), as obtained by regression analysis.

\begin{tabular}{|c|c|c|c|c|c|c|c|c|c|c|c|c|c|c|}
\hline & a1 & a2 & a3 & b1 & b2 & b3 & b4 & c1 & c2 & c3 & d1 & d2 & d3 & d4 \\
\hline A-L & 53 & 714 & 1.576 & 141 & 0.609 & 0.479 & .289 & 0.097 & 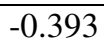 & .936 & 49 & .631 & .482 & .66 \\
\hline & 158 & 760 & 33 & 2 & 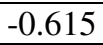 & 526 & 275 & 097 & 18 & 0.936 & 0 & -1 & 502 & \\
\hline A- & 0 & 768 & 1 & & 4 & 26 & 289 & 092 & 23 & 0.945 & 38 & & 0.408 & \\
\hline & & & & & & & & & 46 & 354 & & & 433 & \\
\hline & & & & & & & & & & & & & & \\
\hline & & & & & & & & & & & & & & \\
\hline B-I & 18 & & 1.325 & 99 & -0.577 & 514 & 642 & 083 & & 711 & 127 & & 40 & \\
\hline & 148 & -0.710 & 1.299 & 117 & -0.641 & 499 & 0.594 & .088 & 0.321 & 0.765 & 132 & & 419 & \\
\hline & 154 & & 1.425 & & & 0.476 & 642 & 0.079 & & 0.646 & & & 39 & \\
\hline & 14 & & 1 & & & & 0 & 91 & & $\overline{90}$ & & & & \\
\hline & 19 & 689 & 1.380 & & 5 & 0.571 & 0.623 & 88 & 0.351 & 690 & 0.115 & -0.5 & 77 & 32 \\
\hline & 157 & 0 & 1.205 & 134 & -0. & 9 & .705 & 81 & 0.306 & 658 & 18 & 50 & 427 & 0.740 \\
\hline C- & 152 & -0.659 & 1.2 & 182 & -0.9 & 1.155 & 0.289 & 20 & 0.510 & $\overline{922}$ & 35 & 54 & 788 & .342 \\
\hline & 16 & -0.0 & 145 & 56 & -0.8 & 1.247 & 0.289 & 0.126 & -0. & 839 & 19 & -0 & 99 & 52 \\
\hline & 155 & -0.613 & 1.219 & 71 & $-1 .($ & 1.051 & 0.289 & 0.126 & -0 . & 0.940 & 146 & 7 & 12 & 0.308 \\
\hline & 0 & -0.9 & 2 & & 7 & 15 & 12 & 21 & -0 & $\overline{07}$ & 31 & & 38 & 52 \\
\hline & & & & & & 0 & 12 & & & 0.857 & & & & \\
\hline & 2 & 9 & 1 & 3 & $-0 .$. & 0.772 & 0.412 & .127 & -0.588 & 0.825 & 144 & -0.644 & 754 & 22 \\
\hline D- & 164 & -0.740 & 1.119 & 131 & -0.630 & 0.715 & 0.437 & 0.129 & -0.566 & 0.841 & 133 & -0.637 & 0.745 & 0.367 \\
\hline & 169 & 696 & 1.231 & 122 & -0.6 & 0.651 & 0.45 & 0.1 & -0.594 & .757 & 0.136 & -0.573 & 715 & .396 \\
\hline $\mathrm{D}$ & 162 & 755 & 1.074 & + & -0.662 & 0.644 & 0.450 & 0.121 & -0.515 & 0.807 & 0.146 & -0.592 & 0.805 & 0.334 \\
\hline D-N & 0.169 & -0.733 & 1.141 & 1 & -0.680 & 0.686 & 0.406 & 0.117 & -0.583 & 0.908 & 120 & -0.599 & 0.782 & 0.404 \\
\hline & 0.149 & 0.777 & 1.0 & & 0.5 & 0.6 & 0.4 & 0.132 & 0. & 0.866 & 132 & -0. & 805 & 0.367 \\
\hline D-H & 0.172 & -0.696 & 231 & 122 & -0.624 & 686 & 0.450 & 132 & 23 & 908 & 20 & 30 & 745 & 0.396 \\
\hline
\end{tabular}

Table 5c. Coefficients of Eqs. (4)-(5) for fragility surfaces of perimeter frames with precast horizontal cladding panels (h2), as obtained by regression analysis.

\begin{tabular}{|c|c|c|c|c|c|c|c|c|c|c|c|c|c|c|}
\hline & a1 & a2 & a3 & b1 & b2 & b3 & b4 & c1 & c2 & c3 & d1 & d2 & d3 & d4 \\
\hline 2) & 07 & 0.494 & 0.697 & 0.075 & -0.401 & 0.486 & 0.272 & 0.052 & -0.275 & 524 & 122 & -0.615 & 835 & 0.083 \\
\hline A-L-H- & 0.107 & -0.489 & 0.711 & & -0.361 & 0.501 & 293 & 0.049 & -0.247 & & & & .877 & \\
\hline & & & & & & 82 & & 3 & 83 & & & & & \\
\hline & & & & & & & & & & & & & & \\
\hline & & & & & & & & & & & & & & \\
\hline & & & & & & & & & & & & & & \\
\hline B-I & 070 & -0.341 & 0.500 & 069 & -0. & 0.441 & 54 & 052 & -0.247 & 01 & & & & \\
\hline B-L & 0.071 & -0.317 & 0.495 & 065 & -0.404 & 0.401 & .254 & 0.055 & -0.229 & 409 & 08 & -0.469 & 23 & \\
\hline & & & & & -0.3 & & & .052 & & & & -0.440 & 80 & \\
\hline & & & & & & & & 49 & & & & & & \\
\hline $\mathrm{B}-$ & 2 & 337 & 0.5 & - & -0.39 & 0. & 36 & 47 & 54 & 433 & 90 & 50 & 5 & \\
\hline B- & 063 & 358 & 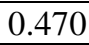 & 067 & -0.341 & 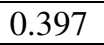 & 22 & 53 & 2 & 413 & 9 & 38 & 53 & 93 \\
\hline$C-1$ & 114 & -0 & 0.846 & 097 & -0.0 & 0.644 & 301 & .064 & -0 & & 46 & -0.689 & 10 & 232 \\
\hline & 0.118 & -0.522 & 0.930 & 0.090 & -0.518 & 0.586 & 0.316 & 0.064 & -0.316 & 0.622 & 0.148 & -0.620 & 0.777 & 0.251 \\
\hline & 0.117 & -0.510 & 0.837 & 91 & -0. & 0.586 & 0.301 & 0.067 & -0 . & 6 & 57 & 62 & 4 & 09 \\
\hline & 1 & & 1 & & & & 75 & 69 & & & & & & \\
\hline & & & & 0 & & 9 & 0 & 65 & 36 & & & & 10 & \\
\hline & 155 & 8 & 1.2 & 074 & -0.379 & 0.448 & 89 & 0.067 & -0.333 & 47 & 106 & 17 & .709 & .235 \\
\hline & 96 & $\underline{0}$ & 0 & 44 & 4 & 5 & 37 & 0.062 & -0.313 & 38 & 63 & 08 & 1.056 & 30 \\
\hline & 087 & 3 & 7 & 099 & -0. & 07 & .244 & .063 & -0.291 & 34 & 161 & .889 & 1.140 & .130 \\
\hline D-M-1 & 0.096 & -0.465 & 0.702 & 0.114 & -0.489 & 0.695 & 0.256 & 0.058 & -0.329 & 0.500 & 0.156 & -0.751 & 1.108 & 0.118 \\
\hline D-1 & 0.092 & -0.479 & 0.640 & 094 & -0.511 & 0.729 & 0.237 & 0.065 & -0.285 & 0.591 & .179 & -0.800 & 0.950 & 134 \\
\hline & 99 & 65 & .7 & 04 & -0. & 0.648 & 21 & 057 & & 4 & .146 & & 08 & 43 \\
\hline $\mathrm{D}$ & 95 & .19 & 661 & 104 & & 607 & 244 & 058 & -0.300 & 4 & 0.179 & -0.751 & 1.140 & \\
\hline
\end{tabular}


Table 5d. Coefficients of Eqs. (4)-(5) for fragility surfaces of perimeter frames with precast vertical cladding panels, as obtained by regression analysis.

\begin{tabular}{|c|c|c|c|c|c|c|c|c|c|c|c|c|c|c|}
\hline Cat & a1 & a2 & a3 & b1 & b2 & b3 & b4 & c1 & c2 & c3 & d1 & d2 & d3 & d4 \\
\hline A-L-L-P(v) & 091 & -0.435 & 0.620 & 0.120 & -0.606 & 0.744 & 0.156 & 0.046 & -0.226 & 0.339 & 0.107 & -0.531 & 0.627 & 0.160 \\
\hline & 0.097 & -0.41 & 0.564 & 0.125 & -0.652 & 0.752 & 0.171 & 0.045 & -0.219 & 0.342 & 0.099 & -0 . & 0.609 & 0.178 \\
\hline A-M & 0.095 & -0.426 & 0.667 & 0.132 & -0.645 & 0.689 & 0.156 & 0.044 & & 0.373 & & 36 & 597 & \\
\hline $\mathrm{A}-_{-}$ & 77 & & 0.693 & 24 & 7 & 9 & 55 & 0. & 51 & 21 & 13 & 54 & 0.646 & \\
\hline & 89 & 88 & 526 & 28 & 1 & 8 & 56 & 0. & 43 & 0. & 0. & 53 & 99 & \\
\hline & 75 & & 0.630 & & & & & & & & & & 0.673 & \\
\hline B-L-L-P(v) & 0.071 & -0.341 & 0.487 & 0.130 & -0.643 & 0.764 & 0.213 & 0.048 & -0.247 & 0.404 & 0.115 & -0.565 & 0.668 & 0.173 \\
\hline B-L-H & 0.069 & -0.363 & 0.443 & 0.140 & -0.649 & 0.840 & 0.203 & 0.048 & -0.235 & 0.449 & 0.113 & -0.628 & 0.696 & 0.160 \\
\hline B-M-I & 0.072 & -0.334 & 0.507 & 0.130 & -0.612 & 0.849 & 0.207 & 0.051 & -0.271 & 0.421 & 0.105 & -0.608 & 0.619 & 0.190 \\
\hline B-N & 0.069 & -0.344 & 0.477 & 0.130 & -0.595 & 0.7 & 0. & 0.053 & -0.240 & 0.374 & 0.128 & -0.601 & 0.636 & 57 \\
\hline B-H & 0.078 & -0.325 & 0.518 & 0.135 & $\begin{array}{l}-0.691 \\
\end{array}$ & 0.8 & 0.207 & 0.047 & -0.263 & 0.392 & 0.116 & -0.514 & 0.619 & 73 \\
\hline B-H & 0.068 & -0.363 & 0.443 & 0.140 & -0.649 & 0.796 & 0.207 & 0.047 & -0.225 & 0.374 & 0.128 & -0.621 & 0.668 & 0.160 \\
\hline C-L-L-P(v) & 0.099 & -0.470 & 0.744 & 0.115 & -0.571 & 0.713 & 0.200 & 0.077 & -0.359 & 0.557 & 0.109 & -0.532 & 0.655 & 0.188 \\
\hline C-L-H & 0.102 & -0.442 & 0.818 & 0.107 & -0.565 & 0.649 & 0.210 & 0.077 & -0.337 & 0.557 & 0.111 & -0.479 & 0.629 & 0.203 \\
\hline$C-1$ & 0.101 & -0.437 & 0.737 & 0.108 & -0.628 & 0.649 & 0.200 & 0.081 & -0.334 & 0.551 & 0.118 & -0. & 0.675 & 0.169 \\
\hline C-1 & 38 & -0.653 & 0.960 & 15 & -0.576 & 0.714 & 47 & 0.086 & -0.397 & 0.596 & 0.100 & -0.490 & 0.593 & 212 \\
\hline & 104 & & 0. & & & & 6 & 0.079 & 0.359 & 0.568 & 0.098 & -0.484 & 0.655 & 03 \\
\hline $\mathrm{C}-\mathrm{H}$ & 0.132 & .607 & 1.056 & .110 & -0.547 & 0.685 & 0.259 & 0.083 & -0.381 & 0.560 & 0.096 & -0.475 & 0.652 & 0.191 \\
\hline D-L-1 & 0.098 & -0.464 & 0.769 & 0.121 & -0.613 & 0.783 & 0.221 & 0.074 & -0.342 & 0.498 & 0.108 & -0.525 & 0.624 & 0.245 \\
\hline D-L-H & 0.089 & -0.487 & 0.723 & 0.116 & -0.570 & 705 & 0.228 & 0.075 & -0.318 & 0.448 & 0.107 & -0.578 & 0.674 & 0.245 \\
\hline D-M-L-P(v) & 0.098 & -0.459 & 0.784 & 0.133 & -0.552 & 0.806 & 0.239 & 0.070 & -0.359 & 0.463 & 0.104 & -0.488 & 0.655 & 0.223 \\
\hline D-M-H-P(v) & 0.094 & -0.473 & 0.715 & 0.110 & -0.576 & 0.846 & 0.221 & 0.078 & -0.311 & 0.548 & 0.119 & -0.520 & 0.562 & 0.252 \\
\hline & 101 & -0.459 & 0.784 & 121 & -0.662 & 0.752 & 0.206 & 0.067 & -0.349 & 0.448 & 0.097 & -0.494 & 0.655 & 0.270 \\
\hline D-H-H-P(v) & 0.097 & -0.473 & 0.738 & 121 & -0.644 & 0.705 & 0.228 & 0.070 & -0.328 & 0.513 & 0.119 & -0.488 & 0.674 & 0.223 \\
\hline
\end{tabular}

The fragility surfaces $\mathrm{R}\left(S_{a}, T_{1}\right)$ allow to consider the uncertainties in the value of $T_{1}$ in the estimation of the vulnerability of a precast frame. A similar tool was proposed by Crowley et al. (2004), with reference to ordinary RC buildings, for the derivation of relationships between the displacement capacity and the fundamental period of a building.

As a general example, a fragility surface for the category A-M-H-I is shown in Figure 13, together with the IDA data adopted in the fitting procedure: for a value of $T_{1}$ ranging between $0.25 \mathrm{~s}$ and $3.0 \mathrm{~s}$, from the 3D fragility surface it is possible to extract the corresponding 2D fragility curve.

The plots of Eq.(4) and (5) are illustrated for some relevant structural categories in Figure 14 and 15, for collapse and severe damage state, respectively. While the trends related to $\sigma$ are characterized by similar wavy shapes, the trend of $\mu$ presents some variations both in case of collapse and severe damage. In particular, for some categories (see sub-Figure a1, c1, d1 and 
e1 in Figure 14) it has have a reversed bell shape, differently from those of the perimeter frame categories with masonry infill walls (sub-Figure b1 in Figure 14). This seems to be linked to the strong influence of the latter cladding typology on the frame response, as masonry infill walls influence, in particular, the highest vibrating periods.

The poor behaviour of the (h2) type of connection for horizontal cladding panels, with respect to the (h1) ones, is once again highlighted by lower values of the $\mu$ functions for both limit states (see sub-Figures $\mathrm{c} 1$ and $\mathrm{d} 1$ in Figure 14). The $\sigma$ functions, related to the frames with the two different horizontal cladding panel connections, have similar trends for high periods, whereas they are very different for low periods (see sub-Figures c2 and d2 in Figure 14). In particular, the (h1) connection typology results in higher $\sigma$ values for the more sensitive structural categories, i.e. A-L-L and A-M-H, at the low period values (see sub-Figure c2 in Figure 14). These different trends are justifiable because the weak (h2) connection, differently from the (h1) typology, is not able to modify considerably the seismic response and the collapse value of the perimeter frames with respect to the internal (bare) frames. Hence, for frames with (h2) connection type, in the whole range of periods investigated, the $\sigma$ value is very similar to the case of internal frames. This effect is no more visible at higher periods for the frames with (h1) connections, because of the presence of remarkable P- $\Delta$ effects (in flexible frames). The same effects can be observed in the curves in Figure 15. 


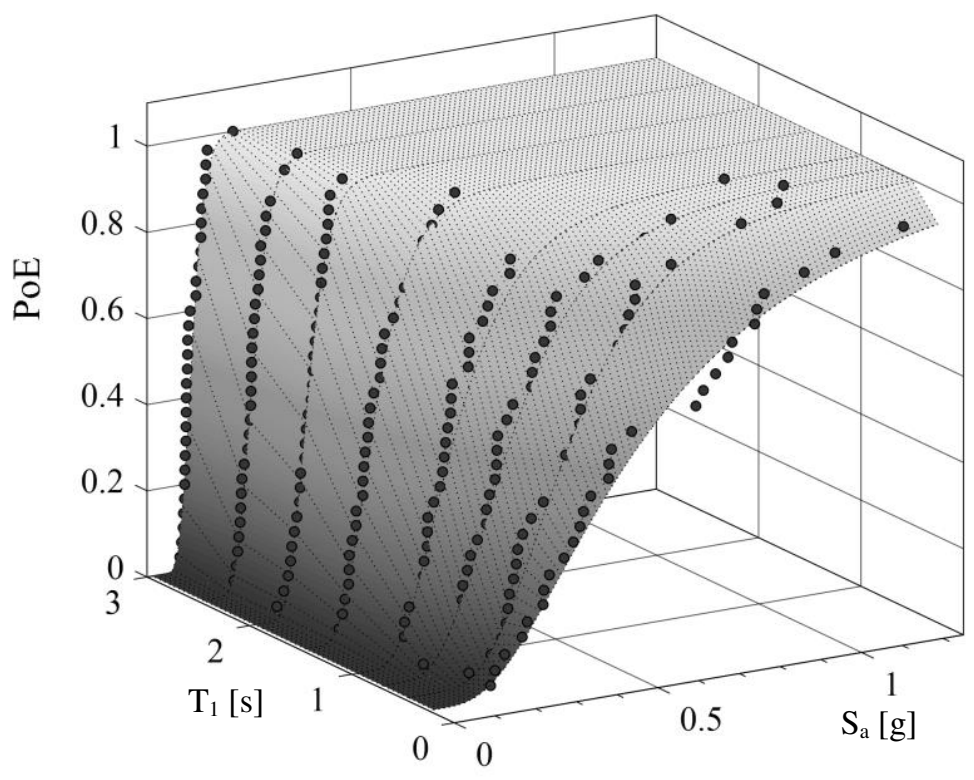

Figure 13. Example of a fragility surface (for A-M-H-I frame category). Points obtained from IDA and best fitting approximation for the different periods.

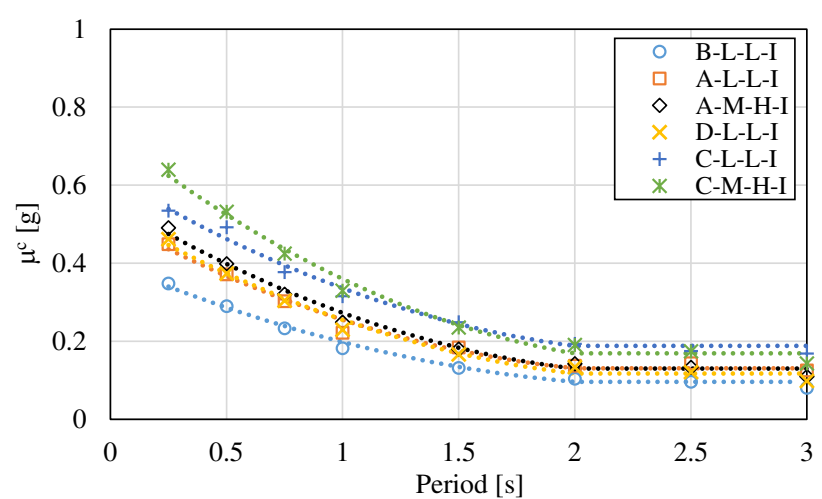

(a1)

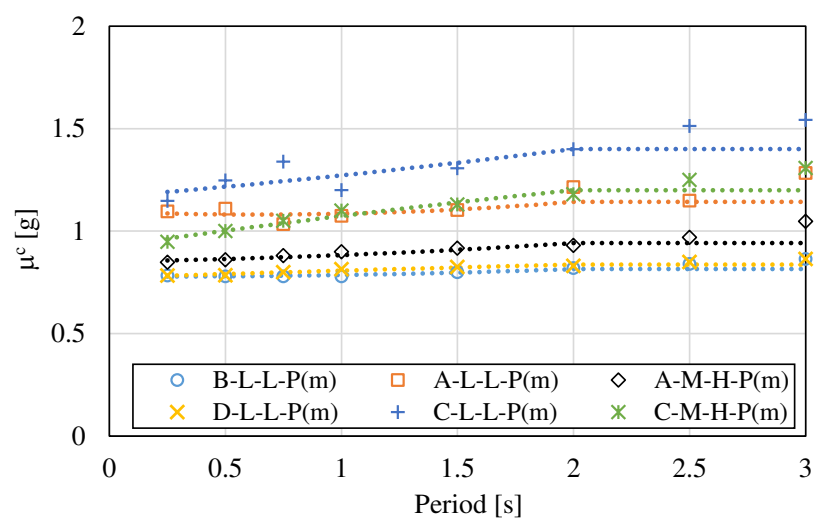

(b1)

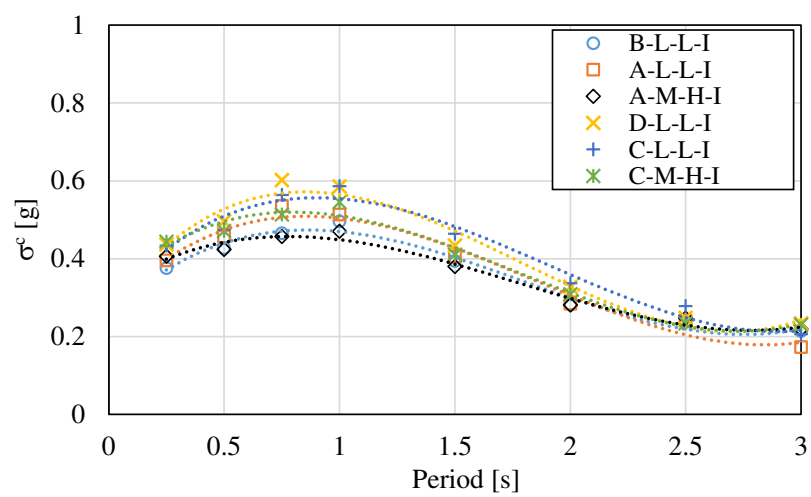

(a2)

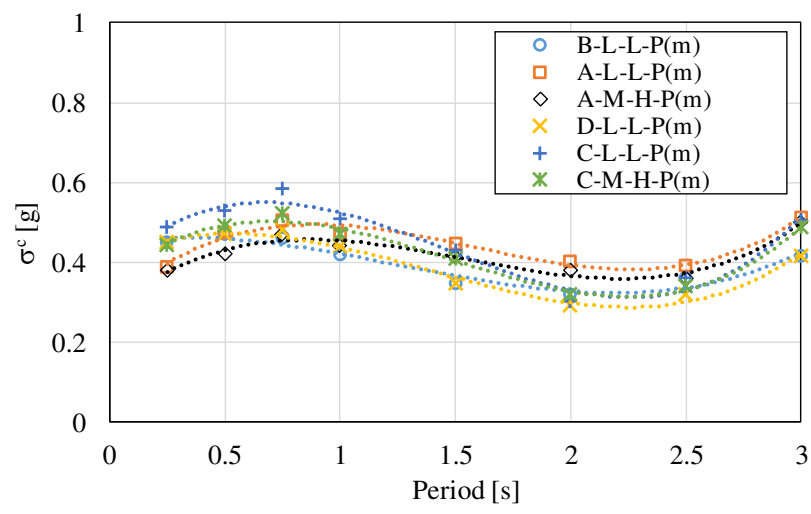

(b2) 


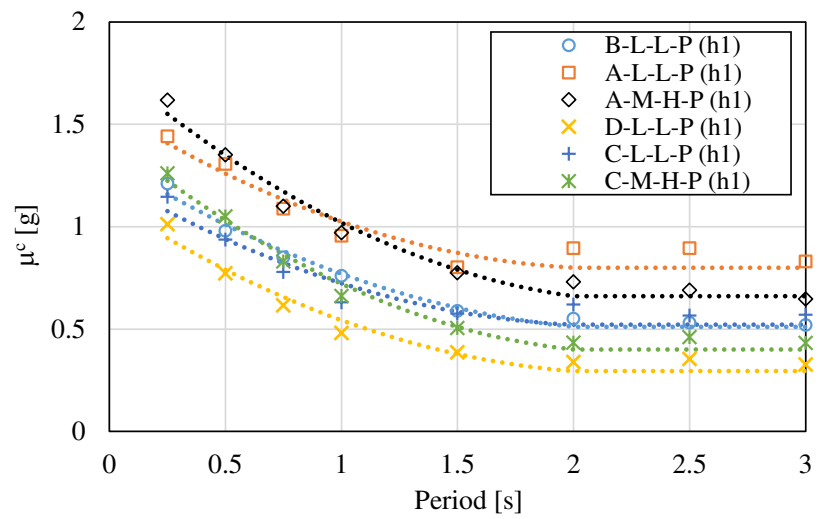

(c1)

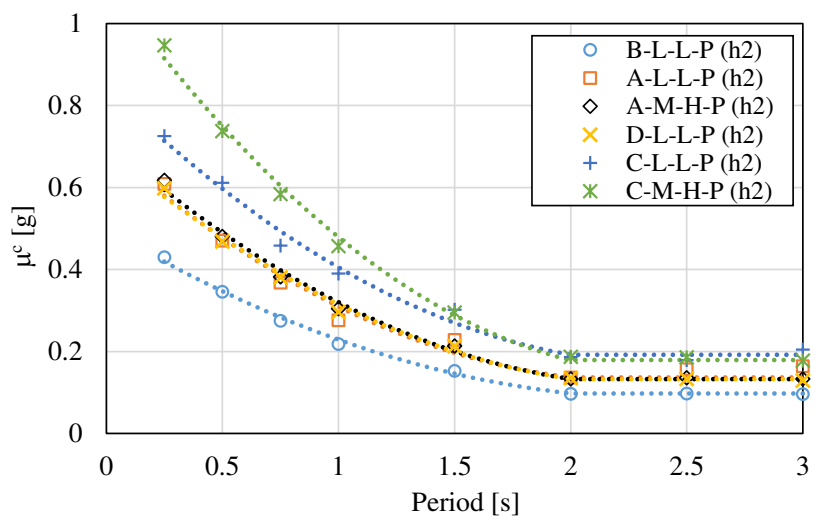

(d1)

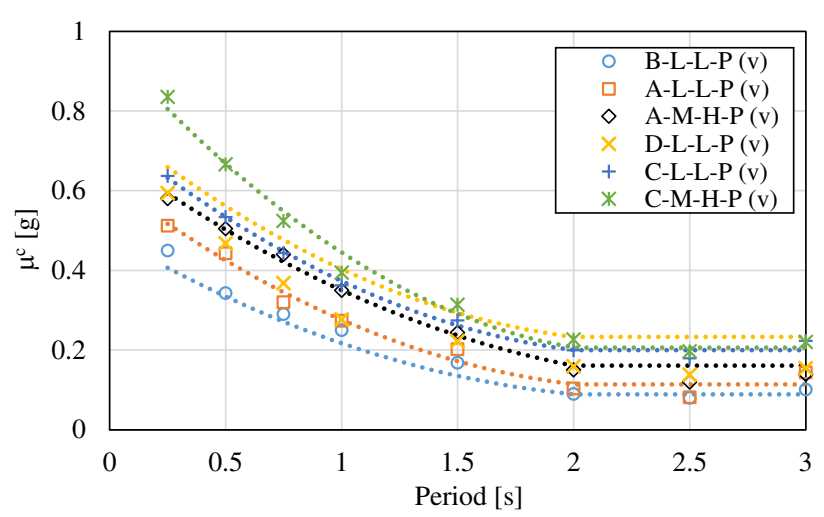

(e1)

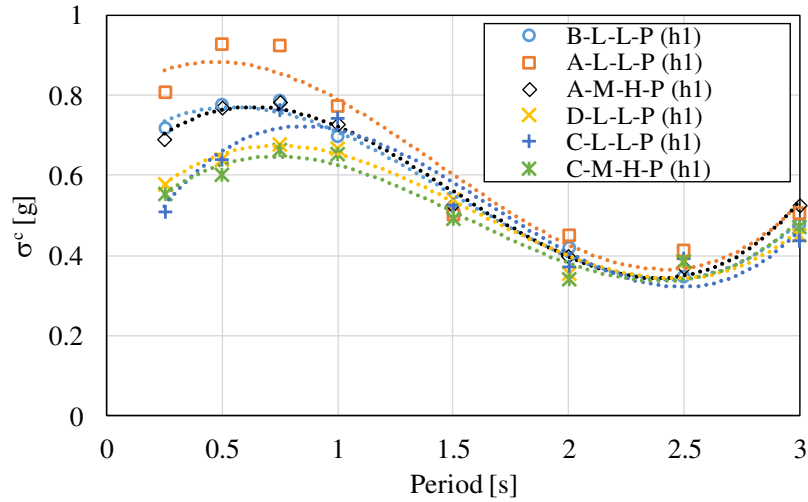

(c2)

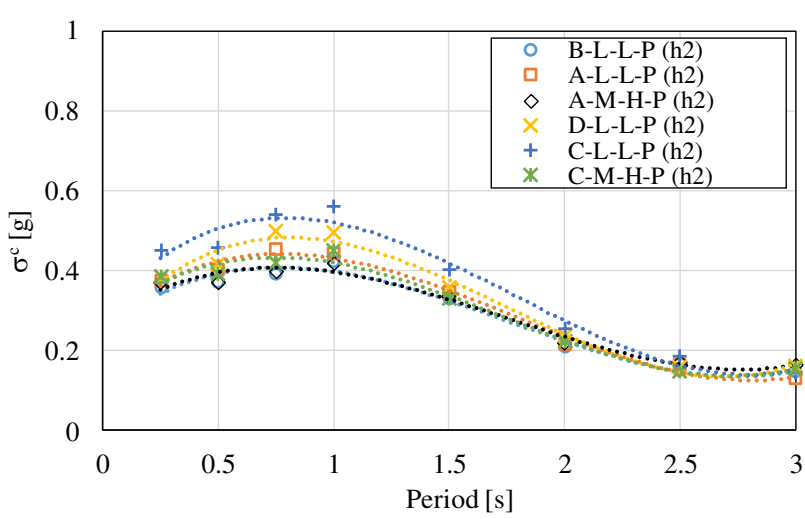

$(\mathrm{d} 2)$

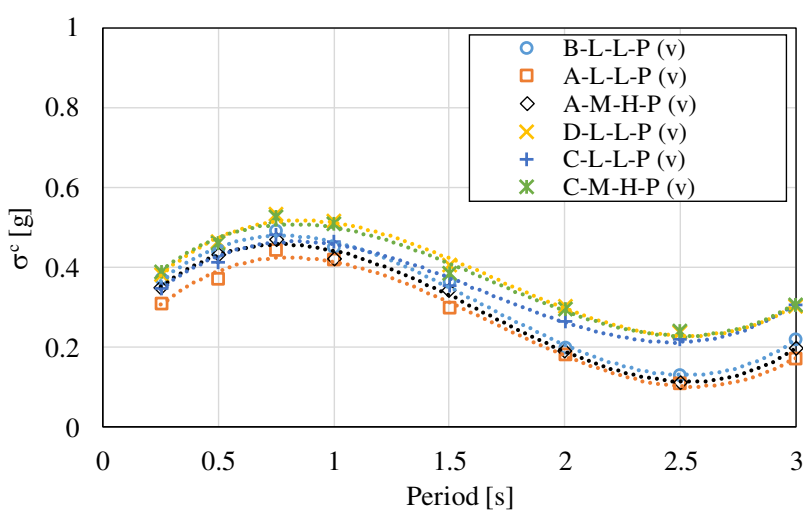

(e2)

Figure 14. Trend of median value $\mu^{\mathrm{C}}$ and standard deviation $\sigma^{\mathrm{C}}$ of lognormal distributions for different vibrating periods $T_{1}$ at collapse for some relevant frame typologies (see Eqs. (4)) for (a) internal frames and perimeter frames with (b) masonry infills, (c) horizontal panels with (h1) connection, (d) horizontal panels with (h2) connection and (e) vertical panels. 


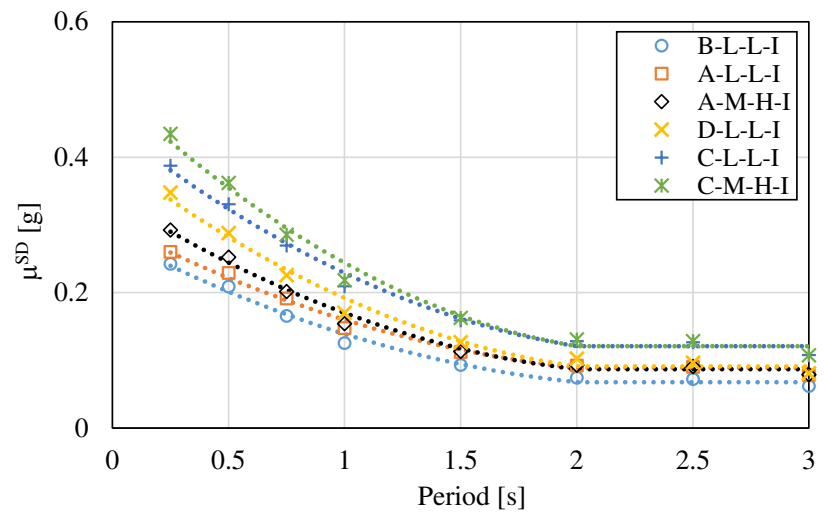

(a1)

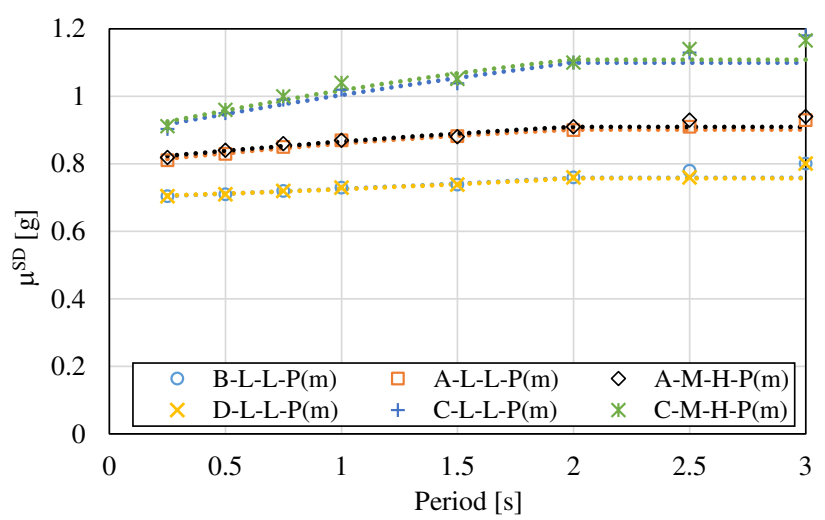

(b1)

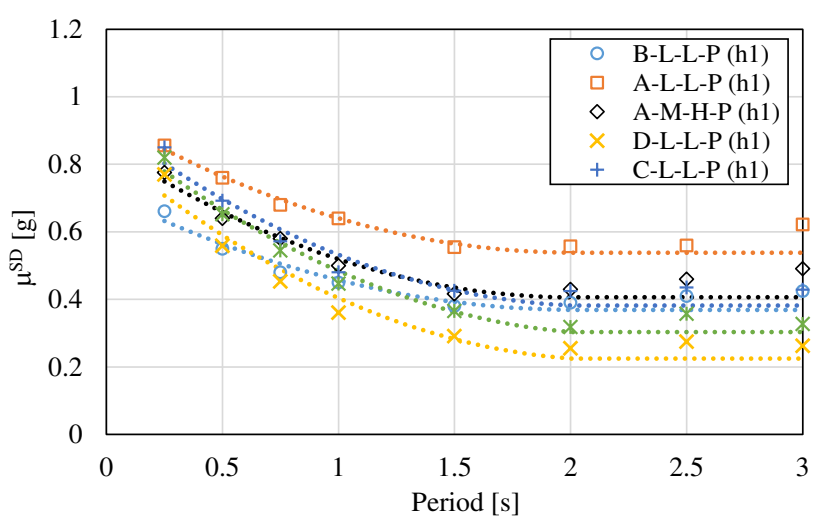

(c1)

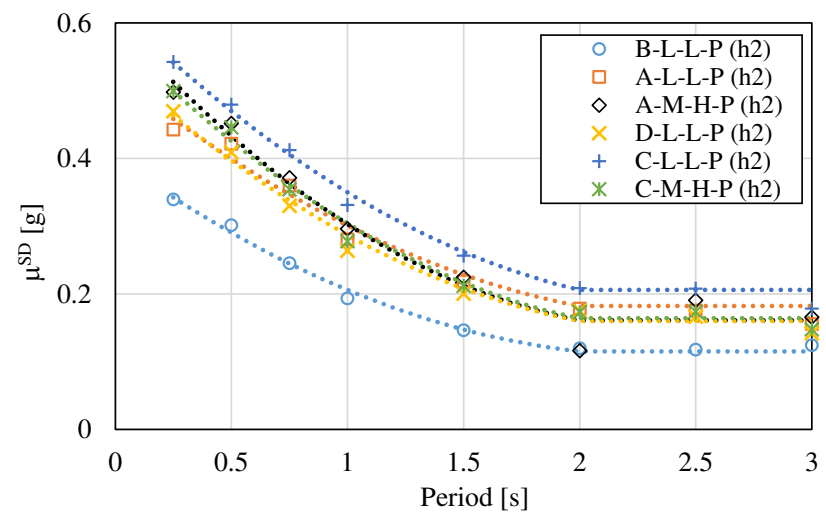

(d1)

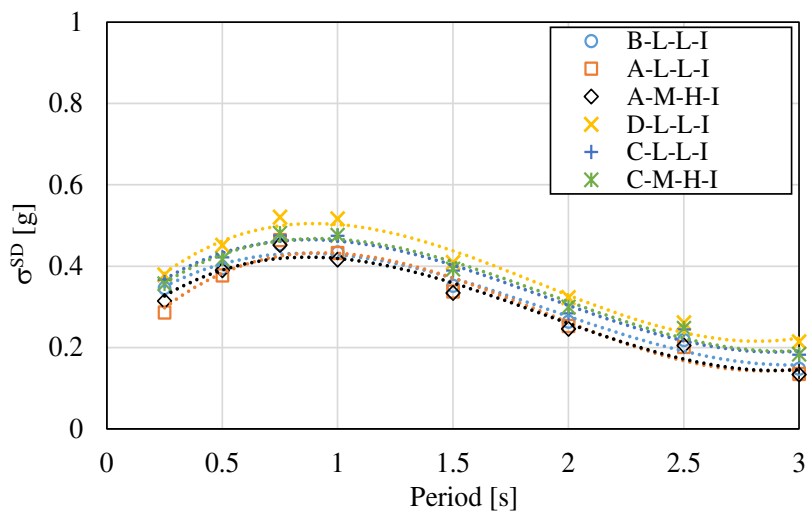

(a2)

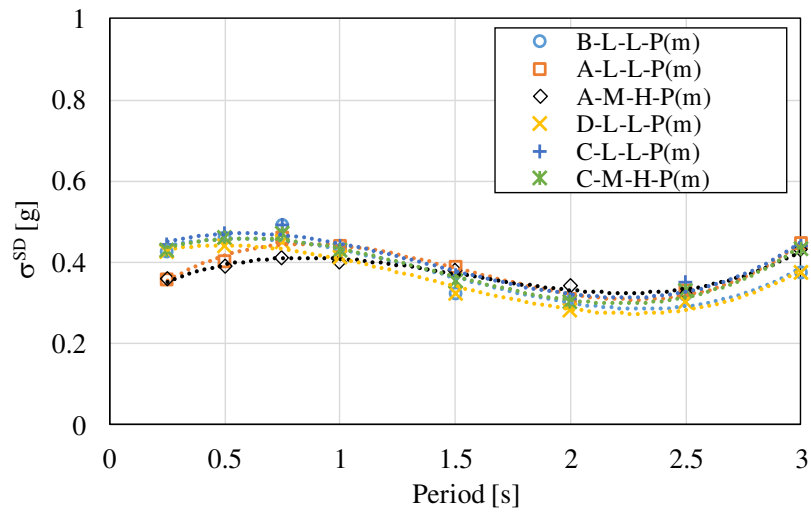

(b2)

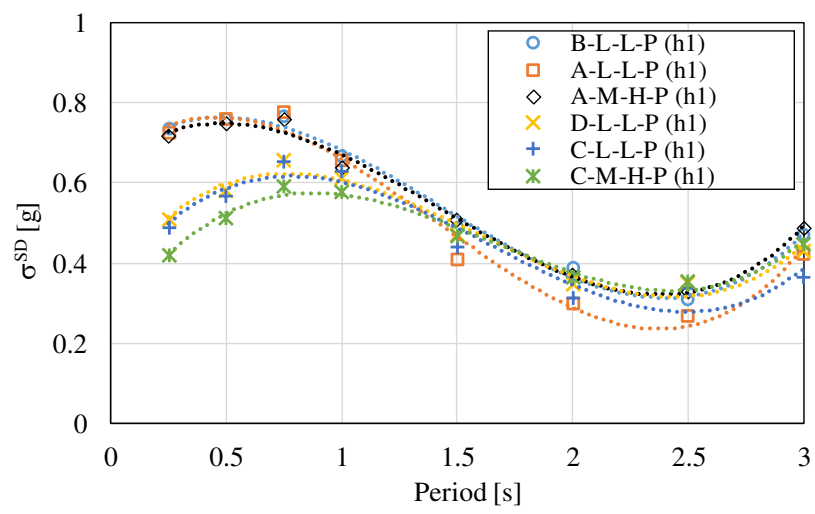

(c2)

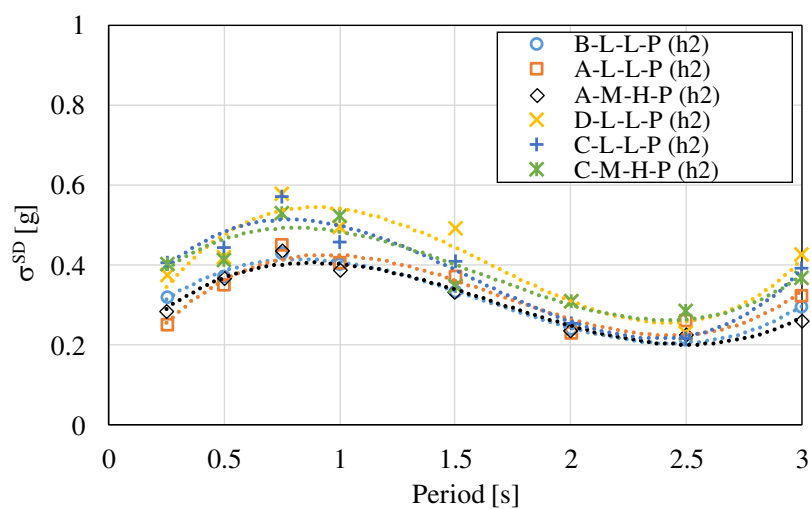

(d2) 


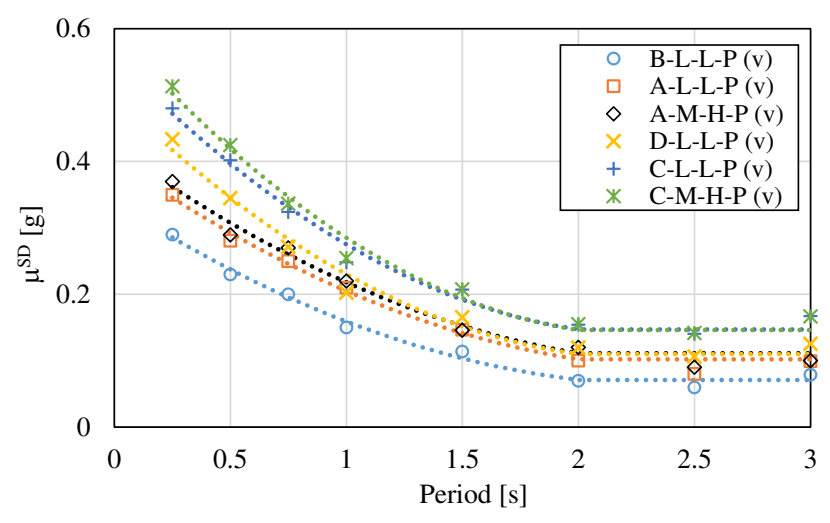

$(\mathrm{e} 1)$

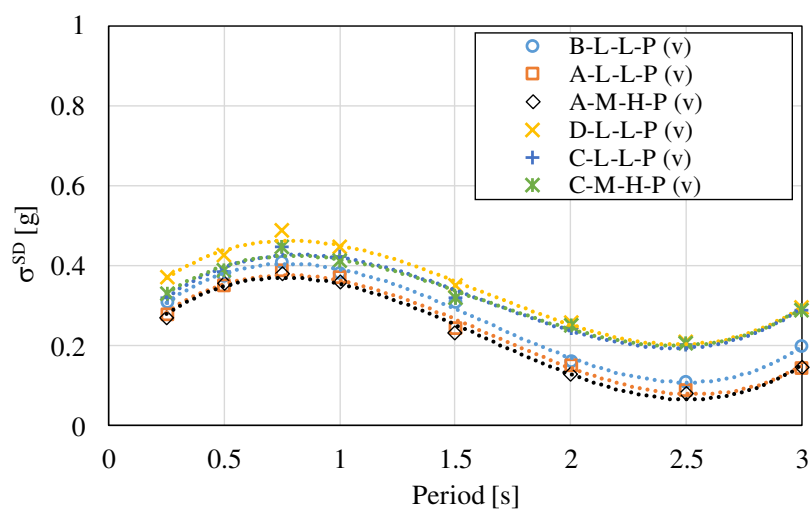

(e2)

Figure 15. Trend of median value $\mu^{\mathrm{SD}}$ and standard deviation $\sigma^{\mathrm{SD}}$ of lognormal distributions for different vibrating period $T_{1}$ at severe damage condition for some relevant frame typologies (see Eqs. (5)) for (a) internal frames and perimeter frames with (b) masonry infills, (c) horizontal panels with (h1) connection, (d) horizontal panels with (h2) connection and (e) vertical panels.

\subsection{Fragility surfaces of infill walls/panels (at failure)}

Analogously to the procedure described in the previous Sections for the structural frames, the IDA outcomes related to the failure of perimeter infill walls and cladding panels have been elaborated to obtain fragility curves (i.e. fragility functions) of the various types of building perimeter elements.

The fragility curves for masonry infill walls have been defined considering the attainment of the peak point in the force-displacement curve of the equivalent struts (see sub-Figure b1 in Figure 7). For the precast RC cladding panels, instead, the failure condition has been set, conventionally, at the attainment of the peak point in the constitutive diagram of the connections hanging the panel (see the laws of the connections in sub-Figures b2 and b3 in Figure 7, and the red circles reporting the label "Failure").

For some frame classes, the structural collapse anticipates the failure of the perimeter elements and, in those cases, i.e. for panels largely more robust than the frame, the IM value causing the collapse is not available. In other cases, the structural collapse and the failure of non-structural elements have comparable values and the walls/panels failure data are available just for some seismic inputs over the whole set investigated. Assuming the fragility functions of the 
walls/panels to be independent from the frame class, the fragilities of a given cladding element have been obtained, irrespective of the frame typology, by considering all the collapse data available (i.e. when the wall failure anticipated the frame structural collapse). In this way, it has been possible to establish, for the different cladding typologies and for each period investigated, the lognormal fragility functions. They have been provided assuming the same laws for the characteristic parameters of the distribution (i.e. $\mu$ and $\sigma$ ) as given in Eq.(4).

The values of $\mu$ and $\sigma$ of the curves of the various perimeter elements are shown in Figure 16 for the different periods of vibration. For the sake of brevity, Eq.(4a) and Eq.(4c) of the fitting curves are reported directly in Figure 16. Obviously, the equations of $\mu$ reported in the figure are valid up to $T_{1}=2.0 \mathrm{~s}$ whereas the trends for vibrating periods higher than $2.0 \mathrm{~s}$ follow Eq.(4b).

For masonry infill walls, a different trend has been obtained from the analyses of the different building categories, especially when comparing categories A-B and C-D. Hence, two different fitting procedures have been followed to obtain the parameters $\mu$ and $\sigma$ of the lognormal collapse fragility surfaces, and the main results of the regression analyses are reported in subFigures a1 and a2 in Figure 16. The results confirm a lower capacity, in terms of median $S_{a}$, for frame categories $\mathrm{C}$ and $\mathrm{D}$ with respect to categories $\mathrm{A}$ and $\mathrm{B}$, with median collapse spectral acceleration around $0.5 g-0.6 g$ for C-D frames and $0.7 g-0.8 g$ for A and B frames. The difference is probably due to the different geometries of frames A-B and C-D (see Table 1). Indeed, due to the higher column's height of the C-D categories, top displacements are larger than those of AB categories for analogous levels of horizontal forces. Anyway, the values of $\mu$ for a given category are quite similar as they seems to be rather insensitive to the period's variation.

The coefficients of the equations obtained from the regression analyses are reported in the same figures. As far as $\sigma$ is concerned, the values related to masonry infills in frame categories 
A-B and C-D have very similar trends, with the former having slightly bigger dispersion values (about 20\% greater) than the latter.

The trends of $\mu$ for the two different horizontal cladding panel connections, at failure, are reported in sub-Figures b1 and c1 in Figure 16, respectively. It is worth noting, as already emerged from the analyses at collapse of the structural frames, that horizontal panel connections (h1) can sustain a higher acceleration before collapse with respect to connections (h2), being $\mu$ about twice in the whole range of the periods investigated. Both panel connections show that their median acceleration value at failure is strongly period-dependent: it changes significantly, for instance for (h1) connection, from about $1 g$ to $0.2 \mathrm{~g}$ by moving from $0.5 \mathrm{~s}$ to $2.0 \mathrm{~s}$ of period values. The trends of $\sigma$ parameter are very similar but with higher variability for (h1) cladding panel system (see sub-Figures b2 and c2 in Figure 16).

The very different acceleration capacities between (h1) and (h2) types of cladding panel connections is in fully agreement with the in situ observations in the aftermath of the Emilia earthquakes (Savoia et al. 2017), confirming the extended damage detected in the buildings with (h2) panel connection type and, on the other hand, very few cases of failure observed for the (h1) type.

A reasonable explanation of the numerous collapses of cladding panels with (h2) connection typology, observed during the Emilia earthquake, can be grasped by Figure 17. Due to the cantilever behaviour of the columns, the highest horizontal inter-panel drift demand (i.e. relative horizontal displacements between two panels) is expected at the top of the columns, firstly involving the upper panel connections. The larger displacement capacity of the (h1) connection type, results in a less seismic-sensitive response of the panels, which are able to confer a considerable contribution to the capacity of the perimeter frames.

Lastly, the outcomes obtained for the vertical RC cladding panels are reported in sub-Figures $\mathrm{d} 1$ and $\mathrm{d} 2$ in Figure 16. For this type of panels, both $\mu$ and $\sigma$ distributions are intermediate between those of the (h1) and (h2) typologies. Also in this case, the $\mu$ value is strongly period- 
dependent and $\sigma$, representing the dispersion of the outcomes basically depending on the record-to-record variability, has the usual wavy trend already observed for the other cladding typologies. It is worth noting that the equations corresponding to the perimeter elements, reported in Figure 16, could result useful also in the framework of a seismic loss evaluation and performance assessment of precast buildings subjected to earthquake (FEMA 2018). Indeed, they represent the component fragility of perimeter walls/panels which are necessary, together with the fragility curves of the structural elements, in order to perform a reliable and robust seismic loss estimation. In fact, while a wide literature already exists with regard to component fragility of masonry infill panels in cast in-situ RC frames (Del Gaudio et al. 2009, Rossetto et al. 2014), the component fragility of precast RC panels provided in the present paper constitute an emerging novelty contribution.

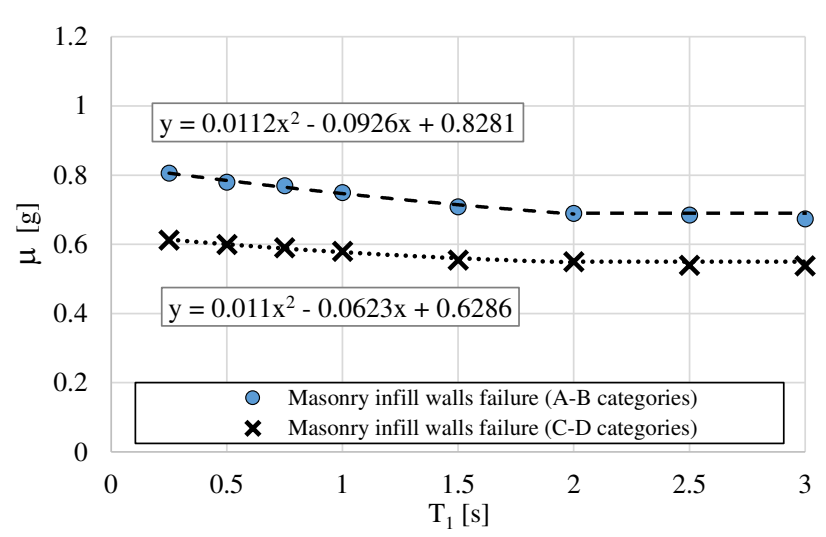

(a1)

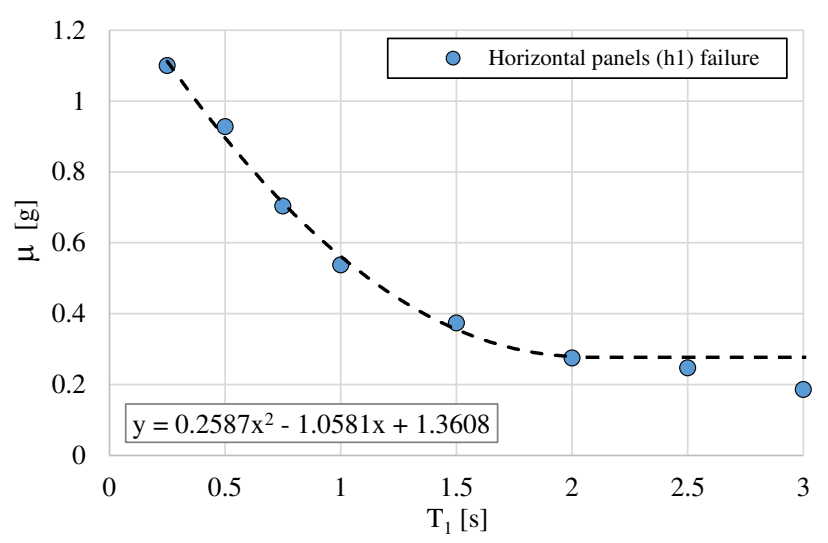

(b1)

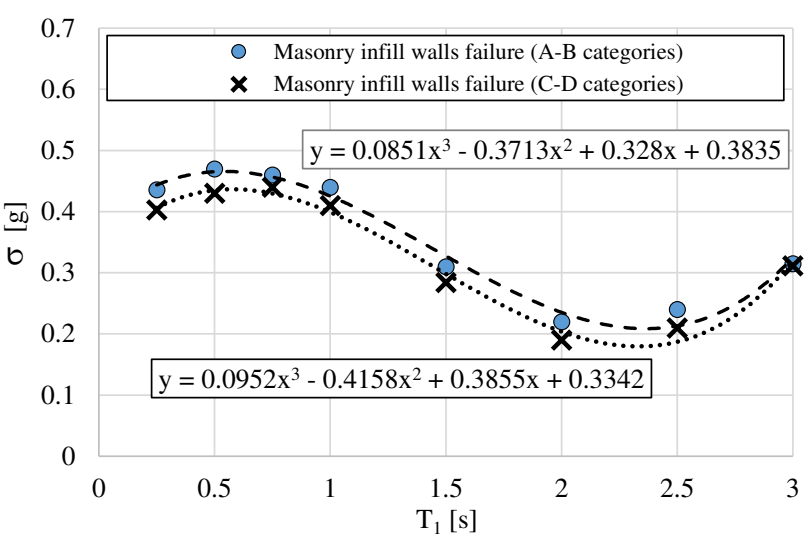

(a2)

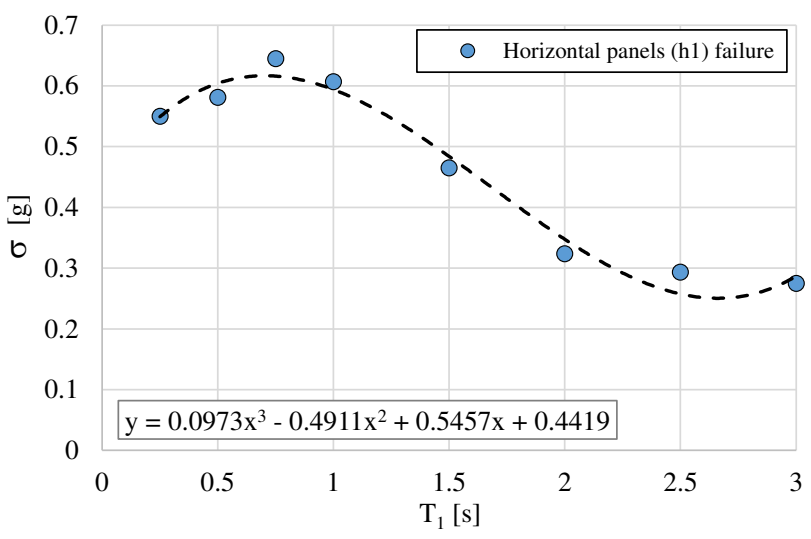

(b2) 


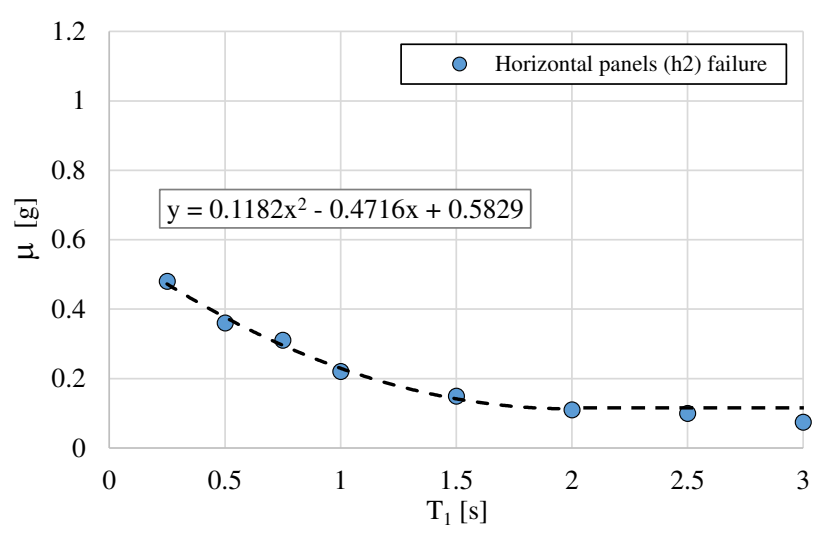

(c1)

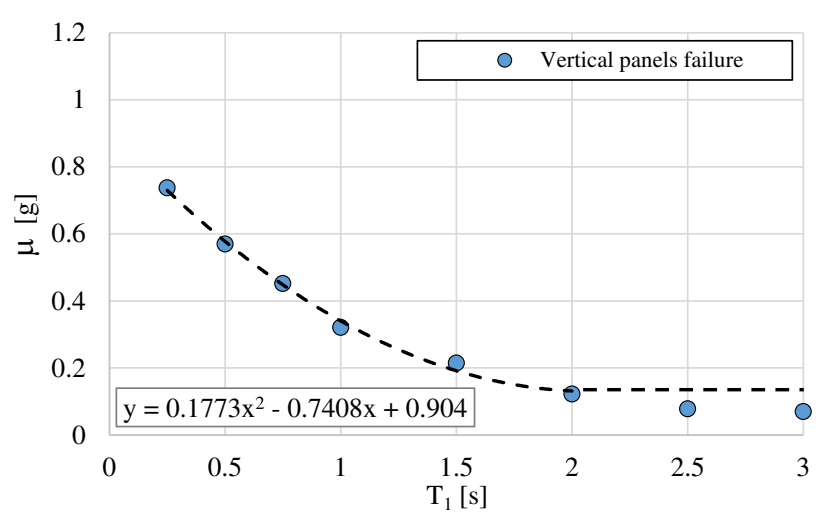

(d1)

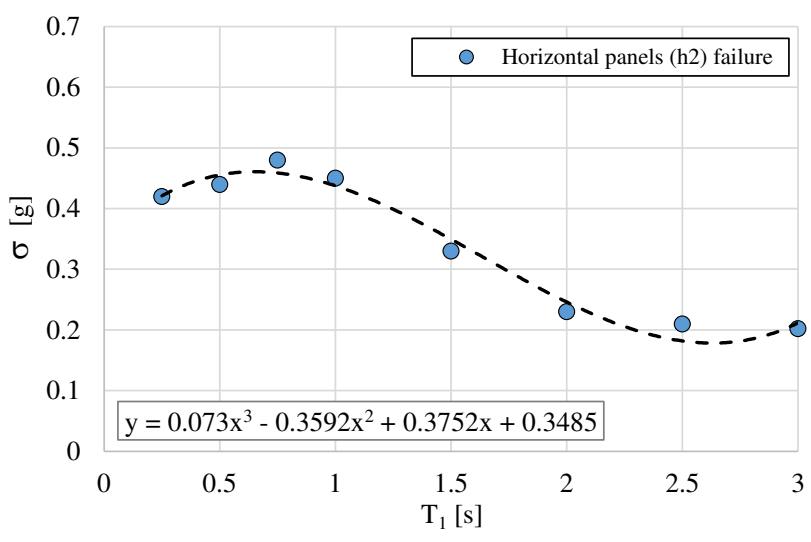

(c2)

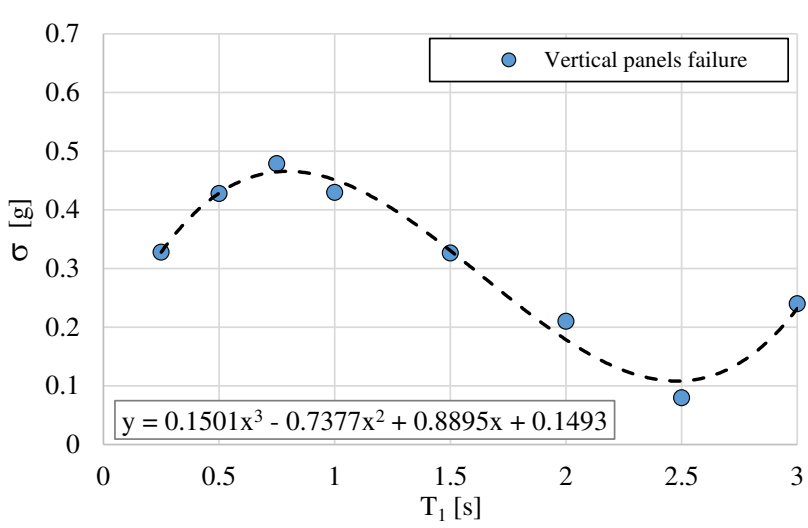

$(\mathrm{d} 2)$

Figure 16. Trend of median value $\mu$ and standard deviation $\sigma$ of lognormal fragility curves at failure of non-structural elements for (a) masonry infilled walls, (b) horizontal cladding panels with (h1) connection, (c) horizontal cladding panels with (h2) connection and (d) vertical cladding panels.
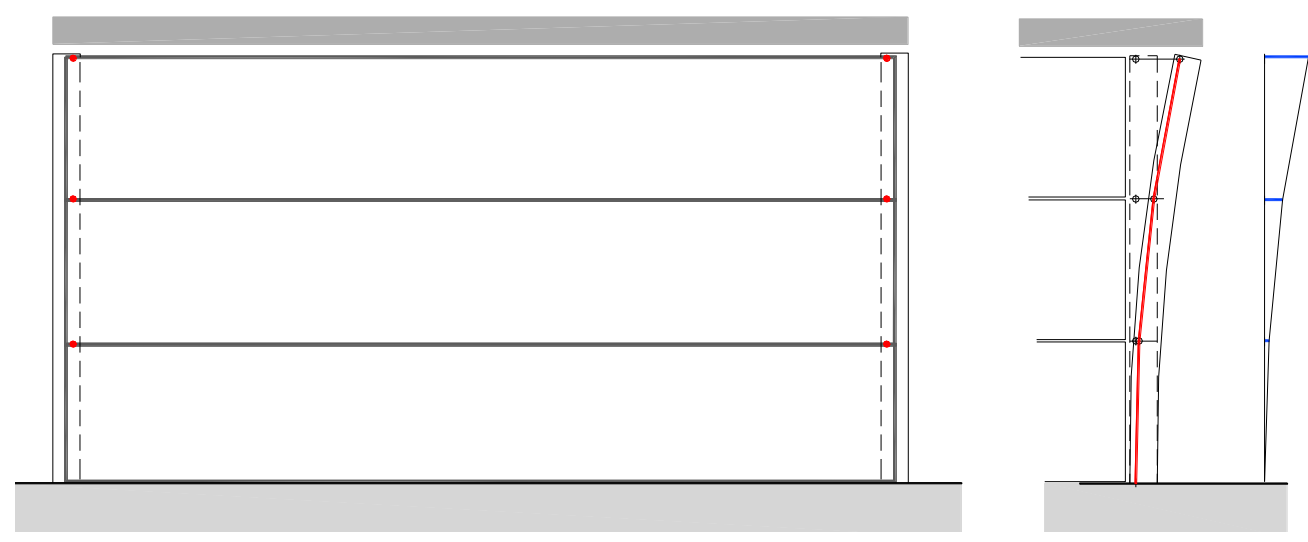

Displacement demand for $3^{\text {rd }}$ connection

Displacement demand for $2^{\text {nd }}$ connection

Displacement demand for $1^{\text {st }}$ connection

Figure 17. Horizontal displacement demand for the (h2) connections supporting horizontal cladding panels positioned at different heights above the ground. 


\section{Definition of fragility curves of the building}

In this study, the precast RC building has been considered to be constituted by different main frames with distinct dynamic behaviours, due to the absence of a rigid diaphragm at the roof level. As mentioned, the 2012 earthquake has revealed the low in-plane stiffness of one-storey precast buildings, being them widely affected by partial collapses of the roof elements belonging to the internal frames, perimeter frames, or both.

Under this light, the fragilities of different frame categories (i.e. internal and perimeter) have been obtained separately, therefore the combined fragility function for the entire building can be statistically derived starting from the knowledge of the fragility functions of its frames (see Figure 1).

Considering the repetitive layout of a precast RC building, it is typically possible to identify one frame category characterizing all the internal frames, and one frame category characterizing the perimeter frames of the building. Under the hypotheses that internal frames are assumed to be identical (in terms of geometry, materials, element dimensions and masses) since they belong to the same structural category, and the same is valid for perimeter frames, the collapse of the entire building can be described considering the combination of these two single events: the collapse of a internal (I) frame and/or the collapse of a perimeter (P) frame. In other words, the collapse of the precast building can be studied with the fundamental axioms of the algebra of sets (Benjamin and Cornell 1970) applied to the single events describing the collapse of the frames. Thus, assuming that the collapse of the internal frames does not affect the probability of occurrence of the collapse of the perimeter frames and vice-versa, the building collapse occurs when one of its frame categories, or both, collapse. Indeed, the events describing the attainment of the collapse of a frame typology can be considered (a) statistically compatible (or non-mutually exclusive) and (b) independent. Since the collapses of the two frame typologies are considered compatible events, named $E_{I}$ and $E_{P}$, the following properties can be derived:

$$
\mathrm{E}_{\mathrm{I}} \cap \mathrm{EP} \neq \varnothing
$$




$$
\mathrm{P}\left(\mathrm{E}_{\mathrm{I}} \cup \mathrm{EP}_{\mathrm{P}}\right)=\mathrm{P}\left(\mathrm{EI}_{\mathrm{I}}\right)+\mathrm{P}\left(\mathrm{EP}_{\mathrm{P}}\right)-\mathrm{P}\left(\mathrm{E}_{\mathrm{I}} \cap \mathrm{EP}_{\mathrm{P}}\right)
$$

where $\emptyset$ is the empty set. Moreover, since the two events are considered independent, the following property is valid:

$$
P\left(E_{I} \cup E_{P}\right)=P\left(E_{I}\right)+P\left(E_{P}\right)-P\left(E_{I}\right) \cdot P\left(E_{P}\right)
$$

Hence, the values of the probabilities of collapse, at each $S_{a}$, are provided by the fragility functions of the two frame typologies. Under the aforementioned conditions, these probabilities can be combined through Eq.(8) at a specific value of seismic intensity in order to estimate the collapse probability of the entire building for that value. In other words, the fragility curve $F_{S T R}(s)$ of the entire building can be obtained in a discrete form at each value of $S_{a}$ considered. Thus, for each $i$-th point (with $i=1, \ldots, m)$ of a generic set $S_{a}=\left(s_{1}, \ldots, s_{m}\right)$ of $m$ seismic intensity values, , the building collapse probability $F_{S T R}\left(S_{i}\right)$ can be obtained with the following equation:

$$
F_{S T R}\left(s_{i}\right)=F_{I}\left(s_{i}\right)+F_{P}\left(s_{i}\right)-F_{I}\left(s_{i}\right) \cdot F_{P}\left(s_{i}\right)
$$

where $F_{I}\left(s_{i}\right)$ and $F_{P}\left(s_{i}\right)$ are the values of the fragility curves of internal and perimeter frames, respectively. It is worth noting that, if $F_{I}(s)$ and $F_{P}(s)$ are lognormal distributions, the entire curve $F_{S T R}(s)$ is no longer a lognormal distribution since the lognormal functions do not have the additive regenerative property (Benjamin and Cornell 1970).

By generalizing to the case of $n$ compatible and independent events $\mathrm{E}_{1}, \ldots \mathrm{E}_{\mathrm{n}}$, (i.e., $n$ different typologies of frames belonging to the building), thus considering $n$ different fragility functions, Eq.(8) and Eq.(9) become respectively:

$$
\begin{gathered}
\mathrm{P}\left(\mathrm{U}_{h=1}^{n} \mathrm{E}_{h}\right)=\sum_{h=1}^{n} \mathrm{P}\left(\mathrm{E}_{h}\right)-\sum_{h, \mathrm{k}} \mathrm{P}\left(\mathrm{E}_{h} \cap \mathrm{E}_{k}\right)+\sum_{h, k, \mathrm{j}} \mathrm{P}\left(\mathrm{E}_{h} \cap \mathrm{E}_{k} \cap \mathrm{E}_{j}\right)+(-1)^{\mathrm{n}+1} \mathrm{P}\left(\bigcap_{h=1}^{n} \mathrm{E}_{h}\right)(10) \\
F_{S T R}\left(s_{i}\right)=1-\prod_{f=1}^{n}\left(1-F_{f}\left(s_{i}\right)\right)
\end{gathered}
$$

with: $\sum_{h, k}$ and $\sum_{h, k, j} \quad$ extended to all values $1 \leq h<k<j<\ldots \leq n$ (Fisz 1963). Note that Eq.(11) is specifically valid under the hypothesis of independent events, and can be demonstrated (Fisz 1963). 
The same approach can be applied in order to evaluate the fragility curve of the entire building at the severe damage limit state, by combining statistically the fragility curves of internal and perimeter frames.

\section{Concluding remarks}

The aim of the study is to provide a fast methodology for the definition of fragility curves of one-story precast RC buildings, typical of the Italian territories, but also present in other European areas. The PRESSAFE-disp (PRecast Existing Structure Seismic Assessment by Fast Evaluation-displacement) methodology, presented in the paper, allows to define the seismic fragilities of precast RC existing buildings in a simplified way starting from the knowledge of very few information that can be collected through a fast visual inspection or building survey. In particular, PRESSAFE-disp is focused on the industrial buildings of the Emilia Romagna region, whose damage during the May 2012 seismic sequence is deeply described in the first part of the paper. An overview of the whole application of the methodology is depicted in Figure 1.

Firstly, the seismic performances of 120 typical frame typologies (24 and 96 for internal and perimeter frames, respectively) of existing single-storey industrial precast buildings have been investigated by incremental dynamic analyses for different periods of vibration. The classes have been selected taking into account different structural configurations, column crosssections, materials and type of connections, in absence or presence of perimeter elements (considered as non-structural components), such as precast RC horizontal, vertical cladding panels or masonry infilled walls.

The fragility curves of the structural frames have been obtained for both severe damage and collapse limit states. The severe damage condition considered in the present work has been the overcome of the yielding strain on the reinforcement bars of the base-section of the columns. 
The collapse condition has been defined at the attainment of one of the following subconditions: (i) the ultimate base rotation for a column or (ii) the displacement capacity at the level of one of the sliding hinges, so adopting a displacement-based collapse criterion for the connections.

Moreover, the component fragility curves, defining the collapse condition of the non-structural elements, have been derived for masonry infill walls, horizontal precast cladding panels (with connection typologies (h1) or (h2)) and vertical precast cladding panels.

By interpolating the fragility functions $\mathrm{F}\left(S_{a}\right)$ over a set of 8 vibrating periods of the frames $\check{T}_{1}$, the fragility surfaces of each category $\mathrm{R}\left(S_{a}, T_{1}\right)$ have been obtained. For each building category, the analytical expressions for the two fragility surfaces (at severe damage and collapse) have been derived. The analytical expressions of the fragility surfaces proposed here provide the PoE for the limit state of interest as a function of $S_{a}$ and $T_{1}$.

Finally, the combined fragility function of the entire building has been derived statistically starting from the fragility functions of its elements (i.e. frames), by assuming the attainments of a prescribed damage state in the individual frames (perimeter and internal) are compatible and independent events.

The method and the outcomes made available from this study allow a fast seismic assessment of the precast RC building fragilities (at both collapse and severe damage), which can be used for earthquake loss assessment and seismic risk analyses of large building stocks in seismic prone areas.

Besides the description and the application of the methodology, the study presents some interesting and general outcomes. For instance, it shows that the presence of the perimeter walls, typically, increases the seismic capacity of a precast frame and in general the perimeter frames result less vulnerable to the seismic action than the internal bare frames. This increase in the capacity for almost all the frame categories has been observed at the severe damage state and, in several cases, also at the collapse state. Obviously, the perimeter frames show an 
increase of the collapse capacity with respect to the internal frames only if the non-structural walls/panels, at the attainment of the frame collapse, are still resisting. The capacity increase is more evident for buildings with masonry infill walls. Hence, the introduction of the perimeter panels in the numerical models increases the values of $S_{a}$ at collapse, but also the dispersion of the IDA curves.

Moreover, the equations of the masonry infill wall/panel collapse fragilities reported in the paper could result useful also for seismic loss evaluation and performance assessment. Indeed, they represent the component fragility of the non-structural elements which are necessary in order to perform complete seismic loss assessments of industrial buildings. Their contribution is often neglected due to the lack of specific reliable fragility curves. It is worth saying that the results presented in this work are representative of common typologies of precast buildings and cladding elements observed in the Emilia Romagna territories, but they can be easily extended. Indeed, additional analyses following the same approach proposed here, but concerning other structural typologies of precast frames, can be conducted to widen the library of the categories included in the PRESSAFE method. The results provided here constitute an emerging novelty contribution of the paper. 


\section{DECLARATIONS}

\section{Funding}

The authors received no specific funding for this work.

\section{Conflicts of interest/Competing interests}

Neither financial nor any other substantive conflict of interest applies. No potential conflict of interest can be construed to have influenced the results or interpretation of the manuscript.

\section{Availability of data and material}

This paper properly acknowledges any work of others that has been influential in determining the nature of the reported work. Any information obtained privately through correspondence or through confidential means is not used without explicit written permission from the source.

\section{Authors' contributions}

Conceptualization: Marco Bovo, Lucia Praticò; Methodology: Marco Bovo and Marco Savoia; Formal analysis and investigation: Marco Bovo and Lucia Praticò; Writing - original draft preparation: Marco Bovo, Lucia Praticò; Writing - review and editing: Marco Savoia, Marco Bovo; Resources: Marco Savoia; Supervision: Marco Savoia. 


\section{REFERENCES}

Agenzia regionale per la Ricostruzione - Sisma 2012. (2018) Analisi tecnico-economica della ricostruzione post sisma degli edifici produttivi. Centro Stampa Regione Emilia-Romagna, Bologna. https://www.regione.emilia-romagna.it/terremoto. Accessed 10 June 2020 (in Italian)

Asteris PG, Antoniou ST, Sophianopoulos DS, Chrysostomou CZ. (2011) Mathematical macromodeling of infilled frames: state of the art. ASCE J Struct Eng 1:1508-1517

ATC - Applied Technology Council. (1989) Procedures for post earthquake safety evaluation of buildings. ATC20-89: Redwood City, CA

Belleri A, Brunesi E, Nascimbene R, Pagani M, Riva P. (2014) Seismic performance of precast industrial facilities following major earthquakes in the Italian territory. J Perform Constr Facil 29(5):04014135

Belleri A, Cornali F, Passoni C, Marini A, Riva P. (2018) Evaluation of out-of-plane seismic performance of column-to-column precast concrete cladding panels in one-storey industrial buildings. Earthq Engng Struct Dyn 47:397-417. https://doi.org/10.1002/eqe.2956

Belleri A, Torquati M, Marini A, Riva P. (2016) Horizontal cladding panels: in-plane seismic performance in precast concrete buildings. Bull Earthq Eng 14:1103-1129. https://doi.org/10.1007/s10518-015-9861-8

Bellotti D, Casotto C, Crowley H, Deyanova MG, Germagnoli F, Fianchisti G, Lucarelli E, Riva S, Nascimbene R. (2014) Single-storey precast buildings: probabilistic distribution of structural systems and subsystems from the sixties. Prog Sismica 5(3):41-70 (in Italian) http://dx.medra.org/10.7414/PS.5.3.41-70

Benjamin JR, Cornell CA. (1970) Probability, statistics, and decision for civil engineers. McGrawHill Book Company, United States of America

Biondini F, Dal Lago B, Toniolo G. (2013) Role of wall panel connections on the seismic performance of precast structures. Bull Earthq Eng 11:1061-1081

Bournas DA, Negro P, Molina F.J. (2013) Pseudodynamic tests on a full-scale 3-storey precast concrete building: behavior of the mechanical connections and floor diaphragms. Eng Struct 57:609-627

Bournas DA, Negro P, Taucer F. (2014) Performance of industrial buildings during the Emilia earthquakes in Northern Italy and recommendations for their strengthening. Bull Earthq Eng 12(5):2383-2404

Bovo M, Buratti N. (2019) Evaluation of the variability contribution due to epistemic uncertainty on constitutive models in the definition of fragility curves of RC frames. Eng Struct 188:700-716. https://doi.org/10.1016/j.engstruct.2019.03.064 
Bovo M, Savoia M. (2018) Numerical simulation of seismic-induced failure of a precast structure during the Emilia earthquake. J Perform Constr Facil 32(1):04017119. https://doi.org/10.1061/(ASCE)CF.1943-5509.0001086

Bovo M, Savoia M. (2019) Evaluation of force fluctuations induced by vertical seismic component on reinforced concrete precast structures. Eng Struct 178:70-8. 10.1016/j.engstruct.2018.10.018

Bovo M, Savoia M. (2021) Fast seismic assessment of existing precast structures by means of fragility surfaces: the PRESSAFE methodology. Submitted for publication in Journal of Earthquake Engineering.

Brunesi E, Nascimbene R, Bolognini D, Bellotti D. (2015) Experimental investigation of the cyclic response of reinforced precast concrete framed structures. PCI J 60(2):57-79

Buratti N, Minghini F, Ongaretto E, Savoia M, Tullini N. (2017) Empirical seismic fragility for the precast RC industrial buildings damaged by the 2012 Emilia (Italy) earthquakes. Earthq Eng Struct Dyn 46(14):2317-35. https://doi.org/10.1002/eqe.2906

Casotto C, Silva V, Crowley H, Nascimbene R, Pinho R. (2015) Seismic fragility of Italian RC precast industrial structures. Eng Struct 94:122-136

Celarec D, Ricci P, Dolšek M. (2012) The sensitivity of seismic response parameters to the uncertain modelling variables of masonry infilled reinforced concrete frames. Eng Struct 35:165-177

Colombo A, Lamperti M, Negro P, Toniolo G. (2016) Design guidelines for wall panel connections. JRC Technical Reports. 10.2788/546845

Crisafulli FJ, Carr AJ, Park R. (2000) Analytical modelling of infilled frame structures - a general review. Bull NZ Soc Earthq Eng 33(1):30-47

Crowley H, Pinho R, Bommer J.J. (2004) A probabilistic displacement-based vulnerability assessment procedure for earthquake loss estimation. Bull Earthq Eng 2: 173-219

Del Gaudio C, De Martino G, Di Ludovico M, Ricci P, Verderame GM. (2017) Empirical fragility curves from damage data on RC buildings after the 2009 L'Aquila earthquake. Bull Earthq Eng 15:1425-1450

Del Monte E, Falsini C, Boschi S, Menichini G, Orlando M. (2019) An innovative cladding panel connection for RC precast buildings. Bull Earthq Eng 17:845-865. https://doi.org/10.1007/s10518-018-0470-1

Ercolino M, Petrone C, Magliulo G, Manfredi G. (2018) Seismic Design of single-story precast structures for P- $\Delta$ effects. ACI Struct J 115(4):943-955

Eurocode 8-Part 1 (2005): General rules, seismic actions and rules for building. European Prestandard EN 1998-1. Brussels, Belgium 
Fardis MN. (1996) Experimental and numerical investigations on the seismic response of RC infilled frames and recommendations for code provisions. LNEC, Lisbon

FEMA (2018) FEMA P-58-1: Seismic performance assessment of buildings: volume 1 methodology. Washington, DC

Fisz M. (1963) Probability theory and mathematical statistics. Wiley, New York

INGV (2020) https://emidius.mi.ingv.it/ASMI/index en.htm. Accessed 10 June 2020

Kurtman B. (2007) A detailed analysis for evaluation of the degradation characteristics of simple structural systems. MS Thesis, Middle East Technical University, Ankara, Turkey

Legislative Decree No. 74/2012 of the $6^{\text {th }}$ June (2012) Italian Parliament

Liberatore L, Sorrentino L, Liberatore D, Decanini L.D. (2013) Failure of industrial structures induced by the Emilia (Italy) 2012 earthquakes. Eng Fail Anal. http://dx.doi.org/10.1016/j.engfailanal.2013.02.009

Magliulo G, Ercolino M, Cimmino M, Capozzi V, Manfredi G. (2015) Cyclic shear test on a dowel beam-to-column connection of precast buildings. Earthq Struct 9(3):541-562

Magliulo G, Ercolino M, Petrone C, Coppola O, Manfredi G. (2014) The Emilia earthquake: seismic performance of precast reinforced concrete buildings. Earthq Spectra 30(2):891912

Ongaretto E, Buratti N, Savoia M. (2019) Empirical seismic fragility of different typologies of precast RC industrial buildings. Proceedings of XVIII Convegno Anidis, Ascoli Piceno, Italy

OpenSees v2.4.0. (2015) Open System for Earthquake Engineering Simulation. Pacific Earthquake Engineering Research Center (PEER)

Pacific Earthquake Engineering Research Center (PEER). Final Report of the NGA-West2 Directivity Working Group, PEER Report 2013/09; 2013

Pacific Earthquake Engineering Research Center (PEER). Structural Performance Database PEER Website, http://nisee.berkeley.edu/spd/index.html. Accessed 10 June 2020

Presidente del Consiglio dei Ministri. OPCM 3274/2003 - Primi elementi in materia di criteri generali per la classificazione sismica del territorio nazionale e di normative tecniche per le costruzioni in zona sismica; 2003 (in Italian)

Regione Emilia Romagna, Terremoto, La ricostruzione, http://www.regione.emiliaromagna.it/terremoto. Accessed 10 June 2020

ReLUIS Report (2007) Strutture prefabbricate: schedario dei collegamenti; 2007(in Italian) 
Rossetto T, D’Ayala D, Ioannou I, Meslem A. (2014) Evaluation of existing fragility curves. SYNER-G: typology definition and fragility functions for physical elements at seismic risk. Springer, Dordrecht, pp. 47-93. ISBN 978-94-007-7871-9

Savoia M, Buratti N, Vincenzi L. (2017) Damage and collapses in industrial precast buildings after the 2012 Emilia earthquake. Eng Struct 137:162-180

Savoia M, Mazzotti C, Buratti N, Ferracuti B, Bovo M, Ligabue V, Vincenzi L. (2012) Damages and collapses in industrial precast buildings after the Emilia earthquake. Ing Sismica 29(2):120131

Silva V, Akkar S, Baker J, Bazzurro P, Castro JM, Crowley H, Dolsek M, Galasso C, Lagomarsino S, Monteiro R, Perrone D, Pitilakis K, Vamvatsikos D. (2019) Current challenges and future trends in analytical fragility and vulnerability modelling. Earthq Spectra 35(4):1927-1952. https://doi.org/10.1193/042418EQS1010

Silva V, Horspool N. (2019) Combining USGS ShakeMaps and the OpenQuake-engine for damage and loss assessment. Earthq Eng Struct Dyn 48:634-652. 10.1002/eqe.3154

Tapan M, Comert M, Demir C, Sayan Y, Orakcal K, Ilki A. (2013) Failures of structures during the October 23, 2011 Tabanlı (Van) and November 9, 2011 Edremit (Van) earthquakes in Turkey. Eng Fail Anal 34:606-628. 10.1016/j.engfailanal.2013.02.013

Tzenov, L, Sotirov L, Boncheva P. (1978) Study of some damaged industrial buildings due to Vrancea earthquake. Proceedings of the 6th European Conference on Earthquake Engineering, Dubrovnik, Yugoslavia, 18-22 September

Vamvatsikos D, Cornell CA. (2002) Incremental dynamic analysis. Earthq Eng Struct Dyn 31:491-514. https://doi.org/10.1002/eqe.141

Vamvatsikos D, Fragiadakis M. (2010) Incremental dynamic analysis for estimating seismic performance sensitivity and uncertainty. Earthq Eng Struct Dyn 39:141-63

Zoubek B, Fischinger M, Isakovic T. (2016) Cyclic response of hammer-head strap cladding-tostructure connections used in RC precast building. Eng Struct 119:135-148 